\title{
Union wage formation and (un)employment
}

Citation for published version (APA):

Lever, M. H. C. (1993). Union wage formation and (un)employment. [Doctoral Thesis, Maastricht University]. Datawyse / Universitaire Pers Maastricht. https://doi.org/10.26481/dis.19931201ml

Document status and date:

Published: 01/01/1993

DOI:

10.26481/dis.19931201ml

Document Version:

Publisher's PDF, also known as Version of record

\section{Please check the document version of this publication:}

- A submitted manuscript is the version of the article upon submission and before peer-review. There can be important differences between the submitted version and the official published version of record.

People interested in the research are advised to contact the author for the final version of the publication, or visit the DOI to the publisher's website.

- The final author version and the galley proof are versions of the publication after peer review.

- The final published version features the final layout of the paper including the volume, issue and page numbers.

Link to publication

\footnotetext{
General rights rights.

- You may freely distribute the URL identifying the publication in the public portal. please follow below link for the End User Agreement:

www.umlib.nl/taverne-license

Take down policy

If you believe that this document breaches copyright please contact us at:

repository@maastrichtuniversity.nl

providing details and we will investigate your claim.
}

Copyright and moral rights for the publications made accessible in the public portal are retained by the authors and/or other copyright owners and it is a condition of accessing publications that users recognise and abide by the legal requirements associated with these

- Users may download and print one copy of any publication from the public portal for the purpose of private study or research.

- You may not further distribute the material or use it for any profit-making activity or commercial gain

If the publication is distributed under the terms of Article $25 \mathrm{fa}$ of the Dutch Copyright Act, indicated by the "Taverne" license above, 



\title{
UNION WAGE FORMATION AND (UN)EMPLOYMENT
}

\author{
PROEFSCHRIFT
}

ter verkrijging van de graad van doctor aan

de Rijksuniversiteit Limburg te Maastricht, op gezag van de Rector Magnificus, Prof. dr. H. Philipsen, volgens het besluit van het College van Dekanen, in het openbaar te verdedigen op woensdag 1 december 1993 om 14.00 uur

door

Marcel Hendrik Christinus Lever 


\section{Promotor:}

Prof. dr. J.A.H. Maks

\section{Co-promotor:}

Dr. P.P. de Gijsel

\section{Beoordelingscommissie:}

Prof. dr. J. Muysken (voorzitter)

Prof. dr. H.J.M. Peters

Prof. dr. J.J.M. Theeuwes (Rijksuniversiteit Leiden)

Union wage formation and (un)employment / Marcel Hendrik Christinus Lever.

-Masstricht: Universitaire Pers Maastricht. -III.

Thesis Mustricht. - With ref. - With summary in Dutch. ISBIN 90-5278-106-0

NUGI 68!/685

Subject headings: trade unions / wages / unemployment

- 1993 M.H.C. Lever, Routerdum 
To Anja and my parents 
4.2 Theory of efficiency wages 45

4.2.1 Basic idea of the efficiency wage theory 45

4.2.2 Rationales for the wage-productivity relationship 46

4.2.3 Implications of the wage-productivity relationship 49

4.2.4 Efficiency wages and unemployment 50

4.3 Union bargaining and efficiency wages 53

4.4 Insiders-outsiders and efficiency wages 54

4.5 Empirical evidence on efficiency wages 58

4.6 Concluding remarks 62

An efficiency wage model of wage drift:

evidence from the Netherlands (1972-1983)

Introduction

The individual worker's effort

Efficiency wage model of wage drift

5.6 Concluding remarks

Insider-outsider vs. human capital effects in union wage formation 
Insider-outsider effects and the persistence of unemployment

Previous employment and wage determination

7.4 Long-term unemployment and wage determination

8.1 Summary and conclusions

References 


\section{Relation between chapters and publications}

\section{chapter 2}

Lever, Marcel H.C. (1989), The labour demand curve model and the contract curve model: which explains the determination of wages and employment, working paper 89.018, University of Limburg, Maastricht.

Lever, Marcel H.C. and A.P. van Veen (1991), Union wage setting, employment and investment: a survey of theory and empirical evidence, Labour 5 (3), pp. 25-61.

\section{chapter 3}

Lever, Marcel H.C. (1991b), Union wage setting and unemployment in the Netherlands (1965-1987), Applied Economics 23 (10), pp. 1579-1585.

\section{chapter 4}

Lever, Marcel H.C. and Peter P. de Gijsel (1992), The interaction between efficiency wage and insider-outsider effects reconsidered, mimeo., University of Limburg, Maastricht.

Lever, Marcel H.C. (1993a), Efficiency wages and unemployment: theory and empirical evidence, research memorandum 93-002, University of Limburg, Maastricht.

\section{chapter 5}

Lever, Marcel H.C. (1991a), An efficiency wage model of wage drift: empirical evidence from the Netherlands (1972-1983), research memorandum 91-016, University of Limburg, Maastricht.

\section{chapter 6}

Lever, Marcel H.C. (1993b), Insider-outsider vs. human capital effects in union wage formation, research memorandum 93-011, University of Limburg, Maastricht. 


\section{chapter 7}

Lever, Marcel H.C. (1992), Insider-outsider effects in union wage determination, research memorandum 92-024, University of Limburg, Maastricht. 


\section{List of symbols}

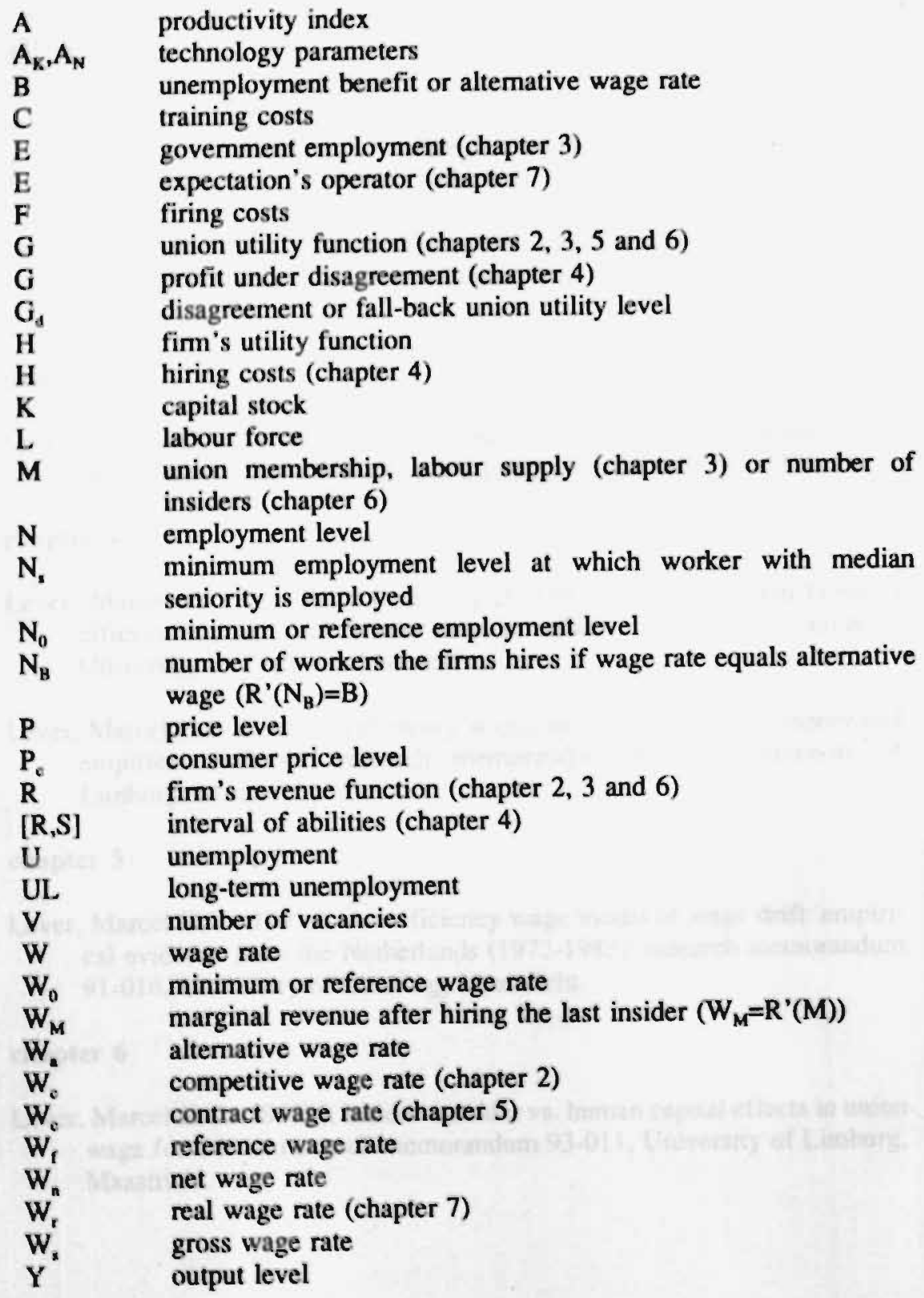


functions introduced for notational convenience (chapter 4) utility of insider under disagreement

\begin{tabular}{|c|c|}
\hline $\begin{array}{l}a_{k}, a_{N} \\
b\end{array}$ & technology parameters $\left(a_{k}=\ln A_{K}, a_{N}=\ln A_{N}\right)$ \\
\hline & replacement ratio $(b=B / W)$ \\
\hline $\begin{array}{l}e_{1}, e_{2}, e_{3} \\
e_{3}\end{array}$ & $\begin{array}{l}\text { effort level (chapters } 4 \text { and 5) } \\
\text { error terms (chapter } 3 \text { ) }\end{array}$ \\
\hline & $\begin{array}{l}\text { error terms (chapter } 3 \text { ) } \\
\text { production function }\end{array}$ \\
\hline $\mathrm{g}$, & 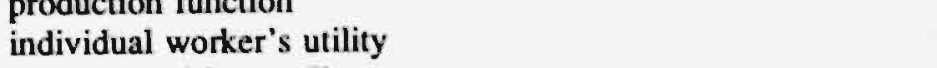 \\
\hline k, k' & parameters (chapter 7) \\
\hline 1 & log of labour force \\
\hline Is & log of labour supply \\
\hline m & $\log$ of union membership or log of labour supply \\
\hline $\mathbf{n}$ & $\log$ of employment \\
\hline p & log of price level \\
\hline $\mathbf{P}_{\mathrm{c}}$ & log of consumer price level \\
\hline q & chance to remain unemployed (chapter 5) \\
\hline q & relative weight of outsiders in union utility function (chapter 6) \\
\hline $\mathbf{r}$ & Arrow-Pratt measure of relative risk aversion \\
\hline s & partial adjustment coefficient (chapter 7) \\
\hline $\begin{array}{l}s_{1} \\
s_{2}\end{array}$ & employers' tax rate \\
\hline$s_{2}$ & employees' tax rate \\
\hline t & time index \\
\hline $\begin{array}{l}\mathrm{t} \\
\mathrm{u}\end{array}$ & t-statistic \\
\hline $\begin{array}{l}u_{u} \\
u_{e q}\end{array}$ & unemployment rate $(\mathrm{u}=\mathrm{U} / \mathrm{L})$ \\
\hline $\begin{array}{l}\mathrm{u}_{\mathrm{eq}} \\
\mathrm{ul}\end{array}$ & equilibrium unemployment rate \\
\hline $\begin{array}{l}\text { ul } \\
\mathbf{v}\end{array}$ & long-term unemployment rate ( $\mathrm{ul}=\mathrm{UL} / \mathrm{L})$ \\
\hline w & vacancy rate $(v=V / L)$ \\
\hline & $\begin{array}{l}\text { log of wage rate } \\
\text { log of contract wage rate }\end{array}$ \\
\hline wcdum & $\begin{array}{l}\text { log of contract wage rate } \\
\text { wage control dummy }\end{array}$ \\
\hline$w_{\mathrm{d}}$ & wage drift $\left(w_{d}=\Delta \ln \left(1+w_{g}\right)\right)$ \\
\hline$w_{s}$ & relative wage gap $\left(W=W_{g}\left(1+W_{k}\right)\right)$ \\
\hline$w_{n}$ & log of net wage rate \\
\hline$w_{r}$ & log of real wage rate (chapter 7 ) \\
\hline y & log of output level \\
\hline$\Delta$ & first-difference operator \\
\hline$\Pi$ & short-run profit function \\
\hline$\Pi_{0}$ & minimum profit level \\
\hline$\Pi_{d}$ & disagreement or fall-back profit level \\
\hline$\Omega$ & Nash bargaining function \\
\hline
\end{tabular}




\begin{tabular}{|c|c|}
\hline$\alpha, \beta$ & parameters (chapter 7) \\
\hline$\alpha_{\mathrm{K}}, \alpha_{\mathrm{N}}$ & $\begin{array}{l}\text { capital-augmenting and labour-augmenting technical progress } \\
\text { productivity responsiveness coefficient (chapter } 4 \text { ) }\end{array}$ \\
\hline$\gamma, \gamma_{i}, \gamma_{i j}$ & parameters \\
\hline & risk aversion parameter \\
\hline$\delta_{\text {NM }}$ & Kronecker delta $\left(\delta_{N M}=1\right.$ for $N \leq M, \delta_{N M}=0$ for $\left.N>M\right)$ \\
\hline$\varepsilon$ & demand shock \\
\hline $\begin{array}{l}\zeta, \eta, \theta \\
\theta\end{array}$ & $\begin{array}{l}\text { parameters union utility function (chapters } 3 \text { and 5) } \\
\text { applicant's ability (chapter } 4 \text { ) }\end{array}$ \\
\hline$\lambda, \mu$ & union's bargaining power \\
\hline$\mu$ & parameter (chapter 5) \\
\hline v & $\begin{array}{l}\text { relative weight of long-term unemployment in union utility } \\
\text { function }\end{array}$ \\
\hline$p$ & technology parameter \\
\hline$\sigma$ & elasticity of factor substitution \\
\hline$\phi$ & objective function of the insider \\
\hline$\Psi$ & objective function of the firm (chapter 4 ) \\
\hline
\end{tabular}

notes

Each symbol is unique in each chapter. Some symbols have different meanings in different chapters. This is denoted above between brackets. The symbols are defined in each chapter.

Derivatives of functions of one variable are denoted by ' (first order), " (second order), etc. Partial derivatives of functions of more than one variable are denoted by subscripts. The subscript $i(i=1,2,3, \ldots)$ denotes the first-order partial derivative to the $i$-th variable, the subscripts $i, j(j=1,2,3, \ldots)$ denote the second-order derivative to the $i$-th and $j$-th variable.

Some symbols are used both as a variable and as a function. If it is used as a function, this is generally indicated by brackets. For example, e denotes the effort level, whereas e(.) denotes the effort function. In the definition of functions exogenous variables are generally not included as arguments. 


\section{Preface}

Unemployment is one of the major social problems in Westem Europe. The experience of the last ten years (1983-1993) in the European Community has shown that unemployment can be high and persistent. This book considers the relevance of three alternative theories why wages do not adjust to provide more opportunities for employment. Firstly, three standard models of union wage setting and employment are reviewed. One of these models is used to analyze the causes of the rise in the unemployment rate in the Netherlands between 1965 and 1987. The results suggest that the increase in taxes and in the discrepancy between consumer and producer prices (among other things due to value added taxes), and the increase in benefits have caused a higher unemployment rate. Secondly, four different efficiency wage models are surveyed. It is argued that it is doubtful whether efficiency wage effects are sufficiently strong and widespread to cause unemployment. Nevertheless, the efficiency wage theory appears to be useful to explain wage drift. Empirical estimates for the Netherlands reveal that there is an inverse relationship between contract wage changes and wage drift. Thirdly, the empirical implications of several insider-outsider models are considered. The survey of empirical evidence shows that the extreme versions of the models which imply full hysteresis must be rejected. Furthermore, it is argued that depreciation of human capital caused by long-term unemployment may affect union wage formation. The impact of insider-outsider and of human capital (or duration) effects on wages and (un)employment appears to be different.

This study is part of a research project "Labour market and labour organizations" at the University of Limburg in Maastricht, the Netherlands.

It has benefited from the help of many people. Peter de Gijsel and Hans Maks provided stimulating discussions, critical comments and wise advice. Joan Muysken, Hans Peters and Jules Theeuwes refereed the study and suggested some improvements. Johan Graafland provided some data and gave useful comments. John Addison, Joop Hartog, Erik de Regt, Tom van Veen, Maarten Vendrik, Marc van Wegberg, other colleagues, some anonymous referees and participants at seminars in Amsterdam, El Escorial (Spain), Groningen, Leuven, Lisbon and Maastricht gave helpful comments. Ella LeverWiersema (my mother) gave excellent linguistic advice. My parents provided moral and financial support. My friends and co-founders of the "Ketelbinkiedispuut" Alwin Oerlemans and Hans Voordijk made my stay in Maastricht nice. Last but not least my wife Anja Koster encouraged me and endured living apart while I finished this thesis. Thank you all for your help. 


\section{Introduction and overview}

\section{Abstract}

This chapter provides an introduction to the subject of this study. Furthermore, it gives an overview of the other chapters. 


\section{Chapter I}

\section{Introduction}

During the eighties Western Europe suffered from high and persistent unemployment. Different from what the neoclassical perfect competition model suggests, the labour market did not clear via wage rate adjustment. To explain this phenomenon several theories are put forward in the literature in this field. Firstly, there is renewed interest in the role of trade unions in wage and employment determination. Secondly, the efficiency wage theory is proposed to explain why unemployment may be an equilibrium phenomenon. The efficiency wage hypothesis is based on the assumption that there is a positive causal relationship between the wage rate and the worker's productivity. Thirdly, unemployment is explained by the difference in bargaining status between employed (insiders) and unemployed workers (outsiders).

Of the three theories mentioned above I consider union bargaining theory as the most important in explaining wages and (un)employment. The reason is that in Westem Europe trade unions play such a dominant role in wage determination. In the Netherlands, for example, 80 per cent of the employees is covered by some collective wage agreement. As set out in chapter 2, the three basic models in union bargaining theory are the monopoly model, the right-to-manage model and the efficient bargain model. In the first two models the bargaining outcome is on the firm's labour demand curve, in the efficient bargain model it is not. An outcome off the demand curve results when union and firm bargain about both wage rate and employment. Whereas bargaining about employment is rare in most Western European countries, it seems unlikely that outcomes off the labour demand curve will result. Therefore, the monopoly model and the right-to-manage model seem most relevant.

The previous paragraph may suggest that the three theories do exclude each other. That is not true, however. Several authors introduce a trade union to pursue the goals of the insiders. In this respect insider-outsider theory can be interpreted as a complement to union bargaining theory. The relationship between insider-outsider theory and efficiency wage theory is investigated by Lindbeck and Snower (1991). They present a model which combines insideroutsider and efficiency wage effects. They conclude that the model implies that insider-outsider and efficiency wage effects do not reinforce one another. In chapter 4 I will argue that their conclusion is not correct. Insider-outsider and efficiency wage effects appear to reinforce one another. The relationship between union bargaining theory and efficiency wage theory is less clear. In chapter 5 I will show that the theories can be combined.

Despite its attractiveness, union bargaining theory does not exlain everything about wages and (un)employment. One phenomenon that the theory does not explain is that in unionized labour markets the average wage rate rises mostly somewhat faster than the average contract wage rate. This phenomenon, which is called wage drift, is observed in countries such as Scandinavia and the 
Netherlands. So far, the theoretical explanations offered for wage drift are somewhat ad hoc. A recent exception is Holden (1989). His explanation is based on the assumption that workers bargain collectively at firm level after wage negotiations at national or industry level. This assumption does not apply in the Netherlands, where wage drift arises mainly through interaction between the employer and the individual employee. Whereas strikes can be used to threat the firm in collective bargaining, the individual worker can only threat to quit or to shirk. Therefore, wage drift which arises at the individual level requires another explanation than proposed by Holden. Besides explaining wage drift itself, the relationship between contract wage changes and wage drift requires more attention. For example, it is unclear whether wage drift is an alternative for contract wage increases or an independent additive to contract wage increases. In chapter 5 I propose a model which combines union bargaining theory and efficiency wage theory to explain contract wage changes and wage drift. This model is applied empirically to investigate the relationship between contract wage changes and wage drift.

Another phenomenon which union bargaining theory does not explain is that unemployment is concentrated among specific groups of workers. One can explain this by arguing that the union is only interested in employment of its members. This assumption is adopted in the insider-outsider model proposed by Carruth and Oswald (1987). If their assumption is correct, nonmembers are never employed under a monopoly trade union. I have two objections against the approach which emphasizes the role of union membership in wage formation. One objection is that, unless there is a closed shop, the union is unable to select workers. In this situation unemployment is more or less equally spread among members and nonmembers (more or less, because some workers might change membership status while becoming (un)employed). Another objection is that the labour market is not as static as the approach suggests. Due to labour tumover the population of employed workers (called membership in these models) changes from year to year. If one wants to introduce heterogeneity of labour in models of union wage formation it must not be the distinction between members and nonmembers. Since unemployment is concentrated among workers with little education and working experience I propose in chapter 6 to make a distinction between trained workers with high human capital endowments and untrained workers with low endowments.

The purpose of this dissertation can be summarized as follows. Firstly, to evaluate the contribution of union bargaining theory, efficiency wage theory and insider-outsider theory to the explanation of wage formation, employment and unemployment. Secondly, to present an empirical application of union wage setting theory to the Netherlands (1965-1987). Thirdly, to investigate theoretically the relationship between insider-outsider and efficiency wage effects. Fourthly, to investigate empirically the relationship between contract wage changes and wage drift. Finally, to offer a theoretical explanation for 
unemployment of untrained workers. A more extensive overview of each chapter is given below.

\section{Overview}

Chapter 2 summarizes the theory and empirical evidence on union wage formation and employment. The theoretical part starts with a discussion of the assumptions with respect to the union's and the firm's preferences. Secondly, the three basic models, the monopoly union model (Dunlop (1944)), the rightto-manage model (Nickell (1982)) and the efficient bargain model (Leontief (1946), McDonald and Solow (1981)), are presented as special cases of the more general sequential bargaining model by Manning (1987). Thirdly, the implications of recent contributions in game theory to wage bargaining are discussed. The empirical evidence can be split into two parts. The first part contains estimates on revealed union preferences. The second part summarizes the results of testing between the three basic models.

Chapter 3 presents an empirical model of union wage setting and unemployment. The basic idea of the model, which is also found in Layard and Nickell $(1985,1986,1987)$ and in Layard et al. (1991), is that there are several 'push' factors which incite the union to demanding a higher wage rate. These factors include taxes, social security payments and the gap between consumer and producer prices. A new element in the model is that attention is paid to the role of labour productivity in union wage setting. The model is estimated with annual data of the private sector in the Netherlands (1965-1987). The analysis suggests that Dutch unemployment has been pushed up by the increase in tax rates and the price gap, but has been reduced by productivity effects.

Chapter 4 considers whether efficiency wages can explain unemployment. Theoretically the hypothesis that high wages improve worker productivity provides an explanation for natural or structural unemployment. One objection against this explanation is that more complex contracts may provide incentives to workers without causing unemployment. Another objection is that efficiency wages do not cause unemployment if there is a competitive secondary sector. The empirical evidence supports that high wages reduce shirking and tumover and increase productivity. It remains unclear whether the efficiency wage effects are sufficiently strong and sufficiently widespread to cause unemployment. Further the relations between unions and efficiency wages and between insiders-outsiders and efficiency wages are discussed. The chapter shows that insider-outsider and efficiency wage effects, if combined in a simple model, reinforce one another if the worker has complete market power. This result contrasts with the conclusion by Lindbeck and Snower (1991).

In chapter 5 an efficiency wage model is proposed to explain wage drift. In the literature wage drift is attributed to excess demand for labour, productivity increases of piece workers, price increases, excess profits, distortions of the 
relative wage structure, tax rates and inventories. So far, no coherent theoretical explanation for this phenomenon has been provided. It is shown that most of the hypotheses mentioned before fit in the proposed model. The model is estimated with aggregate data from the Netherlands (1972-1983). In line with the theoretical model wage drift appears to be positively related to price changes and changes in the vacancy rate and negatively related to contract wage changes and changes in the unemployment rate.

Chapter 6 summarizes and presents two approaches to distinguish insiders and outsiders in models of union wage determination. In the union membership approach, which is adopted by Carruth and Oswald (1987), the insiders are union members and the outsiders are nonmembers. In the human capital approach the insiders are trained workers and the outsiders are untrained workers. The two approaches appear to have different implications. Firstly, in the union membership approach a monopoly union will not allow employment of outsiders. In the human capital approach the union might set the wage rate such that besides all insiders some outsiders are hired as well. Secondly, in the union membership approach the contract curve coincides with the downwardsloping labour demand curve for employment levels beyond the number of insiders if union and firm bargain efficiently about wages and employment. In the human capital approach the contract curve is upward sloping for employment levels beyond the number of outsiders.

Chapter 7 summarizes the literature on insider-outsider and duration effects in union wage setting. It is argued that these theories imply testable effects of previous employment, unemployment and long-tern unemployment on the wage rate. The empirical results can be interpreted as evidence in favour of some versions of insider-outsider theory and duration theory. The effects may cause some persistence in unemployment. They are, however, not strong enough to cause full hysteresis.

Chapter 8 summarizes and concludes the study. Furthermore, it describes some policy implications and offers some suggestions for further research. 



\section{Union wage formation and employment: a review}

\section{Abstract}

This chapter provides a survey of recent theoretical and empirical research on union wage formation and employment. The basic models of union wage formation and employment, the monopoly model, the right-to-manage model and the efficient bargain model, are presented in a unified framework. Finally, the empirical evidence on union preferences and on the performance of the various models is discussed. 


\section{Introduction}

The relationship between trade unions, wages and employment has gained interest in the last decade, because it was recognized that the high unemployment rates in Westem Europe are possibly related to labour market institutions. The integration of trade unions in economic theory dates back to the work by Dunlop (1944) and Leontief (1946), and is popularized by McDonald and Solow (1981) and Oswald (1982). In the words of Oswald (1982), "at the heart of the approach is the notion that the trade union is like any other economic agent and can be thought of as attempting, subject to certain constraints, to maximize an objective function" (p. 576).

The purpose of this chapter is to present a survey of the theory of union wage formation and employment and to summarize the empirical evidence in this area. Due to limitations of space several topics are not included. To compensate for these omissions, some references are given. Firstly, a review on the relationship between trade unions and the government is provided by Abraham (1989). Secondly, the issue of trade unions and productivity is reviewed in Addison and Hirsch (1989) and in Kraft (1989). Thirdly, contributions on union wage setting and taxation are offered by Hersoug (1984), Hersoug et al. (1986), Malcomson and Sartor (1987) and Van Rompuy et al. (1988). Fourthly, the relationship between centralization of union wage setting and unemployment is taken up by Calmfors and Driffill (1988), Freeman (1988) and Jackman et al. (1990). Fifthly, Lewis (1986) deals with the relative wage effects of trade unions. Finally, the impact of unions on investment is reviewed by Lever and Van Veen (1991).

Earlier survey articles include Oswald (1985), Pencavel (1985), Farber (1986) and Addison (1989). Recent textbooks are written by Hirsch and Addison (1986) and by Carnuth and Oswald (1989). The surveys by Oswald, Pencavel and Farber and the textbook by Hirsch and Addison were published too early to cover some recent contributions, such as the sequential bargaining model of Manning (1987a). Nor do these reviews include the bulk of empirical studies testing between two competing models of union wage setting and employment, which were published in the past few years. Addison's survey is more up to date, but differs in scope from ours. We present the basic models of union wage formation and employment in the encompassing sequential bargaining framework, while Addison refers to this framework only in the conclusions. Of course, Hirsch and Addison (1986) and Carruth and Oswald (1989) cover some subjects which are beyond the scope of this chapter.

The structure of the chapter is as follows. Section 2 reviews the theoretical literature on union wage formation and employment. Section 3 summarizes the empirical research on union preferences and on the perfor- 
mance of the various models. An evaluation of the state of the ant and suggestions for further research are offered in section 4 .

\section{Modelling union wage formation and employment}

According to Johnson (1975) "the problem of modelling trade union behaviour has proved to be virtually intractable. This is because (1) there is no consensus on the goals of union activity ... such as exists with respect to the firm or consumer and (2) the received pure theory of bargaining is devoid of operational content" (pp. 23-24). Although there is no consensus on some important issues, the problem is not considered as intractable any more. Several concepts, such as utility maximization subject to a budget constraint, were borrowed from consumer theory. This paved the way for a large number of contributions to modelling trade union behaviour. The review of theoretical work starts in 2.1 with a discussion of union preferences. The basic models of union wage formation and employment are presented in 2.2 . In 2.3 the seniority model is discussed. The game theoretic foundation for the Nash bargaining solution and the modelling of the disagreement points are considered in 2.4 .

\subsection{Union preferences}

"Are trade unions economic or political entities?" Under this title, Burton (1981) joined the debate which started between Ross and Dunlop about the role of trade unions in society. Dunlop (1944) suggested to represent trade union preferences by a wage bill objective. Ross (1948) criticized the approach, arguing that trade unions are primarily political organizations. Although many economists would not deny the political function of trade unions. Dunlop's approach is widely accepted as an appropriate way of integrating trade unions in economic theory. One reason for this popularity is probably that the approach of Dunlop fits in the neoclassical methodology of explaining economic agents' behaviour by modelling preferences and constraints and by solving a maximization problem. Union preferences have often been formalized by specifying a utility function. Before discussing functional forms, it seems appropriate to discuss what the arguments of a utility function should be.

Following Dunlop, many authors have assumed that unions care about their members' wage rate and about the employment level. It is, however, less clear whether union membership is exogenous, and also how the wage rate and the employment level should be defined. Mostly, union membership is assumed to be fixed and exogenous, which is not quite satisfying. There have been some attempts to make it endogenous; cf. Grossman (1983), Booth (1984) and Kidd and Oswald (1987). A second 
issue is whether nominal or real wages should enter the utility function. Most people agree that workers are primarily interested in the real wage rate and that money illusion is absent. It is questionable, however, whether unions are able to set the real wage rate, because the price level is not under their discretion; cf. Solow (1986). A third issue is whether employment itself should enter the utility function, or that employment relative to membership or to labour supply is the relevant concept. Stated differently, do unions care about unemployment? These are important questions, which deserve more attention.

The utility function representing union preferences is generally required to be increasing and quasi-concave in the wage rate and the employment level. Among the functional forms which have been proposed in the literature is, firstly, the Stone-Geary function

$$
G(W, N)=\left(W-W_{0}\right)^{\theta}\left(N-N_{0}\right)^{1-8}, W \geq W_{0}, N \geq N_{0},
$$

where $G, W$ and $N$ denote union utility, the wage rate and the employment level, respectively. Throughout this chapter wages, as well as benefits, revenues and profits, are assumed to be in real terms. $W_{0}$ and $N_{0}$ can be interpreted as minimum or reference levels of wages and employment. $\theta$ reflects the relative importance of wages and employment above the reference level.

Secondly, the expected utility or utilitarian utility function is widely found. The expected utility function is of the form (abusing notation)

$$
G(W, N)=\frac{N}{M} g(W)+\frac{M-N}{M} g(B), W \geq B, N \leq M,
$$

while the utilitarian function is specified as

$$
G(W, N)=N g(W)+(M-N) g(B), W \geq B, N \leq M,
$$

where $M$ denotes union membership and $B$ represents the unemployment benefit or the alternative wage. Both union membership and the alternative wage are assumed to be exogenous in this thesis. Note that if union membership is fixed, the two utility functions are equivalent. The idea behind the expected utility function, which is e.g. adopted by McDonald and Solow (1981), is that every member has a chance of N/M of being employed and a chance of $(\mathrm{M}-\mathrm{N}) / \mathrm{M}$ of being unemployed. The employed members enjoy utility $g(W)$ from the wage rate they eam, while the unemployed achieve utility $g(B)$ from the unemployment benefit or the altemative wage. The utilitarian function reflects the idea that the union treats all members identically and that the union's utility is the sum of its members' utility.

If the individual worker is uncertain about the wage rate he/she will eam, preferences with respect to risk become important. The utility function $\mathrm{g}(\mathrm{W})$ 
in the expected utility or utilitarian utility function can represent these preferences. The functional form which is most popular assumes constant relative risk aversion: $g(W)=W^{3} / \delta$. By differentiation of $g$, it is easy to see that the Arrow-Pratt measure of relative risk aversion, which is defined as $r=-W g " / g '$, equals $1-\delta$. If $\delta<1(D 0)$, workers are said to be risk averse; if $\delta>1(r<0)$, they are risk loving; if $\delta=1 \quad(r=0)$, they are called risk neutral.

The Stone-Geary function (1) includes as special cases two objectives which were proposed in the early literature. Dunlop (1944) proposed a union objective function of the form $G(W, N)=W N$, which is known as the wage bill maximization hypothesis. To see that the Stone-Geary function includes the wage bill maximization hypothesis, set $\mathrm{W}_{0}=\mathrm{N}_{0}=0$ and $\theta=0.5$. Note further that $\max (\mathrm{WN})^{0.5}$ is equivalent to $\max W N$, because the solution to an optimization problem is invariant under positive monotonic transformations. Rosen (1970) and De Menil (1971) suggested an objective of the form $G(W, N)=\left(W-W_{c}\right) N$, where $W_{c}$ denotes the competitive wage rate. The objective function measures the rents of unionization. The utilitarian utility function (3) is a straightforward extension of the wage bill maximization objective.

Comparing the Stone-Geary (1) and the expected utility (2) or utilitarian utility function (3), the former has the advantage of its flexibility, which is convenient for empirical work. The latter utility functions have the advantage of including the utility of workers not employed by the firm. Further, these functions are derived from individual workers' preferences, while this is not the case with the Stone-Geary function. References of empirical applications of the Stone-Geary function and the expected utility or utilitarian utility function are found in section 3. Oswald (1985) provides a list of authors using either of these utility functions in theoretical work.

Oswald $(1984,1987$ a) criticizes the implicit assumption in the utilitarian utility function that workers are laid-off at random. He presents evidence for Britain and the United States that in practice lay-offs are by inverse seniority. Therefore, the median union member should not be afraid of losing his/her job. Under majority voting the "union's preferences can be thought of merely as the desire for higher wages" $(1987 ;$ p. 12). Oswald proposes an altemative utility function

$$
G(W N)=g(W) \text { for } W>B, N \geqslant N_{s},
$$

where $N_{s}$ is the minimum employment level at which the worker with median seniority is employed. Oswald does not define $G(W, N)$ for $N<N_{x}$. A natural extension would be

$$
G(W, N)=g(B) \text { for } W>B, N<N_{s} .
$$

I accept Oswald's criticism of the implicit assumption of random lay-offs, but at this stage I am unwilling to conclude that unions do not care about 
employment. Firstly, Ross (1948) already argued that union leadership may be expected to pursue their own interests rather than those of the membership. Secondly, there is no reason to assume a priori that the median member is only interested in his own wage. "Altruism may well not be a relevant factor in a number of cases, but at the same time in parts of North American and West European societies there are deep traditions of working class fellowship and in such instances it would be short-sighted to presume that such sentiments have no behavioral consequences" (Pencavel (1985); p. 199). Thirdly, under centralized wage bargaining or decentralized financing of social security the union should take into account that the wedge between the gross wage rate and the net wage rate probably rises with the unemployment rate. Therefore, I am not convinced that union indifference curves are (always and everywhere) flat in the (W,N) space. In $3.2 \mathrm{I}$ will examine some empirical evidence on this issue.

\subsection{Basic models}

Manning (1987a,b,c) presents a sequential bargaining model which encompasses all basic models of union wage formation and employment. His general model is adopted to present the monopoly model, the right-tomanage model and the efficient bargain model. After presentation of the general model as set out in Manning (1987a), it is shown how the respective models can be obtained by restrictions on the relative bargaining power of union and firm.

In the sequential bargaining model the bargaining process is divided into two stages. In the first stage the union and the firm bargain over the wage rate (or the employment level) and in the second over the employment level (or the wage rate). The relative bargaining power of the union and the firm may differ in the two stages. Assume that the sequence of bargaining is that the wage rate is determined before employment. This is called the wageemployment sequential bargain. Let $G(W, N)$ and $H(W, N)$ respectively denote the union's and the firm's utility function with respect to real wage rate and employment. $G$ and $H$ are assumed to be quasi-concave. Let $\lambda$ and $\mu(0 \leq \lambda, \mu \leq 1)$ be measures of the union's influence over wage rate and employment, respectively. In the second stage of the bargaining process employment is chosen taking the wage rate as given. That is, employment is chosen so as to solve

$$
\max _{N} \mu \log G(W N)+(1-\mu) \log H(W, N) .
$$

The solution to this problem, which is assumed to be unique, may be written as $N(W, \mu)$. In the first stage of the bargaining process, the wage rate is chosen so as to solve 


$$
\max _{W} \lambda \log G[W, N(W, \mu)]+(1-\lambda) \log H[W, N(W, \mu)] .
$$

Equations (6) and (7) characterize the sequential bargaining model. Now, let us consider the implications of some restrictions on bargaining power and on preferences.

Firstly, assume that employment is determined by the firm and that the wage rate is set by the union, i.e. let $\lambda=1, \mu=0$. Assume further that the firm's preferences are represented by its short-run profit function

$$
H(W, N)=\Pi(W, N)=R(N)-W N, R^{\prime}(.)>0, R^{\prime \prime}(.)<0,
$$

where $R(N)$ denotes the firm's revenues (in real terms). Under these assumptions, (6) reduces to (the logarithm can be dropped, because it is a positive monotonic transformation)

$$
\max _{N} R(N)-W N .
$$

The first order condition gives the inverse of the labour demand equation

$$
R^{\prime}(N)=W \text {. }
$$

As the revenue function is monotone, (10) can be inverted to give the conventional labour demand curve. Now, (7) can be written as

$$
\max _{W} G(W, N)
$$

$$
\text { s.t. } R^{\prime}(N)=W \text {. }
$$

In other words, the union maximizes its utility function under the restriction that the outcome is on the labour demand curve. This model of wage and employment determination is known in literature as the monopoly model. It dates back to Dunlop (1944), and was formalized by Fellner (1947) and Cartter (1959). The model is illustrated in figure 1. The labour demand curve is downward sloping, because of diminishing marginal returns $\left(R^{\prime \prime}<0\right)$. The union indifference curves are convex, due to the quasi-concavity of the utility function. The highest attainable indifference curve for the union is tangent to the firm's labour demand curve.

Secondly, retain the assumption that the employment level is chosen unilaterally by the firm, but assume that wages are determined in a bargaining process between union and firm, i.e. assume $0 \leq \lambda \leq 1, \mu=0$. Let the firm again maximize short-run profits by solving (9). Making use of the monotony of the exponential function, the optimization problem in the first stage (7) can be written as 


\section{Chapter 2}

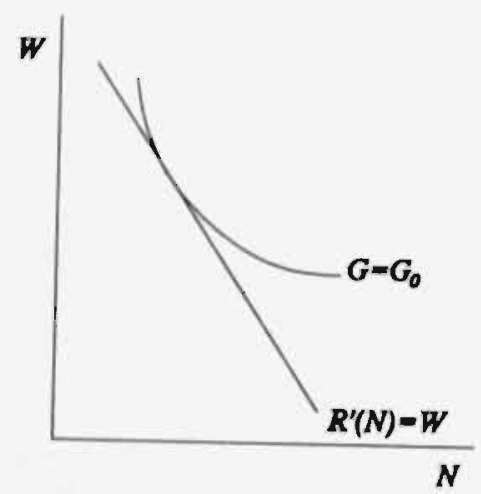

Figure 1 Monopoly model

$$
\max _{W}[G(W, N)]^{\lambda}[\Pi(W, N)]^{1-\lambda}
$$

$$
\text { s.t. } R^{\prime}(N)=W \text {. }
$$

The bargaining problem amounts to maximizing an asymmetric Nash bargaining function (Harsanyi and Selten (1972)) of union and firm utility under the restriction that the outcome is on the labour demand curve. The model (12) is a special case of the more general model

$$
\begin{aligned}
& \max _{W}\left[G(W, N)-G_{d}\right]^{2}\left[\Pi(W, N)-\Pi_{d}\right]^{1-\lambda} \\
& \text { s.t. } R^{\prime}(N)=W .
\end{aligned}
$$

where $G_{d}$ and $\Pi_{d}$ denote the disagreement or threat point of the union and the firm, respectively. This kind of model is introduced by Nickell (1982) and Nickell and Andrews (1983) under the name "right-to-manage model", referring to managerial freedom to set the employment level. The monopoly model is a special case of the right-to-manage model. The right-to-manage model is also called labour demand curve equilibrium model (MaCurdy and Pencavel (1986)) or shortly labour demand curve model. The model is illustrated in figure 2. Note that the wage employment outcome is the point of tangency of an isoquant of the Nash product and the labour dernand curve. It is also a point of intersection of the labour demand curve and a union indifference curve (not drawn). 


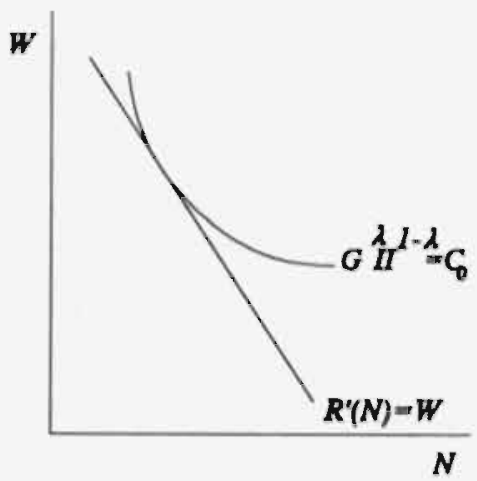

Figure 2 Right-to-manage model

Thirdly, assume that each party's bargaining power in the first stage is equal to its own bargaining power in the second stage, i.e. let $\lambda=\mu$. Assume the firm's objective is to maximize short-run profits. Then the sequential bargaining model requires choosing employment by solving

$$
\max _{N} \lambda \log G(W, N)+(1-\lambda) \log H(W, N)
$$

after determining the wage rate by solving

$$
\max \lambda \log G[W, N(W, \lambda)]+(1-\lambda) \log H[W, N(W, \lambda)],
$$

where $N(W, \lambda)$ is the solution of (14). Note that the objective function in (14) and (15) is the same, while the function in (15) is evaluated in the optimum of (14). Therefore, the envelope theorem can be invoked to combine (14) and (15) to

$$
\max _{W, N}[G(W, N)]^{\hat{\lambda}}[\Pi(W, N)]^{1-\lambda} .
$$

Again, the presented model is a special case of the more general model

$$
\max _{W, N}\left[G(W, N)-G_{d}\right]^{2}\left[\Pi(W, N)-\Pi_{d}\right]^{1-\lambda} .
$$

The optimization problem results in an asymmetric Nash bargaining solution. Irrespective of the value of $\lambda$, these solutions satisfy the first-order condition 


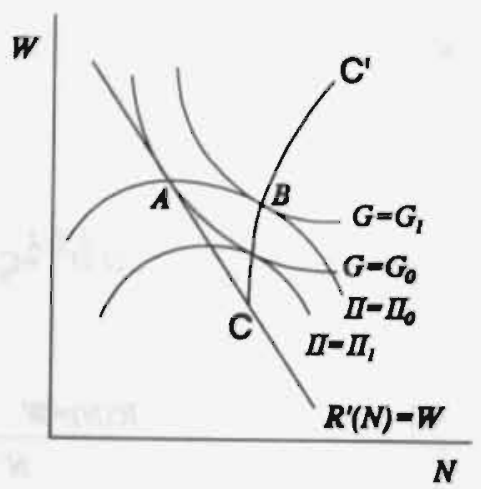

Figure 3 Efficient bargain model

$$
\frac{G_{2}}{G_{1}}=\frac{\Pi_{2}}{\Pi_{1}}=-\frac{R^{\prime}(N)-W}{N} .
$$

The first equality reminds us of the contract curve of Edgeworth (1881). Therefore, this kind of model is called efficient bargain model, contract curve equilibrium model (MaCurdy and Pencavel (1986)) or shortly contract curve model. The idea of bargaining about both wages and employment is introduced by Leontief (1946). More recently, it is found in Hall and Lilien (1979) and McDonald and Solow (1981). The contract curve, in figure 3 denoted by $\mathrm{CC}^{\prime}$, consists of points of tangency of union indifference curves and firm's isoprofit curves. If both the individual worker is risk averse and the union has utilitarian preferences, the contract curve is upward sloping $(\mathrm{d} W / \mathrm{dN}>0)$.

As the name of the model suggests, contracts which result from the efficient bargain model are Pareto efficient with respect to trade union and firm, while contracts which originate from the monopoly model or the rightto-manage model are not. In figure 3 it can be seen that point $A$, which is on the labour demand curve, is a point of intersection of a union indifference curve and a firm's isoprofit curve. At the south-east of this point, there is an area enclosed by this indifference curve and this isoprofit curve in which both the union and the firm are better off. The union comes at a higher indifference curve, while the firm reaches a lower isoprofit curve, corresponding to a higher profit level. This result is no coincidence, because it is easy to show that the union indifference curve is downward sloping ( $\left.d W / d N \mid\left[G(W, N)=G_{0}\right]=-G_{2} / G_{1}<0\right)$ and the isoprofit curve reaches a 
maximum at the labour demand curve $\left(\mathrm{dW} / \mathrm{dN} \mid\left[\Pi(\mathrm{W}, \mathrm{N})=\Pi_{0}\right]=-\Pi_{2} / \Pi_{1}=0\right.$, because $\Pi_{2}=0$ at the labour demand curve). At points on the contract curve no Pareto improvements are possible. The indifference curves and the isoprofit curves have the same slope at points of tangency. Therefore, there is no area where one party can be made better off without making the other party worse off.

Bargaining outcomes resulting from the efficient bargain model are not enforceable. This is seen as follows. Take a point in the (W,N) space which is on the contract curve, but is off the labour demand curve; for example, point $B$ in figure 3. At the going wage rate, the firm can reach a lower isoprofit curve, corresponding to a higher profit level, by reducing employment until it is on the labour demand curve. In other words, there is an incentive for the firm to cheat. If the union is unable to enforce such a contract, it probably prefers a contract with a high wage rate and a low employment level according to the labour demand curve model to a contract with a lower wage rate and a higher employment level according to the contract curve model. This suggests that efficiency can be improved by incentive compatible contracts, which make it unprofitable for the firm to deviate. Leontief (1946) and, more recently, Hall and Lilien (1979) show that such contracts can be devised by specifying a wage rate or a wage bill which is contingent on the employment level. Profit maximization by the firm $\left(R^{\prime}(N)=W(N)+N W^{\prime}(N)\right)$ leads to the efficient employment level if the contract is specified such that the firm internalizes the union's opportunity cost of supplying labour. Under uncertainty and asymmetric information, e.g about the firm's product demand, the scope of contingent contracts is limited, due to costs of gathering information and problems of moral hazard. More on this issue is found in e.g. Hall and Lilien (1979), Malcomson (1983), Horn and Svensson (1986), Black and Bulkley $(1984,1989)$ and Oswald (1987b).

Besides the models discussed above, the sequential bargaining framework offers a new class of models in which the union's influence over employment is neither zero $(\mu \neq 0)$, nor equal to the union's influence over the wage rate $(\lambda \neq \mu)$. This has an important implication for empirically testing between bargaining outcomes on the labour demand curve and on the contract curve (for a summary cf. subsection 3.2 of this chapter). If observed wage rates and employment levels tum out to be inconsistent with the labour demand curve model, this model can be rejected. However, this does not imply that the outcomes are on the contract curve. The sequential bargaining framework shows that there is a whole class of models which lead to bargaining outcomes which are neither on the labour demand curve, nor on the contract curve. 


\subsection{Seniority model}

As explained before, Oswald $(1984,1987$ a) criticizes the standard utility functions (1)-(3). He argues that the implicit assumption that lay-offs are by random draw is incorrect. In his seniority model, which is an altemative to the efficient bargain model of section 2.2, lay-offs are by inverse seniority. In order to specify union preferences let $N_{s}$ denote the minimum employment level at which the worker with median seniority is employed; see (4). This implies that the initial employment level at which all workers are employed is $2 \mathrm{~N}_{s}$. Union preferences are specified such that the indifference curves are horizontal in the $(\mathrm{W}, \mathrm{N})$ space for $\mathrm{N} \geq \mathrm{N}_{\mathrm{g}}$. For obvious reasons his model is also called flat indifference curve model.

In the seniority model the firm's minimum profit level is assumed to be $\Pi_{0}$. The union's optimization problem can be written as '

$$
\max _{W} G(W, N)=g(W)
$$

$$
\text { s.t. } \Pi(W, N) \geq \Pi_{0}, W>B, N \geq N_{s} \text {. }
$$

The model is illustrated in figure 4. Union's utility is maximized at the highest attainable indifference curve. If the restriction $N \geq N_{s}$ is not binding,

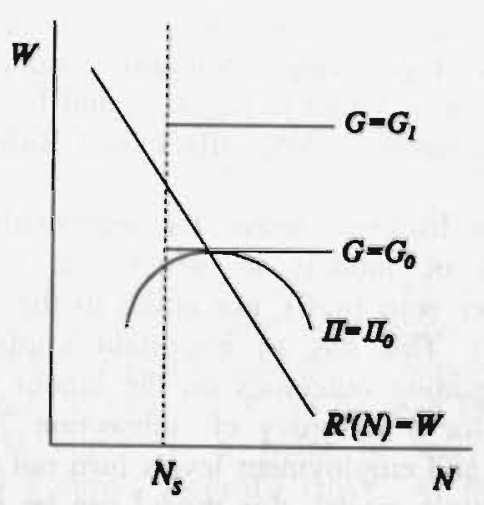

Figure 4 Seniority model

1 Whereas the efficient bargain model in 2.2 is written as an asymmetric Nash bargaining problem, the seniority model is written as a constrained maximization problem. The difference is not relevant, because the efficient bargain model can be written as a constrained maximization problem as well. 
this indifference curve is tangent to the minimum isoprofit contour. The point of tangency is at the maximum of the isoprofit curve, which is on the firm's labour demand curve. If the restriction $N \geq N_{s}$ binds, union's utility is maximized at the point of intersection of the line $\mathrm{N}=\mathrm{N}_{\mathrm{s}}$ and the minimum isoprofit curve. Comer equilibria are likely to be exceptional. Only a startling market shock could produce a comer allocation, because the initial employment level was twice as high. Oswald concludes that efficient contracts are on the labour demand curve.

\subsection{Bargaining theory}

In presenting the basic models of union wage setting and employment in section 2.2 two issues have been neglected. Firstly, the usage of the Nash bargaining solution has not been justified. Secondly, no attention has been paid to the effect of threats on the bargaining outcome. Since there have been important contributions on these issues in recent years, they are taken up in this section.

Basically, two approaches can be distinguished in solving a bargaining problem, namely the axiomatic approach and the strategic approach. In the axiomatic approach assumptions are made about the bargaining outcome without specifying the bargaining process. In the words of Nash (1953), "one states as axioms several properties that it would seem natural for the solution to have and then one discovers that the axioms actually determine the solution uniquely" (p. 219). The strategic approach describes the bargaining process itself. As Rubinstein (1982) points out, "the players' negotiating maneuvers are moves in a noncooperative game" (p. 98). Nash (1953) already tried to complement the axiomatic approach proposed in Nash (1950) with the strategic approach. According to Rubinstein (1982), the models proposed by Nash are highly stylized and artificial.

Binmore et al. (1986) establish the relationship between the two approaches. They present two strategic bargaining models in which the outcome approaches the Nash bargaining solution. In the first model the parties' incentive to reach an agreement is the bargainers' time preference. In the second model it is the exogenous risk of breakdown of negotiation. The utility functions are chosen to reflect the incentive to settle. In the timepreference model they reflect the relative impatience of the parties to settle. In the exogenous-risk model the utility functions express the parties' attitudes towards risk. The choice of the disagreement or threat points depends on the context as well. In the time-preference model the disagreement points correspond to the outcome that has the property that each of the parties is indifferent between reaching this outcome now or reaching it at any future time. In the exogenous-risk model the disagreement points correspond to the outcome obtained in the event of a breakdown of the bargaining process. 
The results by Binmore et al. (1986) provide a guide for the application of the Nash bargaining solution. In wage bargaining the central motive that drives the bargaining parties to reach an agreement is probably time preference. The relationship between the strategic and the axiomatic approach suggests that the disagreement points in the Nash bargaining model should be set equal to the parties' income streams during the dispute.

This interpretation of the disagreement points is used by Moene (1988) in a study of the effect of different kinds of industrial action on the bargaining outcome. He presents a time-preference model with several bargaining rounds. In each round either the union or the firm proposes a wage rate and the opposing party can accept or reject the offer. If the offer is rejected, there is a conflict. The income streams of both parties during a conflict depend on the kind of industrial action. The workers' income during a goslow action is assumed to be higher than their strike support. The compensation given to the firm during a strike (e.g. by the employers' organization) is supposed to be higher than the profit during a go-slow action. The outcome of the strategic game is shown to be equal to the solution of a Nash bargaining model in which the disagreement or threat points are set equal to the parties' income streams during a conflict. By choosing altemative disagreement points the effects of different kinds of industrial action on the bargaining outcome are studied. If there is a strike during a conflict, the bargaining process results in a higher employment level and a lower wage rate than if there are go-slow actions. Which kind of industrial action is used is determined either by law or by the credibility of the threats.

\section{Empirical research}

The empirical research can be split into two parts. In the first part the model of wage and employment determination is taken as given. The data are used for different purposes, such as to reveal union preferences, to test the empirical applicability of the model itself, or to draw inferences on the implications of union wage setting. The second part concerns testing between competing models of wage and employment determination, especially between the labour demand curve model and the contract curve model. The results of the first part are summarized in 3.1, the results of the second part in 3.2 .

\subsection{Estimation results}

The model which is estimated most often is the monopoly model. Some of these studies are based on micro-data, others on aggregate data. The aim of the first group of studies is mainly to draw inferences on union preferences. 
The studies by Farber $(1978 \mathrm{a}, \mathrm{b})$ seem to be the first empirical applications of the monopoly model. Later, empirical work was done by Dertouzos and Pencavel (1981), and Pencavel (1984a,b). The study of Carruth and Oswald (1985) is the only one which is based on European micro data. As is clear from table 1. Dunlop's wage bill maximization hypothesis is decisively rejected. Evidence on the rents of unionization hypothesis is too scarce to draw a conclusion. The aim of the second group of studies is more diverse. Pencavel (1985) finds that the parameter restrictions inaplied by the monopoly model must be rejected against an unconstrained loglinear model. A problem with this result, which is not unusual, is that the unconstrained loglinear model is difficult to interpret theoretically. In a later study, Pencavel and Holmlund (1988) conclude that hours of work play a role in the union objective function which is distinct from eamings.

The right-to-manage model is firstly implemented by Nickell and Andrews (1983). According to Nickell and Andrews, this model is to be preferred to the efficient bargain model, because firms find it advisable to make continuous adjustments to their total level of employment. The estimation results suggest that around 400,000 people in Britain are unemployed due to the effect of unions on real wages. Hoel and Nymoen (1988) use the framework of Nickell and Andrews to model the relationship between real wages, unemployment and inflation. Instead of a natural unemployment rate or NAIRU, they find that any constant unemployment rate is compatible with a constant rate of inflation and a real wage growth equal to productivity growth.

The efficient bargain model is used in empirical work by Svejnar (1986). The bargaining process is modelled as an asymmetric Nash bargaining problem. The relative bargaining power of the union and the firm depends on exogenous factors, such as the unemployment rate and the rate of change of consumer prices. The estimates, based on time series data of U.S. industry, support the view that exogenous changes in the bargaining environment influence the outcome. The results also provide some indirect evidence that bargaining outcomes are not on the labour demand curve, but on a vertical contract curve. The model developed by Svejnar is estimated by Veugelers (1989) using cross-section data of Belgian manufacturing. The empirical results indicate that in the division of the price-cost margin unions gain less than management. Product market concentration has a significant positive impact on cross-industry variation of bargaining power, whereas unemployment has an insignificant positive impact. The bargaining outcomes are assumed to lie on a vertical contract curve a priori, so the results cannot be interpreted as indirect evidence against the labour demand curve model. 


\section{Table 1 Summary of estimation results}

study

monopoly model with micro data

Farber $(1978 a, b)$

Dertouzos/Pencavel (1981)

Pencavel (1984a)

Pencavel (1984b)

Carruth/Oswald (1985)

monopoly model with aguregatc data

Pencavel (1985)

Pencavel/Holmlund (1988) sample

specification of union objective function

estimation/testing

result

wage bill maximization

expected utility function with constan relative risk aversion

United Mine Workers. annual observations from 1946 to 1973

US newspaper industry, Iypographical workers in 8 towns belonging to Intemational Typographical Union, annual observations frorn 1946 to 1965

US newspaper industry. typographical workers in 10 towns belonging to ITU, annual observations from 1946 to 1965

cl. Pencavel (1984a)

Stone-Geary

British coal industry, workers belonging to National Union of Mineworkers, annual observations from 1950 to 1980

Sweden, manufocturing and mining sector. annual observations from 1968 10 1982

Sweden, manufacturing and mining sector. annual observations from 1950 to 1983
Stone-Geary (logarithmic form)

utilitarian utility function with constant relative risk aversion rejected

wage bill and rent maximization rejected

rent maximization cannot be rejected

wage bill maximization rejected

wage bill maximization rejected
Stone-Geary (logarithmic form) parameter restrictions implied by structural form are rejected against unconstrained loglinear model

hours of work have a role in union objective which is distinct from earnings 
specification of union objective function

estimation/testing

result

Right-to-manage model

\section{Nickely/Andrews}

HoelNymoen (1988)

\section{Efficient bargain model}

Svejnar (1986)

Veugelers (1989)
Greal Britain, aggregate labour markeh annual observations firm 1951 to 1979

Norway, manufacturing sector, quarterly obser. vations from 1968 to 1983

US industry, workers from 12 major unionized companics, annual observations from mid 1950 's to late 1970 's

Belgian manufacturing. workers from 30 industries, cross-sectional data for the year 1978 utilitarian utility function with constant rela. tive risk aversion

utility function is not explicitly speified

expected utility function with constant relative risk aversion

expected utility function with risk neutral preferences the impact of unions via real wages on unemployment is around 400,000

any constant unemployment rate is compatible with a constant rate of inflation and a real wage growth equal to productivity growth

exogenous changes in environment influence bargaining outcome

unions gain less than management in division of price-cost margin; product market concentration has a significant positive impact on union bargaining power, unemployment rate has insignificant positive impact 


\subsection{Testing results}

Results of testing between the labour demand model and the efficient bargain model are presented by Brown and Ashenfelter (1986), Card (1986), MaCurdy and Pencavel (1986), Eberts and Stone (1986), Bean and Tumbull (1988), Nickell and Wadhwani (1988) and Martinello (1989). All studies, except two, are based on U.S. data. Due to differences in institutional setting there clearly remains scope for empirical research in Europe.

The testing procedures centre around the specification of labour demand. In the labour demand curve model the firm equates the value of marginal productivity to the wage rate

$$
R^{\prime}(N)=W .
$$

In the efficient bargain model the slope of the isoprofit curves and indifference curves are equal. The contract curve can be described by (cf. 18)

$$
R^{\prime}(N)=W-N \frac{G_{2}(W, N)}{G_{1}(W, N)} .
$$

The labour demand curve equation can be considered as a special case of the contract curve equation, namely the case where the last term of (21) is equal to zero. Notice that in the efficient bargain model the employment level depends on the alternative wage rate ${ }^{2}$, whereas in the labour demand curve model it does not. Brown and Ashenfelter, Card, Bean and Turnbull and Nickell and Wadhwani exploit this fact to distinguish between both models. MaCurdy and Pencavel allow for more factors of production and test whether the ratio of marginal products equals the ratio of input prices. Eberts and Stone introduce employment-security provisions which might lead to wage-employment combinations off the labour demand curve. The testing procedure seeks to ascertain whether the strength of these provisions increases the gap between the wage rate and the value of marginal productivity. Martinello, finally, proposes a non-nested testing procedure.

The empirical evidence, which is summarized in table 2 , suggests that wage-employment combinations off the labour demand curve are observed. The results should be interpreted with care, however. Brown and Ashenfelter get estimates which are either insignificant or of the wrong sign. Card's model does not provide a credible interpretation of observed movements in wages and employment. MaCurdy and Pencavel notice that the test to discriminate between the labour demand curve model and the efficient bargain model requires much more of the former than of the latter.

${ }^{2}$ Employment depends on the altemative wage unless the argument $\mathrm{B}$ vanishes in the ratio $G_{2}(W, N ; B) / G_{1}(W, N ; B)$. 
Hirsch and Addison (1986; p. 17) note that the results of Eberts and Stone pertain to the public sector, which is not-for-profit. Therefore they are reluctant to generalize the results to the private sector. Bean, Turnbull, Nickell and Wadhwani argue that the results obtained may also be explained by efficiency wage considerations; see chapter 4 for a review of the efficiency wage theory. The testing results of Martinello are inconclusive. Further, it should be noted that in most cases the labour demand curve model is rejected, but the efficient bargain model remains untested. For example, the fact that alternative wages play a role in the determination of employment casts some doubt on the validity of the labour demand curve model, but does not imply that the efficient bargain model is correct. Although the performance of the labour demand curve model is unsatisfying, at this stage I am unwilling to reject it in favour of the efficient bargain model.

There remains scope for improvement of the proposed testing procedures. Firstly, most authors estimate a single equation, namely a labour demand equation. A better approach is to estimate simultaneously a labour demand equation and a wage equation to avoid identification problems. Secondly, the testing procedures are based on static theoretical models, whereas labour demand is highly dynamic; an exception is the model by Card (1986). For example, it can be assumed that unions aim at maximizing the discounted value of some utility function. This would imply that unions aim at reaching an optimal utility path instead of a discrete point as in the static case. Problems of credibility and reputation may be integrated in such a dynamic analysis. Further, there remains scope for empirical work based on other data sets. At the moment it is unclear whether the empirical results, which are nearly all based on data from the U.S., are valid in other countries as well. Unlike the U.S., wage bargaining in countries such as Norway, Sweden, Denmark, Austria, Germany, Belgium and the Netherlands often takes place at sectoral and/or national level. In this situation it seems unlikely that a union is able to enforce employment levels that deviate from firms' labour demand curves. Additional evidence for the relevance of the bargaining environment is provided by Calmfors and Driffill (1988), Freeman (1988) and Layard (1989). They show that differences in employment records may be related to the bargaining environment. Therefore, empirical evidence from the U.S. in favour of the efficient bargain model cannot be generalized to Western Europe.

A test of the seniority or flat indifference curve (FIC) model against the monopoly union and efficient bargain model is provided by Carruth et al. (1986). The idea behind the test is as follows. In both the monopoly and efficient bargain frameworks the union's utility depends on employment. In the FIC model, however, the trade union is not concerned with the utility of the unemployed and should therefore not react to a rise or fall in those 


\section{Table 2 Summary of testing results}

study
Brown/Ashenfelter
(1986)

Card (1986)

MaCurdy/Pencavel (1986)

Eberts/Stone (1986)

Rewn/umbull (1988)

\author{
sample
}

US newspaper industry. typographical workers in 10 towns belonging to International Typographical Union, annual observations in various years from 1948 to 1965

US airline industry, mechanics at 7 firms, belonging 10 Transpor Workers Union, the Teamsters and the Machinists, quanerly observations from 1969 to 1976

US newspaper industry. typographical workers in 13 wowns belonging to ITU, annual observations in various years from 1945 to 1973

New York State, public school teachers, belonging to New York State United Teachers, 7905 observations for the school years 1972-1973 and 1976-1977

British coul industry. 12 coal hoard areas, annual observations frum 1967 iv 1083

\section{testing procedure \\ employment depends on contract wage (mono- polistic wage setting), on altemative wage (strongly efficient bar- gaining) or on both (wealkly efficient bar= gaining)}

\section{cf. Brown/Ashenfelter (1986) \\ both monopolistic wage setting and strongly efri- cient bargaining are rejected in favour of weakly efficient har- gaining}

ratio of marginal products is equal to ratio of input prices (i.e. outcome on labour demand curve) or is not (outcome possibly on contract curve)

gap between wage rate and marginal productivity increases with strength of employmentsecurity provisions (contract curve model) or does not (possibly labour demand curve model)

employment depends on altemative wage and employment possibitities (labour demand curve model rejected) or does not (outcome possibly on contraxt curve)

\section{testing result}

no convincing evidence of strongly efficient bargaining. some support for weakly efficient bargaining

solid evidence against bargaining outcome on labour demand curve, estimation results are generally consistent with outcome on contract curve

the estimates support the contract curve model and rejoct the labour demand curve model

results reject Labour demand curve model and are in accord with contract curve model 
study

Nickell/Wadhwani (1988)

Martinello (1989)

Carruth et al. (1986) sample

British firm-level data. 219 firms, annual observations from 1974 to 1982

British Columbia wood products industry. workers belonging to Internationg̨! Woodworkers of Âmerica. 4 industries, annual ob. servations from 1963 to 1983

British coal and mining industry, annual observations from 1950 to 1980

\section{testing procedure}

employment depends positively (efficiency wage contraci) or depends negatively on altemative wage (contract curve model), or is independent of alternative wage (labour demand curve model)

non-nested hypothesis testing between monopoly model and efficient bargain model

wage and employment in sector are independent of unemployment benefit and of aggregate unemployment (FIC model) or are not (monopoly model or efficient bargain model) testing resulı

evidence is consistent with labour demand curve modef, suitably augmented to allow for efficiency wage considerations

failure to decisively rejest one model in favour of the other

results reject flat inditference curve mode] 
variables which affect an unemployed person's welfare. The level of utility of union members who lose their jobs is unobserved. The unemployment benefit and aggregate British unemployment are used as a proxy. If the unemployment benefit and aggregate level of unemployment can be shown to have no influence on pay and the level of jobs, this should count as evidence in favour of the FIC model. The data consist of annual observations of the British mining industry and the British steel industry over the post-war period. The results imply that the FIC model must be rejected. This concludes our review of the empirical evidence on union wage setting and employment.

\section{Concluding remarks}

Evaluating the state of the art, the integration of trade union behaviour into economic theory has made clear that wage rates are not determined by perfect competition. Nevertheless, there remains much to be explained. Firstly, dynamics of union wage setting have been nearly neglected so far. Exceptions include Kidd and Oswald (1987), Driffill (1985), Van der Ploeg (1987) and Lockwood and Manning (1989). Secondly, long-term analysis with endogenous investment requires more attention. Thirdly, the relationship between union wage formation theory and competing theories of wage and employment determination, such as insider-outsider theory and efficiency wage theory, is not clear. A problem to discriminate empirically between the competing theories is that they give rise to more or less similar regression equations; $c f$. the discussion in Layard and Nickell $(1985,1986)$. Another problem is that relatively short time series of aggregate data often do not "deliver unambiguous answers to the sort of questions economists ask of them" (Pencavel (1989), p. 32). Hopefully, the use of micro-data, as in Nickell and Wadhwani (1988), or the use of aggregate data of several countries helps to answer these questions. The relationship between the theories can also be investigated by combining them. The interaction between insider-outsider and efficiency wage effects is studied in chapter 4 . Chapter 5 presents an integration of trade union theory and efficiency wage theory via contract wages and wage drift. Insider-outsider effects in union wage formation are discussed in chapters 6 and 7. Before, an empirical application of union wage formation theory is presented in chapter 3. 


\title{
3 Union wage formation and unemployment in the Netherlands (1965-1987)
}

\begin{abstract}
This chapter presents an empirical model of union wage formation and employment. The (Stackelberg) equilibrium unemployment rate is shown to be a function of taxes, the replacement ratio, the gap between consumer and producer prices, productivity effects, and the rate of long-term unemployment. The model is estimated with aggregate data of the private sector in the Netherlands (1965-1987). The results suggest that the equilibrium unemployment rate is pushed upwards by taxes, the replacement ratio and by the gap between consumer and producer prices, and is reduced by productivity effects. Insideroutsider effects appear insignificant.
\end{abstract}




\section{Chapter 3}

\section{Introduction}

During the nineteen eighties, Western Europe suffered from persistently high unemployment rates. One explanation for this phenomenon, as suggested by Layard and Nickell (1985, 1986, 1987), is that several factors, such as taxes and terms of trade effects, have pushed up wages above the market clearing level. In other words, changes in the natural rate or NAIRU are attributed to these 'push' factors. An altemative explanation, as proposed by Lindbeck and Snower (1986, 1987a, 1988). Solow (1985), and Blanchard and Summers (1986, 1987), is that wage determination is dominated by employed insiders, who do not care about unemployed outsiders. These explanations are fruitfully combined in an empirical study of wage determination in the U.K. by Nickell (1987).

This chapter presents an application of the theory of union wage formation, summarized in chapter 2 , to explain equilibrium unemployment. The model of union wage formation and labour demand (which is assumed to be equal to employment) integrates the push factors and the insider-outsider effects mentioned above. The equilibrium unemployment rate is shown to be a function of tax rates, the replacement ratio, the gap between consumer and producer prices, productivity effects, and insider-outsider effects. The model is estimated with aggregate annual data of the private sector in the Netherlands (1965-1987).

The rest of this chapter is set up as follows. Section 2 presents some data to give an impression of the economic situation in the Netherlands. The empirical model is derived in section 3. The data and estimation results are described in section 4 . Section 5 provides a decomposition of changes in the equilibrium unemployment rate. A summary and suggestions for further research are offered in section 5.

\section{Economic situation in the Netherlands}

During the nineteen eighties, the Netherlands was among the countries with the highest unemployment rate in the E.C.. As is illustrated in figure 1, from 1965 until 1971 unemployment was below 2.2 per cent. Between 1971 and 1975 unemployment rose to some 5 or 6 per cent, where it remained until 1979. Between 1980 and 1983 unemployment increased sharply from 6 per cent to 15 per cent. In the second half of the nineteen eighties, unemployment slowly diminished. The long-term (over one year) unemployment rate was below 0.4 per cent from 1965 until 1974. In the second half of the nineteen seventies, it was little above I per cent. Between 1981 and 1984 . the long-tern unemployment rate rose from 1.6 per cent to 8.4 per cent. In the second half of the nineteen eighties, the long-term unemployment rate 


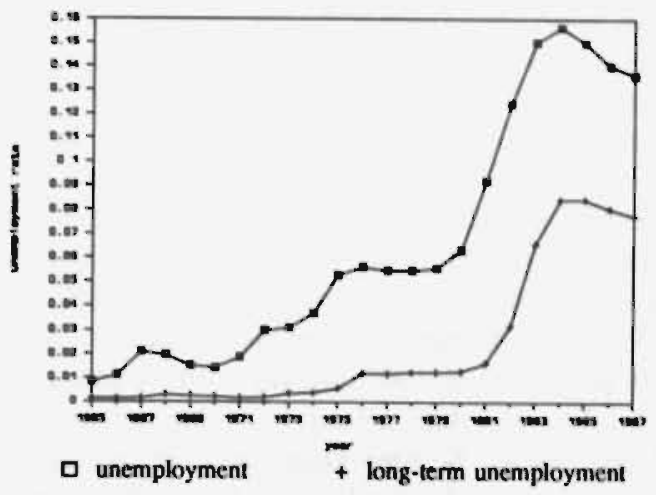

Figure 1 Unemployment and long-term unemployment

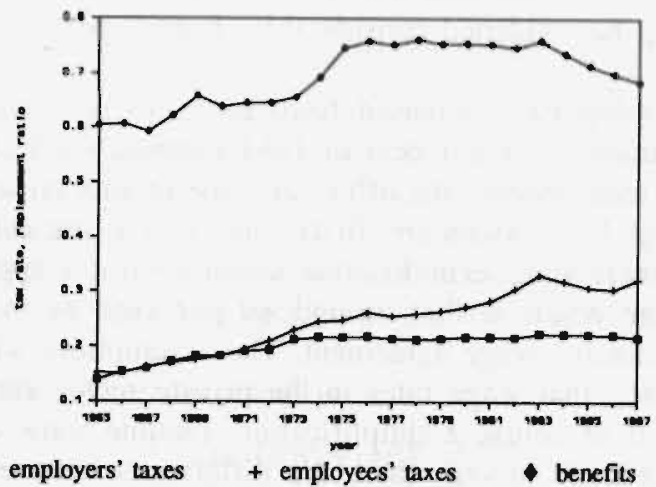

Figure 2 Taxes and benefits

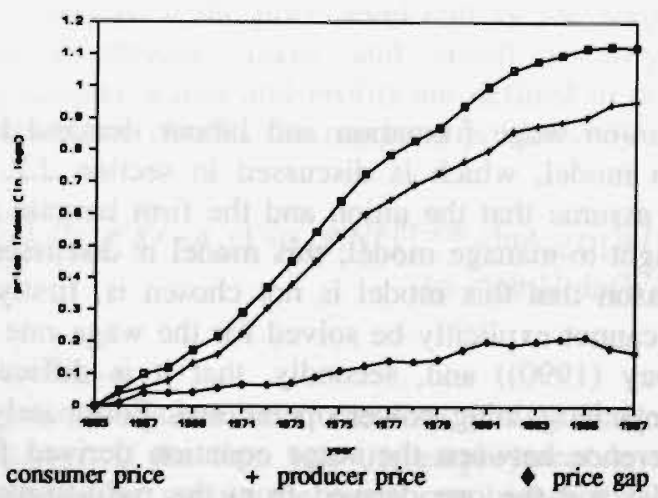

Figure 3 Consumer and producer prices 
slowly diminished. Note that since 1984 the share of long-term unemployed in total unemployment is above 50 per cent.

Turning to the 'push' factors, figure 2 illustrates the increase in the employers' and employees' rate of taxes and social security contributions and the replacement ratio. The rate of employers' contributions rose from 14 per cent in 1965 to 22 per cent in the late nineteen eighties. The employees' tax rate increased from 15 per cent in 1951 to 33 per cent in 1983. The replacement ratio grew as well, from 60 per cent in 1965 to 75 per cent in 1975. It remained at this level until 1983, after which it diminished to 69 per cent in 1987. Besides the enormous increase in tax burden, a considerable gap has arisen between consumer prices and producer (value added) prices. Setting both the consumer price index and the producer price index of 1965 equal to 1 , figure 3 shows that the relative change of consumer prices vis-a-vis producer prices has been about 20 per cent between 1965 and the mid nineteen eighties. Especially between 1973 and 1981 the gap has widened considerably: from 7 per cent in 1973 to 20 per cent in 1981.

Union membership has decreased from some 40 per cent in the fifties, sixties and seventies to 29 per cent in 1987 (source: CBS (1987)). Despite the reduction in membership, the effect of trade unions on wage determination is still strong. The reasons are, firstly, that unions are authorized by law to represent workers and, secondly, that union contracts apply to nonmembers as well. The result is that around 80 per cent of the employees is covered by a collective wage agreement. The assumption, which is maintained in this chapter, that wage rates in the private sector are deternined by one trade union is of course a simplification. Despite some coordination by confederations of trade unions, there are differences between sectors. Note that also the phenomenon of wage drift is neglected in this chapter. Let us tum to the derivation of the empirical model.

\section{Model}

The model of union wage formation and labour demand is based on the monopoly union model, which is discussed in section 2.2. An alternative possibility is to assume that the union and the firm bargain about the wage rate, as in the right-to-manage model; this model is discussed in section $\mathbf{2 . 2}$ as well. The reason that this model is not chosen is, firstly, that the firstorder condition cannot explicitly be solved for the wage rate (cf. De Bruyne and Van Rompuy (1990)) and, secondly, that it is difficult to make the theoretical concept bargaining power operational. Fortunately, there appears to be little difference between the wage equation derived from the monopoly union model and the one derived from the right-to-manage model. A third possibility is to assume that the wage employment outcome is on a 
contract curve, as in the efficient bargain model; cf. section 2.2. Since bargaining about employment is rare in the Netherlands, this does not seem realistic. In the monopoly model, the union sets the wage rate taking into account the trade-off between the wage rate and the employment level as specified by the firm's labour demand curve. The equilibrium is of the Stackelberg type, where the union acts as leader and the firm as follower. The wage employment outcome is always on the labour demand curve. The outcome is an equilibrium in the sense that it does not pay the firm to deviate by choosing an employment level which is not the corresponding point on the labour demand curve. 'It is assumed that the union and the firm take the price level as given.

Let the representative firm's technology be represented by a constant retums to scale production function of the CES type,

$$
\begin{gathered}
Y=\left[A_{K}\left(1+\alpha_{K}\right)^{\rho /} K^{\rho}+A_{N}\left(1+\alpha_{N}\right)^{\rho / N^{\rho}}\right]^{1 / \rho}, \\
0 \neq \rho<1, A_{K}, A_{N}>0, \alpha_{K}, \alpha_{N} \geq 0,
\end{gathered}
$$

where $\mathrm{Y}, \mathrm{K}$ and $\mathrm{N}$ denote value-added output, capital stock and employment, respectively. Capital-augmenting and labour-augmenting technical progress are captured by $\left(1+\alpha_{K}\right)^{t}$ and $\left(1+\alpha_{N}\right)^{\prime}$, respectively, where $t$ is a time index. The parameter $\rho$ is related to the elasticity of factor substitution by $\sigma=1 /(1-p)>0$. The firm is assumed to maximize its short-run profits taking the output price and the wage rate as given. The capital stock is predetermined.

The firm's maximization problem is

$$
\max _{N} \Pi(W, N)=P Y-W N
$$

s.t. (1),

where $\Pi$ denotes profits, $P$ the price level and $W$ the wage rate (including employers' and employees' taxes and social security contributions). Throughout this chapter wages and profits are defined in nominal terms. As first-order condition one obtains the marginal productivity condition (taking logarithms)

$$
\begin{array}{r}
\ln \left[A_{K}\left(1+\alpha_{K}\right)^{\rho t} K^{\rho}+A_{N}\left(1+\alpha_{N}\right)^{\rho} N^{\rho}\right]^{(1-\rho) / \rho}+\ln A_{N}+\rho t \ln \left(1+\alpha_{N}\right) \\
+(\rho-1) \ln N-\ln (W / P)=0 .
\end{array}
$$

1 There results no equilibrium if the firm acts as Stackelberg leader and the union as follower. If the firm sets the employment level, the union can obtain a higher utility by setting the wage rate higher than indicated by the labour demand curve. 
Combining the marginal productivity condition with the production function gives the labour demand equation (lower case letters denote natural logarithms, unless otherwise stated)

$$
n=a_{N} \sigma+\alpha_{N} \rho \sigma t-\sigma(w-p)+y,
$$

where $\ln \left(1+\alpha_{N}\right)$ is approximated as $\alpha_{N}$ and where $a_{N}$ denotes $\ln A_{N}$.

Let the representative union's preferences be represented by a utility function $G(W, N)$. The union is supposed to maximize its utility subject to the firm's labour demand function (because output is endogenous, (3) is used as constraint instead of (4)), taking the price level as given

$$
\max _{W, N} G(W, N)
$$

\section{s.t. (3).}

The first-order conditions for a maximum, combined with the production function (1) and the marginal productivity condition (3), give the wage equation (in logs)

$$
w=p+y-n+\ln \left[1-\sigma \frac{N G_{2}(W, N)}{W G_{1}(W, N)}\right]
$$

The utility function I propose is a generalization of $\mathrm{G}=\mathrm{WN}^{\zeta}$, which is proposed by Nickell and Andrews (1983). Assuming that the weight the union attaches to employment depends positively on the aggregate unemployment rate $(\mathrm{u})$ possibly corrected for long-term unemployment (ul) and negatively on the replacement ratio (b), union preferences are represented by

$$
G(W, N)=W N \zeta+\eta(u-v u r)-\theta b
$$

The union is supposed to take the aggregate unemployment rate and the replacement ratio as given. Using (7), the wage equation becomes

$$
w=p+y-n+\ln [1-\sigma(\zeta+\eta(u-v u l)-\theta b)]
$$

The wage rates in the data-set include employers' and employees' taxes and social security payments. It seems reasonable to assume that the union is unwilling to accept a lower net wage if employers' taxes are increased. Possibly also a higher gross wage rate is demanded if the employees' taxes are increased. Note that the relationship between the gross wage rate (including both employers' and employees' taxes) $\left(W_{3}\right)$ and the net wage rate $\left(W_{n}\right)$ is given by $W_{s}\left(1-s_{1}\right)\left(1-s_{2}\right)=W_{n}$, where $s_{1}$ and $s_{2}$ denote the employers' and employees' tax rate, respectively. Taking logs and rearranging gives $w_{3}=w_{n}-\ln \left(1-s_{1}\right)-\ln \left(1-s_{2}\right)$. Therefore, the wage equation is augmented 
with the terms $-\ln \left(1-s_{1}\right)$ and $-\ln \left(1-s_{2}\right)$. The former's coefficient should be close to 1 , the latter's coefficient somewhere between 0 and 1 . At the outset it is not clear whether the union uses a consumer or producer price deflator. Therefore, the wage rate is allowed to increase with the gap between consumer prices and producer prices, $\mathrm{p}_{\mathrm{c}}-\mathrm{p}$. Somewhat linearizing $(8)$ and including the terms discussed leads to the following wage equation

$$
w=\gamma_{0}+p+y-n-\gamma_{1} \ln \left(1-s_{1}\right)-\gamma_{2} \ln \left(1-s_{2}\right)+\gamma_{3} b+\gamma_{4}\left(p_{c}-p\right)-\gamma_{5}\left(u-\gamma_{6} u l\right)
$$

Aggregating over all firms leads to an identical labour demand equation (4) and an identical wage equation (9), except that output and employment are replaced by their aggregate values. Apologizing for the abuse of notation, let $y$ and $n$ denote aggregate values from now on. Combining the aggregate employment equation (4) and the aggregate wage equation (9) gives the aggregate unemployment rate equation

$$
\begin{aligned}
u= & \gamma_{7}+\rho / \gamma_{5}\left(y-n-\alpha_{N} t\right)-\gamma_{1} / \gamma_{5} \ln \left(1-s_{1}\right)-\gamma_{2} / \gamma_{5} \ln \left(1-s_{2}\right)+\gamma_{3} / \gamma_{5} b \\
& +\gamma_{4} / \gamma_{5}\left(p_{c}-p\right)+\gamma_{6} u l,
\end{aligned}
$$

where $\gamma_{7}=\left(-a_{N}+\gamma_{0}\right) / \gamma_{5}$. From (10) it is easily seen that the equilibrium unemployment rate is not independent of labour productivity. In this respect the model differs from the model by Layard and Nickell (1986), who assume that this independence does hold.

If the production technology can be described by a Cobb Douglas function, which is a special case of the CES function, it is easy to show that the intersection of (4) and (9) is a stable equilibrium. By setting $\rho=0 \quad(\sigma=1)$ equation (4) becomes

$$
w+n-p-y=-\alpha_{N} \sigma .
$$

Equation (9) becomes

$$
w+n-p-y=\gamma_{0}-\gamma_{1} \ln \left(1-s_{1}\right)-\gamma_{2} \ln \left(1-s_{2}\right)+\gamma_{3} b+\gamma_{4}\left(p_{c}-p\right)-\gamma_{5}\left(u-\gamma_{6} u l\right)
$$

Drawing these two curves in the $(w+n-p-y, u)$ space, equation (11) gives a horizontal labour demand curve, whereas equation (12) gives a downwardsloping wage demand curve. The intersection of the two curves gives the equilibrium share of labour in value added and the equilibrium unemployment rate. ${ }^{2}$ The Stackelberg equilibrium is stable unless the follower wants to act as a leader.

2 If the production process cannot be described by a Cobb Douglas function it is more difficult to illustrate the equilibrium graphically, because the productivity terms in (4) and (9) are different. 


\section{Chapter 3}

The empirical model is based on the labour demand equation (4) and the wage equation (9). The unemployment equation (10) is not included in the estimation procedure to avoid singularity problems. In the real world, labour demand and wage rate cannot instantaneously be adjusted due to adjustment costs or to long-term contracts. Therefore some form of dynamics is required in the equations for empirical work. Assume that actual labour demand and wage rate follow a second-order partial adjustment process (AR2) to the equilibrium values as derived above. Then the empirical model can be written as

$$
\begin{aligned}
& n=\gamma_{11} n_{-1}+\gamma_{12} n_{-2}+\left(1-\gamma_{11}-\gamma_{12}\right)\left[\gamma_{10}+\rho \alpha_{N} \sigma t-\sigma(w-p)+y\right]+e_{1}, \\
& 0 \leq \gamma_{11}+\gamma_{12}<1,0 \neq \rho<1, \sigma=1 /(1-\rho)>0 . \\
& w=\gamma_{21} w_{-1}+\gamma_{22} w_{-2}+\left(1-\gamma_{21}-\gamma_{22}\right)\left[\gamma_{20}+p+y-n\right. \\
& \left.\quad-\gamma_{23} \ln \left(1-s_{1}\right)-\gamma_{24} \ln \left(1-s_{2}\right)+\gamma_{25} b+\gamma_{26}\left(p_{c}-p\right)-\gamma_{27}\left(u-\gamma_{28} u l\right)\right]+e_{2}, \\
& 0 \leq \gamma_{21}+\gamma_{22}<1,0 \leq \gamma_{23}, \gamma_{24}, \gamma_{25}, \gamma_{26} \leq 1, \gamma_{27}>0,0 \leq \gamma_{28} \leq 1 .
\end{aligned}
$$

The vector of error terms $e^{\prime}=\left(e_{1}, e_{2}\right)$ is assumed to be independently and identically distributed over time. The vector is assumed to have zero mean; the contemporaneously covariance matrix is finite. In the wage equation, prices are lagged half a year corresponding to wage indexation clauses. Unemployment in the wage equation is lagged one year. This concludes the modifications for empirical work.

\section{Empirical results}

The data consist of annual observations of the private sector in the Netherlands (1965-1987) and are obtained from the Central Planning Bureau. Earlier data on the replacement ratio are not available. Note that the output level and (possibly) the price level are endogenous. To avoid simultaneity bias, the parameters are estimated by 3SLS, using exogenous and lagged endogenous variables as instruments for $y$ and $p$. The results are reported in table 1 .

In the labour demand equation, the parameter estimates imply a short-run real wage elasticity (taken positively) of 0.21 , which is between the estimate by Bean et al. (1986) for the Netherlands $(0.11)$, and the estimate by Layard and Nickell (1986) for the U.K. (1954-1983), namely 0.29. The long-run real wage elasticity (which is also the elasticity of factor substitution) of 0.65 is smaller than that obtained by Bean et al. (1.15), but close to the 
Table 1 Estimation results

labour demand equation

$\begin{array}{llcl}\text { constant } & \gamma_{10} & -1.36 & (0.17) \\ \text { 1st adjustment coefficient } & \gamma_{11} & 1.17 & (0.13) \\ \text { 2nd adjustment coefficient } & \gamma_{12} & -0.50 & (0.11) \\ \text { factor substitution } & \rho & -0.53 & (0.13) \\ \text { technical progress } & \mathrm{B} & 0.033 & (0.0033) \\ & & & \\ \text { standard error of regression } & & 0.0079 & \\ \text { R-squared } & & 0.77 & \\ \text { Durbin-Watson d-statistic } & & 1.62 & \\ & & & \\ \text { wage equation } & & & \\ & & & \\ \text { constant } & \gamma_{20} & -0.55 & (0.13) \\ \text { 1st adjustment coefficient } & \gamma_{21} & 1.23 & (0.15) \\ \text { 2nd adjustment coefficient } & \gamma_{22} & -0.86 & (0.21) \\ \text { employers' tax rate } & \gamma_{23} & 1.00 & (\mathrm{t}=0.72) \\ \text { employees' tax rate } & \gamma_{24} & 0.28 & (0.23) \\ \text { replacement ratio } & \gamma_{25} & 0.16 & (0.15) \\ \text { consumer/producer price gap } & \gamma_{26} & 0.57 & (0.29) \\ \text { unemployment rate } & \gamma_{27} & 1.50 & (0.24) \\ \text { long-term unemployment rate } & \gamma_{28} & 0.00 & (\mathrm{t}=0.43) \\ & & & \\ \text { standard error of regression } & & 0.0091 & \\ \text { R-squared } & & 0.96 & \\ \text { Durbin-Watson d-statistic } & & 2.68 & \end{array}$

notes

a The data consist of annual observations of the private sector in the Netherlands (1965-1987); source: Central Planning Bureau, The Hague.

b Estimation is carried out by the iterative 3SLS routine of TSP 4.1.

c Unless otherwise stated, standard errors are given in parentheses. 
estimates by Layard and Nickell $(0.68)$ and by Graafland (1989) for six E.C.-countries (1962-1985), namely 0.63. CED (1987) cites evidence that a value of 0.5 is a reasonable estimate for the Netherlands and the OECD for the short run and a value between 0.5 and 1.0 for the long run. The rate of labour augmenting technical progress is estimated at nearly 3.3 per cent, which is close to the estimate of Graafland.

Tuming to the wage equation, the unrestricted estimate of the long-term employers' tax rate coefficient exceeds unity. In line with the theoretical model the coefficient is restricted to unity. Empirically this restriction is easily accepted ( $t=0.72)$. The employees' tax rate coefficient is estimated at nearly 0.28 , but is not significantly different from 0 . This suggests that mainly employers' taxes increase wages. Graafland obtained an overall estimate of 0.34 . The coefficient of the discrepancy between the consumer and the producer price level is estimated at 0.57 , which implies that the wage rate is fully corrected for changes in producer prices (by assumption) and only partly compensated for the additional change in the consumer price level. Note that this estimate is below one, as it sometimes is assumed to be. Layard and Nickell find an estimate of around 0.5 for the gap between import prices and value added prices. The unemployment elasticity of the wage rate is 1.50, which is smaller than the estimate of Layard and Nickell (2.47), who use the short-run unemployment rate as explanatory variable. Graafland uses a hysteresis model and finds $1.79\left(\mathrm{u}_{-1}-0.86 \mathrm{u}_{-2}\right)$. The long-term unemployment rate (besides the total unemployment rate) appeared insignificant $(t=0.43)$ and is omitted. This suggests that insideroutsider effects in union wage setting are not significant.

Summarizing, the parameter estimates satisfy the restrictions as derived in the theoretical analysis and are largely in line with earlier studies.

\section{Unemployment accounting}

The estimated model can be used to compute the long-run equilibrium unemployment rate. Firstly, the long-run versions of the labour demand and wage equation are taken by setting the adjustment parameters $\left(\gamma_{11}, \gamma_{12}, \gamma_{21}\right.$ and $\gamma_{22}$ ) of equations (13) and (14) equal to zero. By combining the longrun versions of these equations one obtains the following equation for the long-run equilibrium unemployment rate

$$
\begin{aligned}
u_{e q}= & {\left[-(1-p) \gamma_{10}+\gamma_{20}+\rho\left(y-n-\alpha_{N} t\right)-\gamma_{23} \ln \left(1-s_{1}\right)-\gamma_{24} \ln \left(1-s_{2}\right)\right.} \\
& \left.+\gamma_{25} b+\gamma_{26}\left(p_{c}-p\right)\right] / \gamma_{27} .
\end{aligned}
$$

Estimates of the long-run equilibrium unemployment rate are found by substituting the parameter estimates and the observations. As can be seen 


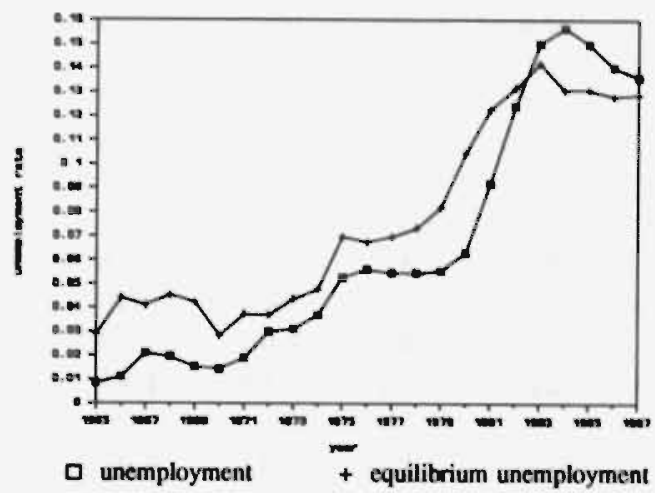

Figure 4 Equilibrium unemployment

from figure 4 , the equilibrium unemployment rate slightly overstates the observed unemployment rate in the period 1965-1982 and underestimates it somewhat in the period 1983-1986. Overall, the actual unemployment rate lags somewhat behind the equilibrium unemployment rate. This lag is probably caused by adjustment costs of labour and long-term wage contracts.

Other reasons which might explain the discrepancy between the observed and the equilibrium unemployment rate include the following. Firstly, the discrepancy might be due to short-run aggregate demand effects, which have been neglected. Secondly, working with aggregate data requires many simplifying assumptions which do not allow differences in developments between sectors. Finally, there are some problems with the accuracy of the unemployment data.

Changes in the equilibrium unemployment rate can be attributed to changes in tax rates, in the replacement ratio, in the gap between consumer and producer prices and in labour productivity. Taking first differences in (15) gives

$$
\begin{aligned}
\Delta u_{e q}= & {\left[\rho \Delta\left(y-n-\alpha_{N} t\right)-\gamma_{23} \Delta \ln \left(1-s_{1}\right)-\gamma_{24} \Delta \ln \left(1-s_{2}\right)\right.} \\
& \left.+\gamma_{25} \Delta b+\gamma_{26} \Delta\left(p_{c}-p\right)\right] / \gamma_{27}
\end{aligned}
$$

From table 2 it is clear that taxes, the replacement ratio and the gap between consumer and producer prices have pushed up equilibrium unemployment, while labour productivity (more precisely, the gap between average and marginal labour productivity) has reduced it. Employers' taxes had their greatest impact in the late sixties and in the early seventies, while their effect diminished in the eighties. Employees' taxes and the gap 
Table 2 Decomposition of change in unemployment rate

$\begin{array}{lrrrrrr}\text { period } & 65-68 & 69-72 & 73-76 & 77-80 & 81-84 & 65-68 \\ & 69-72 & 73-76 & 77-80 & 81-84 & 85-87 & 85-87 \\ & & & & & & \\ \text { employers' taxes } & 2.51 & 2.35 & -0.11 & 0.44 & -0.00 & 5.19 \\ \text { employees' taxes } & 0.71 & 1.31 & 0.41 & 1.23 & 0.06 & 3.72 \\ \text { replacement ratio } & 0.43 & 0.69 & 0.44 & -0.07 & -0.51 & 0.98 \\ \text { consumer prices } & 1.39 & 1.44 & 1.94 & 2.02 & -0.05 & 6.74 \\ \text { productivity } & -5.42 & -3.70 & -0.15 & 1.33 & 0.25 & -7.69 \\ & & & & & & \\ \text { equilibrium rate } & -0.37 & 2.10 & 2.52 & 4.94 & -0.24 & 8.95 \\ \text { actual rate } & 0.45 & 2.46 & 1.28 & 7.36 & 1.15 & 12.70\end{array}$

note

All values are in percentage points.

between consumer and producer prices mostly contributed to equilibrium unemployment in the early seventies and in the early eighties. The increase in the replacement ratio pushed up unemployment in the early seventies. During the late sixties and early seventies these effects were partly compensated by productivity effects. In the early eighties the slow-down in labour productivity growth caused an increase of equilibrium unemployment.

Comparing the period 1965-1968 with 1985-1987, the equilibrium rate rose by nearly 9 per cent. This was due to an employers' tax effect of 5.2 per cent, an employees' tax effect of 3.7 per cent, a replacement ratio effect of 1.0 per cent, a consumer price effect of 6.7 per cent, and a productivity effect of -7.7 per cent. The actual rate increased 12.7 per cent between the periods $1965-1968$ and 1985-1987.

\section{Concluding remarks}

This chapter presents a model of labour demand and union wage setting. The (Stackelberg) equilibrium unemployment rate is shown to be a function of the employers' and the employees' tax rate, the replacement ratio, the gap between consumer and producer prices, productivity effects and insideroutsider effects. The empirical application to data of the Dutch private sector (1965-1987) suggests that the increase in the equilibrium unemployment rate is due to the rise of the tax rates and of the replacement ratio and to the widening gap between consumer and producer prices. Productivity effects seem to have reduced the equilibrium unemployment rate, while 
insider-outsider effects appear insignificant. Of course, these results should be interpreted with care. The standard errors of the estimates are relatively large, which means that the decomposition of changes in the equilibrium unemployment rate is not very precise. Nevertheless, the analysis provides some insight in the causes of unemployment.

The presented model can be improved and extended in several ways. Firstly, attention should be paid to short-run aggregate demand effects. Secondly, the model should include utilisation rates and inventories. Thirdly, the dynamics of the model should not be introduced ad hoc, but theoretically explained from adjustment costs. Fourthly, by modelling the output market the effects of economic policy and international competitiveness can be evaluated. 


\section{Data appendix}

\section{variable definition}

E govemment employment.

N total employment excluding government employment in labour years corrected for changes in hours worked per week and for changes in days worked per year.

Y value added output enterprise sector excluding natural gas and housing, factor costs, prices 1980.

W wage rate, including taxes and social security contributions corrected for changes in hours worked per week and for changes in days worked per year.

$P \quad$ value added price index.

$P_{c} \quad$ consumer price index.

U number of unemployed, registered at labour office, including nonregistered $57.5-65$ years.

M labour supply $(\mathrm{M}=\mathrm{U}+\mathrm{N})$.

u unemployment rate $(\mathrm{u}=\mathrm{U} /(\mathrm{M}+\mathrm{E}))^{3}$.

ul long-term unemployment rate (over one year).

$s_{1} \quad$ employers' tax rate.

$s_{2} \quad$ employees' tax rate, constructed as in Graafland (1988), p. 519.

b replacement ratio.

3 In accounting the unemployment rate the denominator includes also government employment, because intuitively the resulting rate seems most important in wage setting. 


\title{
4 Efficiency wages and unemployment
}

\begin{abstract}
This chapter considers whether efficiency wages can explain unemployment. Further it presents a new result on the interaction between insider-outsider and efficiency wage effects. Theoretically the efficiency wage hypothesis that high wages improve productivity may explain natural or structural unemployment. However, more complex contracts may improve worker productivity without causing unemployment. Further, efficiency wages do not cause unemployment if there is a competitive secondary sector. The empirical evidence provides some support for the hypothesized wage-productivity relationship, but does not establish whether efficiency wages cause unemployment. Finally, insider-outsider and efficiency wage effects appear to reinforce one another.
\end{abstract}




\section{Chapter 4}

\section{Introduction}

The high rates of unemployment in Western Europe in the 1980's raise the question why wage rates do not always adjust to equalize demand and supply in the labour market, as the neoclassical perfect competition model suggests. Keynesian theory argues that unemployment is due to shortage of effective demand, assuming nominal wages are sticky. Unfortunately, the theory does not justify this assumption in a satisfactory way. The efficiency wage theory argues that real wages are sticky and that involuntary unemployment is an equilibrium phenomenon. The basic hypothesis of the efficiency wage theory is that it is not profitable for the firm to reduce the wage rate, because this would reduce the workers' effort or the applicants' ability (more shortly, workers' productivity). The rationales for the relationship between the wage rate and workers' effort include shirking, labour turnover and sociological motives; the rationale for the relationship between the wage rate and the applicants' ability is adverse selection. Besides providing an explanation for unemployment, the efficiency wage theory also implies that wages for identical workers may differ between firms due to different wage-productivity relationships. Critics have argued that there are more profitable ways than paying efficiency wages to make workers productive, such as the posting of performance bonds or the use of steep age-eamings profiles. The empirical evidence, although scarce, provides some support for the hypotheses that high wages reduce shirking and labour turnover and increase productivity. Further, there is some evidence that wages for identical workers differ between industries. The empirical evidence is too limited to conclude that efficiency wages cause unemployment.

The purpose of this chapter is, firstly, to consider whether the efficiency wage theory provides an explanation for unemployment. Secondly, to examine its relationship with two alternative theories of wage formation and (un)employment, namely the union bargaining theory and the insideroutsider theory. Thirdly, to evaluate the empirical evidence on efficiency wages. Before, the efficiency wage theory has been reviewed by Yellen (1984). Stiglitz (1986, 1987), Katz (1986), Carmichael (1990) and Teulings and Webbink (1992). The early reviews do not contain recent empirical work. None of these papers considers the relationship between efficiency wage theory on the one hand and union bargaining theory and insideroutsider theory on the other.

The set-up of the chapter is as follows. Section 2 summarizes the efficiency wage theory and considers whether it can explain unemployment. Section 3 deals with the relationship between union bargaining and efficiency wages. The interaction between insider-outsider and efficiency 


\section{Efficiency wages and unemployment}

wage effects is considered in section 4. The empirical evidence is summarized in section 5 . Section 6 concludes the chapter.

\section{Theory of efficiency wages}

\subsection{Basic idea of the efficiency wage theory}

The efficiency wage theory is based on three assumptions:

(i) the worker's productivity, (e) increases with the firm's real wage rate (W), but in the relevant range at a decreasing rate: $e=e(W)$ for $W \geq 0$, $e(0)<0$, $e^{\prime}>0, e^{\prime \prime}<0$. The restriction $e(0)<0$ is sufficient to prevent the firm from obtaining infinite effort per dollar by setting the wage equal to zero. The assumption $e^{\prime \prime}<0$ is made to satisfy the second-order condition for a maximum in the firm's profit maximization problem which is defined below.

(ii) the profit-maximizing firm has imperfect information about the individual worker's effort; therefore, the effort level cannot form an enforceable clause of a contract. If assumption (ii) were not satisfied, the firm would set the productivity level such that the worker is indifferent to either working in the firm or being unemployed (or working elsewhere). In other words, without assumption (ii) there would be no involuntary unemployment.

(iii) more profitable ways to maintain productivity do not exist.

Under these three assumptions it may be profitable for the firm to raise the wage rate above the market-clearing level, because the returns from increased productivity may more than outweigh the increase of labour costs. Throughout this chapter the wage rate and the firm's profits are defined in real terms. The output price of the representative firm is assumed to be equal to the aggregate price level. As the aggregate price level is taken as given, the distinction between nominal and real wage rates is not too important.

The efficiency wage theory can be formalized as follows. The firm maximizes its profits by setting the wage rate and the employment level $(\mathrm{N})$

$$
\max _{W, N} \Pi(W, N)=A f(e(W) N)-W N .
$$

The symbol A denotes the productivity shifter; alternatively, it can be interpreted as the firm's output price (defined in real terms). The symbol $f$ denotes the production function, which is increasing $(f>0)$ at a decreasing rate $\left(f^{\prime \prime}<0\right)$ in labour inputs $\mathrm{eN}$. Assuming an interior solution the first-order conditions for a maximum are

$$
A f^{\prime}(e(W) N) e^{\prime}(W)=1,
$$




$$
A f^{\prime}(e(W) N) e(W)=W .
$$

Combining these equations yields

$$
e^{\prime}(W) \frac{W}{e(W)}=1 .
$$

Equation (4), which is known as the Solow condition, says that in the optimum the elasticity of productivity with respect to the wage rate equals unity; see Solow (1979). As it stands, the Solow condition implies that the wage rate is unaffected by changes in the firm's relative output price or by labour productivity shocks. However, this result does not hold in more complex efficiency wage models. For example, the firm may take the employment level as given in the short run. It can maximize short-run profits by setting the wage rate according to (2). In general, the short-run wage rate depends on the firm's relative output price or on labour productivity shocks. Altematively, if worker's productivity depends on the ratio of wages to profits, in other words, if workers want a fair share of value added, than even under efficiency wage considerations the wage rate may depend on output prices and productivity. An implicit assumption of the optimization problem is that the optimal wage rate is high enough to attract workers; in other words, the wage must exceed the market-clearing wage. It is easy to show that if the wage-productivity elasticity at the market-clearing wage is less than or equal to one, it is optimal for the firm to pay the market-clearing wage. In other words, if the incentive effect is not strong enough, the firm will not pay an efficiency wage.

The rest of this section deals with the following issues. The rationales behind the hypothesized wage-productivity relationship are considered in 2.2. The implications of the relationship with respect to wage rigidity, unemployment, wage differentials, unemployment pattems and labour productivity are discussed in 2.3. The question whether efficiency wage models explain unemployment is more extensively considered in 2.4 .

\subsection{Rationales for the wage-productivity relationship}

The idea that higher wage rates improve productivity was first proposed by Leibenstein (1957). He argued that in developing countries a higher wage rate enables better nutrition, which leads to higher productivity. In developed countries four other rationales for the wage-productivity relationship are relevant. Three rationales, which are formalized in the shirking model, the labour tumover model and the sociological models, establish a positive relationship between the wage rate and the workers' effort. The fourth rationale. which is formalized in the adverse selection 
model, results in a positive relationship between the firm's wage rate and the applicants' ability.

\section{The shirking model}

One rationale for the wage-productivity relationship is provided by the shirking model which is proposed by Shapiro and Stiglitz (1984); see also Foster and Wan (1984). The worker is assumed to dislike effort and to maximize his utility by choosing either to work or to shirk. The firm monitors its workers imperfectly. If a worker is caught shirking, he is fired. Suppose that the wage rate is such that the labour market clears. If a worker is caught shirking, he can immediately find another job at the same wage. Therefore, it is optimal for the worker to shirk. The firm raises its wage rate in order to make it attractive for workers to stay and to be found nonshirking. If all firms do so, the initial incentive effect disappears. However, labour demand is reduced by increasing the wage rate. For this reason a worker who is fired faces the probability of remaining unemployed for some time. If this is unattractive enough, the worker will not take the risk to be caught shirking.

\section{The labour turnover model}

A second rationale for the wage-productivity relationship is given by the labour turnover model by Salop (1979). In this model workers are heterogeneous with respect to nonpecuniary characteristics of the jobs offered by a firm. The workers do not know these characteristics in advance, but learn them on the job. If a worker is dissatisfied and believes other firms offer more attractive jobs, he quits and joins the unemployment pool to search for another job. On-the-job search is ruled out by assumption. Labour tumover involves hiring and training costs to the firm. In order to keep turnover low, the firm tries to pay a wage rate which is high relative to the wage paid by other firms. If all firms behave the same, the relative wage remains constant. However, a high wage rate keeps labour demand low and possibly labour supply high. Thus, unemployment results. Unemployment makes it costly for workers to quit. In equilibrium the profit-maximizing firm sets the wage rate such that the wage costs of increasing the wage rate are equal to the reduction of training costs. Note that the structures of the labour tumover model and the shirking model are similar. Whereas in the shirking model unemployment prevents the worker from cheating, in the turnover model it prevents the worker from quitting. 


\section{Chapter 4}

\section{Sociological models}

The third rationale for the wage-productivity relationship is proposed by Akerlof (1982, 1984). He argues that for psychological and sociological reasons a high wage rate increases effort by improving workers" morale or by raising group work norms. The idea behind his so-called gift exchange model is that workers feel obliged to be productive as a gift in return for the firm's high wage rate. The justification for this relationship offered in these papers remains somewhat fragile. In a later paper Akerlof and Yellen (1990) propose a fair wage-effort relationship which expresses that workers reduce effort below the normal level if the firm's wage is below the 'fair' wage. This relationship is more convincingly defended by referring to equity theory, relative deprivation theory and social exchange theory. If the incentive effect is strong enough, the profit-maximizing firm sets the wage rate above the market-clearing level.

The idea that workers care about relative wages is generally accepted. However, a problem with the gift exchange or the fair wage approach is that the determination of the fair wage rate and of the normal effort level remains largely unexplained. Whereas these variables play an important role in the model, the results become sensitive to changes in the assumptions. In the words of Carmichael (1990), "the theory is dissatisfying because it has such a short distance between its assumptions and its conclusions" (p. 291). Until the problem of modelling the fair wage rate is solved, it is also difficult to test the approach empirically.

\section{The adverse selection model}

The adverse selection model, which is found in Weiss $(1980,1991)$ and Malcomson (1981), provides the fourth rationale for the wage-productivity relationship. In this model workers are assumed to be heterogeneous in ability and their productivity is assumed to be related to their ability. The model further assumes that workers with a higher ability have a higher reservation wage, e.g. because they can eam more in self-employment. If the firm has imperfect information with respect to the applicants' ability, it may be profitable to pay more than the market-clearing wage to increase the average ability of the attracted pool of applicants. Suppose an unemployed worker offers to work for less than the firm's optimal wage rate. Then the firm will not accept the offer, because the offer itself reveals that the worker cannot be very productive. Unemployed workers whose reservation wage is below the optimal wage rate are involuntary unemployed, the others are voluntary unemployed.

It should be noted that Weiss' assumption that the minimization of labour costs has a unique (interior) solution is quite strong. The assumption implies 
serious constraints on the distribution of abilities and on the relationship between ability and the reservation rate. 'Unfortunately, Weiss does not say anything about the restrictions which are necessary to avoid corner solutions and which are sufficient to satisfy the second-order conditions.

\subsection{Implications of the wage-productivity relationship}

The implications of the hypothesized wage-productivity relationship differ from those of the perfect competition model. This subsection considers the implications of the efficiency wage hypothesis with respect to wages, unemployment, wage differentials, unemployment pattems and labour productivity.

One implication of the hypothesized wage-productivity relationship is that real wages become sticky. The reason is that the equilibrium real wage rate is only indirectly affected by the business cycle. This is most easily seen for the shirking model and the labour turnover model. Changes in nominal variables such as prices have no direct impact on the equilibrium real wage rate. Only if the unemployment rate is affected by the business cycle, the real wage rate adjusts.

A second implication of the wage-productivity relationship is that unemployment may be an equilibrium phenomenon. Stiglitz (1987) calls this 'the repeal of the law of demand and supply'. The equilibrium concept which is used here is that it is not optimal for any agent to change his behaviour. The unemployment is involuntary because unemployed workers strictly prefer to work at the going wage rate rather than being unemployed, but firms have no incentive to hire them (at that wage) or to lower wages. An intuitive explanation why the wage-productivity relationship may cause unemployment is that the wage rate cannot equalize labour demand and labour supply any more if it becomes an instrument to make the worker productive. As in most simple efficiency wage models the aggregate supply curve is vertical, the equilibrium unemployment rate is independent of the business cycle. In other words, the efficiency wage models provide an explanation for natural or structural unemployment. The issue whether the efficiency wage theory can explain unemployment is further discussed in 2.4 .

1 In order to illustrate this, consider the following example which is based on the model in Weiss (1980). Let the relationship between ability $(\theta)$ and the reservation wage be proportionate: $\theta=g(W)=W$. Let the distribution of abilities $(F)$ be uniform over the interval $[R, S], R>0$. In other words, $F(\theta)=(W-R) /(S-R)$ for $R \leq W \leq S$. Then the firm's profit-maximizing wage rate is $R$, which is not an interior solution. 
A third implication of the wage-productivity relationship is that multiple wage equilibria may occur. Stiglitz (1987) calls this phenomenon 'the repeal of the law of a single price'. Multiple wage equilibria can arise if the wageproductivity relationship differs between firms. This seems a plausible assumption, because monitoring problems are probably more prevalent in large firms than in small firms, whereas turnover costs are higher in firms whose production processes require more investment in firm-specific human capital. Different wage-productivity relationships can easily lead to wage differentials between firms or industries for identical workers. Multiple wage equilibria may also occur when the costs per effective unit of labour are not monotonic.

A fourth implication of the wage-productivity relationship is that it can result in different unemployment pattems (and wage differentials) for different types of workers. For example, Akerlof and Yellen (1990) assume that there are two types of workers, say skilled and unskilled workers. The fair wage is assumed to be a weighted average of the market-clearing wage and the wage of other workers in the same firm. In equilibrium the skilled workers obtain the market-clearing wage, which exceeds their fair wage. The unskilled workers obtain their fair wage, which exceeds their marketclearing wage. Consequently, all skilled workers are hired, but some unskilled workers remain unemployed. Note that this result depends crucially on the assumption that the fair wage of the skilled workers is below their market-clearing wage due to the impact of the lower wage of the unskilled workers. In fact, the assumption is inconsistent with the observation by Akerlof and Yellen (1990) that in comparing wages "those people who receive less are of comparatively little interest ...; whereas those people who are paid more are of considerable interest" (p. 259).

A fifth implication of the wage-productivity relationship is that labour productivity is procyclical. This is most easily seen in the shirking and the labour tumover model. If the unemployment rate rises, workers are less likely to shirk or to quit voluntarily. This implication is not in line with Okun's law, which says that observed labour productivity is countercyclical. Akerlof and Yellen (1986, pp. 11-14) argue that the problem can be solved by combining efficiency wages with implicit contracts. Further, it should be noted that Okun's law is not undisputed. For example. Wadhwani and Wall (1988) suggest that the aggregate evidence on Okun's law is not very reliable. For these reasons the productivity implications should not be interpreted as strong evidence against the efficiency wage theory.

\subsection{Efficiency wages and unemployment}

As set out above the efficiency wage theory provides an explanation for natural or structural unemployment. This subsection discusses two 
extensions of the standard efficiency wage models to explain cyclical unemployment and unemployment persistence. It further considers two objections against the efficiency wage explanation of unemployment.

The standard efficiency wage models can be extended to explain the cyclical variation in unemployment. To do so, one must additionally assume that changing the wage rate is costly to the firm. The costs of changing wages (or prices) are called menu costs. Akerlof and Yellen (1985) show that by combining efficiency wage determination with small menu costs nominal wages become sticky. If wages do not adjust, then nominal shocks lead to alterations in the level of employment. So, the efficiency wage theory combined with menu costs can explain why unemployment varies over the business cycle. Whereas Akerlof and Yellen argue that small shocks can lead to large fluctuations in output and employment, Ball and Romer (1989) show that the average impact is only small. The reason is that under sticky wages (or prices) the positive and negative impact of shocks on employment nearly cancel out.

The standard efficiency wage models can also be extended to explain the persistence of unemployment. This can easily be shown in the context of the fair wage model by Akerlof and Yellen (1990). It seems reasonable to assume that workers' wage norms adapt to current and past experience. After an adverse supply shock, such as a fall in labour productivity or an adverse shift in the terms of trade, the firm will not reduce the wage rate below the workers' wage norm in order to prevent the workers from reducing effort. Probably, this results in a rise of unemployment. Unemployment remains high until the wage norms are adjusted. A formalization of this kind of model is presented by Layard et al. (1991, p. 169).

A first objection against the efficiency wage explanation of unemployment is that more profitable contracts may be devised which raise worker productivity without causing unemployment. In other words, the objection is that assumption (iii) is incorrect. To avoid shirking the firm can require the posting of a performance bond which is forfeited if the worker is caught cheating. Similarly, to reduce labour turnover the firm can charge application fees to compensate the hiring and training costs. The fact that performance bonds or application fees are seldom observed in practice does not matter, because the strategy can be implemented more subtly. To avoid shirking the firm can defer payment by paying less than the value of marginal productivity to young workers and by paying more than the value of marginal productivity to older workers or by paying pensions after retirement. If the worker is fired because of cheating, he loses his deferred payments; see Lazear (1979, 1981) and Lazear and Moore (1984). To reduce labour turnover the firm might pay a lower wage rate during the training programme. To reduce adverse selection the firm may find 
screening devices or offer self-selective contracts which reveal the true reservation wage or productivity of applicants. Finally, the firm can provide incentives by offering long-term contracts as the internal labour market contract proposed by Malcomson (1984).

One argument against this objection is that performance bonds or application fees cannot be large due to capital market imperfections. Further, the firm may be unable to shift all training costs to the worker by lowering wages if the training period is short. Carmichael (1985) argues that even if the worker faces constraints in the capital market, unemployment is not involuntary because the firm can charge an entrance fee which makes the utility of the job offer equal to the utility of the worker's reservation rate. Shapiro and Stiglitz (1985) reply that in the model proposed by Carmichael unemployment is only 'voluntary' in a very narrow sense of the term and that the unemployment level is still inefficient.

Another argument against this objection is that workers may be unwilling to accept the payment of bonds or application fees. The reason is that it is profitable to the firm to fire workers who have not cheated or to advertise vacancies which do not exist in order to collect performance bonds or application fees. Because of this moral hazard problem on the side of the firm the worker may also be reluctant to accept the deferment of payments to avoid shirking or the lowering of wages during a period of training (especially if it is firm-specific). Note that in the tumover model the problem of moral hazard on the side of the firm becomes less important after the training period, because it is not in the firm's interest to fire trained workers to collect fees which equal the training costs. Probably the impact of the firm's reputation on future profitability can overcome the moral hazard problem on the side of the firm; see MacLeod and Malcomson (1991).

A second objection is that efficiency wages do not cause unemployment if there is a competitive secondary sector. In other words, the objection is that the wage-productivity relationship mentioned in assumption (i) does not or not sufficiently hold, in all firms. To be more specific, assume that the economy consists of two sectors. The primary sector pays efficiency wages, whereas the labour market of the secondary sector is competitive. In other words, the secondary sector consists of firms for which it is not profitable to pay efficiency wages. All workers who are not employed in the primary sector can obtain a job in the secondary sector.

One argument against this objection is that workers may prefer to stay unemployed rather than accept a job in the secondary sector while searching for a job in the primary sector, see e.g. Bulow and Summers (1986). This may occur if employers interpret working in the secondary sector as a signal that the worker is not very productive or if searching on the job is less effective. As wages in the primary sector exceed wages in the 
secondary sector, there results a queue of unemployed. A similar model was proposed by Harris and Todaro (1970) to explain urban unemployment in developing countries. The higher the unemployment benefits, the lower are the costs of searching for a job in the primary sector and thus the higher is the equilibrium unemployment rate. In my opinion this argument is not very strong, because unemployment is a bad signal as well. Especially long-term unemployment must be worse than acceptance of a job in the secondary sector. Further on-the-job search may be somewhat less effective than searching while unemployed, but the difference is probably small.

Another argument against this objection is that the assumption of a competitive secondary sector is not realistic. Either minimum wage laws or collective wage agreements prevent clearing of the secondary labour market; see e.g. Van de Klundert (1988). In my opinion this argument makes more sense. If one accepts this picture of the labour market, then unemployment must be attributed to the combination of efficiency wage effects and minimum wage laws or collective wage agreements. The relative importance of efficiency wages depends on the relative size of the primary sector.

\section{Union bargaining and efficiency wages}

Union bargaining theory and efficiency wage theory differ in their assumptions with respect to the discretion of union and firm. In the right-tomanage model, a standard model in union bargaining theory (see chapter 2 for a survey), the wage rate is determined in a bargaining process between union and firm, whereas the effort (or ability) level is assumed to be fixed and the employment level is set by the firm. In the standard efficiency wage models the firm sets the wage rate and the employment level, whereas the worker determines the effort level. Combinations of these assumptions give some interesting insights. Firstly, consider the implications of bargaining about the wage rate, whereas the employment level and the effort level are still set by the firm and the worker, respectively. Secondly, consider the implications of bargaining about both the wage rate and the effort level, whereas the employment level is still set by the firm.

The implications of bargaining about the wage rate are studied by Layard et al. (1991, p. 540). The analysis is based on an extension of the right-tomanage model which includes efficiency wage effects. They show that the wage rate and the unemployment rate under bargaining and efficiency wages are higher than under either bargaining or efficiency wages only. They further show that under bargaining and efficiency wages the wage elasticity of effort is below unity; in other words, the Solow condition does not hold any more. The intuition behind these results is not difficult. The wage rate under bargaining and efficiency wages is higher than under efficiency wages only, because both parties gain from increasing the wage 
rate until the efficiency wage level. In other words, the efficiency wage rate is the minimum rate which might result in a model with both efficiency wages and bargaining. It results when the employer has complete market power. Introducing efficiency wage effects in a pure bargaining model makes it less costly for the firm to concede wage increases, because these are partly compensated by higher effort. These arguments explain why the wage rate under bargaining and efficiency wages is higher than under either bargaining or efficiency wages only. The Solow condition does not hold any more because the increase of the wage rate above the efficiency wage level is not fully compensated by increased effort.

The implications of bargaining about the wage rate and the effort level are considered by Rosén (1989). In an extension of the right-to-manage model the bargaining outcome is shown to depend on whether the union and the firm bargain explicitly over effort or not. Assume that the bargain over wages and effort Pareto dominates the bargain over wages only. Then the wage rate and the effort level under bargaining over wages and effort are lower than under bargaining over wages only; employment and output will be higher, the output price will be lower. A problem with the analysis, which is not mentioned by Rosén, is that the firm must have perfect information about the individual worker's effort. This assumption is necessary to make effort negotiable. However, if the firm has perfect information about effort (and it is verifiable by court), it is probably not necessary to pay efficiency wages. Anyway, because the assumption of perfect information is not conform assumption (ii), the model is not really an efficiency wage model.

\section{Insiders-outsiders and efficiency wages}

The efficiency wage and the insider-outsider theories have a similar aim, namely to explain why wages may be set above their market-clearing levels, in other words, why involuntary unemployment may be an equilibrium phenomenon: see e.g. Lindbeck and Snower (1987b, 1991). Despite the similarity of their aim, the rationales which the theories offer for the nonmarket clearing equilibrium wage rate are believed to be different. "In the efficiency wage theory, it is in the firms' interest to keep wages above their market-clearing levels. The differential between the profit-maximizing wage and the market-clearing wage depends primarily on the responsiveness of worker productivity to the wage (and on the imperfection of the firm's information M.L.). In the insider-outsider theory, it is in the insiders' interest to keep wages above their competitive levels and the insiders have the market power to do so. Here, the differential between insider wage and the market-clearing wage depends primarily on the insiders' bargaining strength and the magnitude of labour tumover costs." (Lindbeck and Snower 


\section{Efficiency wages and unemployment}

(1991), p. 193). The implications of the two theories for empirical firm or industry wage equations also seem to be different. Nickell and Wadhwani (1990, p. 497) and Holmlund and Zetterberg (1991, p. 1010) argue that insider-outsider theory implies that the firm's product demand, the output price and labour productivity affect the wage rate, whereas efficiency wage theory implies that no firm-specific variable has any impact on wages. These citations suggest that there is a clear distinction between the efficiency wage and the insider-outsider theory.

However, is the distinction really as clear as it seems to be? At theoretical level bargaining can be introduced in the efficiency wage theory; see the model by Layard et al. (1991) discussed before. On the other hand, imperfect information might play a role in the insider-outsider theory. For example, Fehr (1990) argues that insiders can withdraw cooperation from and engage in harassment activities to outsiders only if the firm cannot observe this behaviour. At empirical level firm-specific variables may enter an efficiency wage equation. As argued before, if the fair wage in the model by Akerlof and Yellen (1990) depends on the firm's profits, then firmspecific variables such as output price and productivity affect the wage rate. On the other hand, aggregate variables may be relevant in an insideroutsider wage equation. For example, the aggregate or industry unemployment rate enters the wage equation if it affects the insiders' fallback utility in case the bargaining parties do not reach an agreement; see chapter 7 for a discussion of this issue. These examples show that the distinction between the two theories is not as clear as it seems at first sight.

The relationship between the two theories can be studied more formally by investigating whether insider-outsider effects and efficiency wage effects reinforce or weaken one another. In order to answer this question, Lindbeck and Snower (1991) present a model of wage formation which combines efficiency wage and insider-outsider effects. Their model can be interpreted as a short-run approach, because the employment level is taken as given. From the signs of the second-order derivatives of the wage setting function they conclude that the efficiency wage and the insider-outsider effects do not reinforce one another. The authors have probably made a mistake in calculus. Anyway, their conclusion is not correct. The rest of this section summarizes their model and shows that the effects do reinforce one another, at least if the insider has complete market power. In some sense this result supports the earlier argument that efficiency wage and insider-outsider theory have a similar impact on wages.

The insider is assumed to maximize the utility surplus of reaching an agreement. Let the utility under agreement be equal to the real wage rate (W) and the utility under disagreement be $\mathrm{Z}$, which can be interpreted as the real reservation wage. So, the objective function of the insider $(\phi)$ is 


$$
\phi(W)=W-Z, \phi_{W}=1 .
$$

The firm is assumed to maximize the real profit surplus of reaching an agreement. Let the profit under agreement be $A W^{\beta}-W$, where $A$ denotes a productivity index. The real output price is set equal to one. Note that the firm's revenues depend on the wage rate, because of the incentive effect on worker effort. The parameter $\beta \quad(0 \leq \beta<1)$ is called the productivity responsiveness coefficient. ${ }^{2}$ Let the profit under disagreement be a function of the firing costs $(\mathrm{F})$ and the hiring costs $(\mathrm{H})$. Denote the profit under disagreement by $\mathrm{G}(\mathrm{F}, \mathrm{H}), \partial \mathrm{G} / \partial \mathrm{F}<0$ and $\partial \mathrm{G} / \partial \mathrm{H}<0$. Then the objective function of the firm $(\psi)$ becomes

$$
\psi(W)=A W^{\beta}-W-G, \Psi_{W}=A \beta W^{\beta-1}-1 \leq 0 .
$$

The inequality of $\psi_{w}$ is explained as follows. If the first-order derivative were positive, it would be optimal for both the firm and the insider to raise the wage rate. So, in the range which is relevant for the bargaining process described below the derivative must be nonpositive. Assume that the wage rate is determined by maximizing an asymmetric Nash bargaining function

$$
\max _{W} \Omega=\phi^{\mu} \psi^{1-p},
$$

where the insider's bargaining power is denoted by $\mu$ and the firm's bargaining power by $1-\mu(0 \leq \mu \leq 1)$. The first-order condition can be written as

$$
\mu \psi+(1-\mu) \Psi_{w} \phi=0 .
$$

By substituting (5) and (6) in (8) a wage setting function can be derived. For notational convenience the substitution is postponed until the secondorder derivatives are obtained. Differentiating (8) totally to respectively $\beta, \mu$ and $\mathrm{G}$ gives

$$
\frac{\partial W}{\partial \beta}=-\frac{\mu \Psi_{\beta}+(1-\mu) \Psi_{W \beta} \phi}{\Psi_{W}+(1-\mu) \Psi_{W W} \phi}>0 \text { if } W>1 \text {, }
$$

2 Note that the effort function $\mathrm{e}=\mathrm{W}^{\beta}$ does not satisfy the restriction $e(0)<0$. In fact, the firm would maximize profits by hiring an infinite number of workers at an infinitesimally low wage rate. Lindbeck and Snower (1991) do not encounter this problem, because the employment level is taken as given. 


\section{Efficiency wages and unemployment}

$$
\begin{aligned}
& \frac{\partial W}{\partial \mu}=-\frac{\psi-\Psi_{W} \phi}{\Psi_{W}+(1-\mu) \Psi_{w W} \phi}>0, \\
& \frac{\partial W}{\partial G}=\frac{\mu}{\Psi_{W}+(1-\mu) \Psi_{w W} \phi}<0 .
\end{aligned}
$$

The first partial derivative implies that the higher the incentive effect, the higher the equilibrium wage rate. The second partial derivative implies that the higher the worker's bargaining power, the higher the equilibrium wage rate. With respect to the third partial derivative, it should be noted that $\mathrm{G}=\mathrm{G}(\mathrm{F}, \mathrm{H})$ is a decreasing function of the firing and hiring costs. So, an increase of the firing or the hiring costs leads, via a decrease of $G$, to an increase of the equilibrium wage rate. The signs of the first-order partial derivatives are as expected.

By differentiating (9) to respectively $\mu$ and $G$ one obtains

$$
\begin{gathered}
\frac{\partial^{2} W}{\partial \mu \partial \beta}=-\frac{\Psi_{\beta}-\Psi_{w \beta} \phi-\Psi_{w W} \phi \frac{\partial W}{\partial \beta}+X \frac{\partial W}{\partial \mu}+Y \frac{\partial W}{\partial \beta} \frac{\partial W}{\partial \mu}}{\Psi_{W}+(1-\mu) \psi_{w W} \phi}, \\
\frac{\partial^{2} W}{\partial G \partial \beta}=-\frac{X \frac{\partial W}{\partial G}+Y \frac{\partial W}{\partial \beta} \frac{\partial W}{\partial G}}{\Psi_{W}+(1-\mu) \Psi_{w W} \phi},
\end{gathered}
$$

where $\mathrm{X}$ and $\mathrm{Y}$ are defined as

$$
\begin{gathered}
X=\psi_{w \beta}+(1-\mu) \Psi_{w w \beta} \phi>0, \\
Y=(2-\mu) \Psi_{w w}+(1-\mu) \Psi_{w w w} \phi<0 .
\end{gathered}
$$

Unfortunately, the second-order derivatives appear difficult to sign. However, it is easy to show that

$$
\begin{gathered}
\lim _{\mu \uparrow 1} \frac{\partial^{2} W}{\partial \mu \partial \beta}=\lim _{\mu \uparrow 1}-\frac{\Psi_{\beta}}{\Psi_{W}}>0 \text { if } W>1, \\
\lim _{\mu \uparrow 1} \frac{\partial^{2} W}{\partial G \partial \beta}=\lim _{\mu \uparrow 1}-\frac{\Psi_{W} \Psi_{W \beta}-\Psi_{\beta} \Psi_{W W}}{\psi_{W}^{3}}=-\frac{1}{(\beta-1)^{2}}<0 .
\end{gathered}
$$




\section{Chapter 4}

In deriving these second-order derivatives, I follow Lindbeck and Snower (1991) in setting $\mathrm{W}=\mathrm{A}^{\mathrm{I} /(1-\beta)}$ at $\mu=1 .^{3}$

The signs obtained for the second-order derivatives of the wage rate differ from those obtained by Lindbeck and Snower (1991). Whereas they find $\partial^{2} W / \partial \mu \partial \beta<0$ and $\partial^{2} W / \partial G \partial \beta=0$ for all values of $\mu(0 \leq \mu \leq 1)$, I find that $\partial^{2} W / \partial \mu \partial \beta>0$ and $\partial^{2} W / \partial G \partial \beta<0$ if the insider has complete market power $(\mu=1)$. By interpreting the last second-order derivative, it should be noted again that $G$ depends negatively on the firing and the hiring costs. The second-order derivatives imply that the sensitivity of the negotiated wage both to insider power $(\mu)$ and to firing $(F)$ and hiring costs $(H)$ depend positively on the productivity responsiveness coefficient $(\beta)$. In other words, the efficiency wage and the insider-outsider effects reinforce one another if the insider has complete market power. Whether this result holds if the insider has less than complete market power remains to be assessed.

\section{Empirical evidence on efficiency wages}

The efficiency wage theory can be tested in two ways, directly and indirectly. The direct way involves testing of the efficiency wage hypothesis that high wages have a positive impact on worker productivity. A problem to test the efficiency wage theory directly is that productivity of an individual worker is costly to observe or difficult to measure. If this were not the case, there would be no reason to pay efficiency wages at all. Some authors have solved this problem by using aggregate data. Others have circumvented this problem by testing the theory indirectly. The indirect way involves testing one of the possible implications of the hypothesized relationship, namely as the existence of wage differentials for observationally equivalent workers. The indirect test has its own problems. Firstly, the existence of wage differentials for observationally equivalent workers does not verify the efficiency wage theory, because the wage differentials may be caused by other factors as well. Secondly, the absence of wage differentials does not falsify the efficiency wage theory, because the hypothesized wage-productivity relationship does not necessarily cause wage differentials. Perhaps because of these problems, the empirical evidence on the efficiency wage theory is somewhat scarce. Unfortunately, the empirical studies do not provide estimates of the relative importance of efficiency wage effects in wage determination. Therefore, it is not possible to establish empirically the impact of efficiency wages on unemployment.

${ }^{3}$ One might argue that the insider can obtain a higher wage rate by exploiting the tumover costs. 
The rest of this section discusses, firstly, the indirect evidence and, secondly, the direct evidence.

Some indirect evidence in favour of the efficiency wage theory is provided by Krueger and Summers (1988). They argue that the phenomenon of wage differences between observationally equivalent workers in different industries which cannot be explained by neoclassical theory supports the efficiency wage theory. The existence of inter-industry wage differences is known from the estimation of wage or earnings functions at individual or industry level. After controlling for human capital effects, such as education and experience, industry specific dummies appear to be significant. The empirical evidence surveyed by Dickens and Katz (1987) reveals that 7 to 30 per cent of all inter-personal wage variance of nonunion workers is due to industry affiliation. Krueger and Summers (1987) show that the industry wage structure is quite constant over long periods of time and very similar across countries. The inter-industry wage differences can be reconciled with neoclassical theory by arguing that they are due to either unobserved worker heterogeneity such as differences in skill or motivation, or to differences in job characteristics which affect worker utility or to short-run immobility of labour. Krueger and Summers (1988) find that their empirical evidence, based on US population survey data for 1974, 1979 and 1984, does not support any of these explanations. Additionally, from longitudinal data Krueger and Summers (1988) conclude that workers who switch industry experience wage changes that closely parallel the industry wage structure found in cross-sectional analyses. Note, however, that this result is not undisputed. Murphy and Topel (1987) find that actual wage changes for workers who switch industry are only weakly related to the industry wage differences that are observed in the cross-section. They estimate that only one-third of observed industry wage differences can be attributed to industry effects, while two-thirds are caused by unobserved worker heterogeneity. Anyway, after concluding that inter-industry wage differences are hard to reconcile with standard neoclassical theory, Krueger and Summers (1988) argue that the differences can easily be explained by efficiency wage theory. The finding that higher wages increase tenure and reduce labour tumover corroborates their interpretation. The presented evidence may be enough to conclude that standard neoclassical theory is unable to explain inter-industry wage differences. The claim that efficiency wage theory can explain the observed wage differences needs more justification, however. For example, one should show that the empirical evidence supports efficiency wage hypotheses like: industries with high tumover costs or high monitoring costs pay high wage rates.

There are some studies that shed more light on the question which industry characteristics can explain inter-industry wage differences or, to be more precise, which industry characteristics can explain the impact of 


\section{Chaper 4}

industry affiliation on individual wage rates. Dickens and Katz (1987) conclude from their literature survey and their own analyses that average years of education in an industry (after controlling for education at the individual level), profits, establishment size and the capital labour ratio all have a positive impact on the wage rate. The result on establishment size and the capital labour ratio can be interpreted as support for the shirking model, because monitoring is more costly in large firms and shirking more costly if production is more capital intensive. The result on profits can be related to the fair wage model, but can also be interpreted as evidence in favour of insider-outsider theory. Brown and Medoff (1989) find a positive relationship between firm size and wages as well. Teulings and Webbink (1992) report for instance a positive impact from easiness to determine worker effort and from extemal training and a negative impact from presence of time-clocks and internal training. The positive impact from external training and the negative impact of working time registration can be interpreted as evidence in favour of the efficiency wage theory, the positive impact from easiness to determine effort and the negative impact from internal training do not support this interpretation. A theoretical weakness of this kind of evidence is that the links between firm size and monitoring costs and between capital intensity and shirking costs etc. are hardly elaborated. An empirical weakness is that no attempt is made to discriminate between alternative explanations, such as offered by the efficiency wage theory and the insider-outsider theory. At this stage the evidence is too weak to conclude that the inter-industry wage differences provide evidence in favour of the efficiency wage theory.

Further indirect evidence on the hypothesized wage-productivity relationship is provided by Lazear and Moore (1984). They argue that the observed positive relationship between age and eamings of wage and salary workers are due to human capital accumulation and incentive effects, whereas the positive relationship between age and earnings for selfemployed has to do with human capital effects only. By comparing the steepness of age-earnings profiles of wage and salary workers with those of self-employed, they conclude that most of the slope can be attributed to incentive effects. It should be emphasized that the evidence implies only that incentive effects are relevant; it does not imply that efficiency wages are paid.

Direct evidence on the efficiency wage theory is obtained by investigating the impact of wages on shirking, tumover and output. A study by Cappelli and Chauvin (1991) provides some evidence on the impact of wages on shirking. They study the frequency of disciplinary lay-offs in the plants of a large US automobile company in 1982. The company pays the same wage to identical workers irrespective of the alternative industry wage in the plant's region. The authors find that in plants where the firn's wage 


\section{Efficiency wages and unemployment}

rate is high relative to the alternative wage the frequency of disciplinary problems is low. A high unemployment rate also leads to a low frequency of disciplinary lay-offs, but this effect is not significant. Their results can be interpreted as partial evidence in favour of the shirking model. On the one hand I agree with the authors that the equality of wages at all plants strengthens the evidence, because it does not give rise to simultaneity problems of wages and lay offs at plant level. On the other hand I would say that it weakens the evidence, because full application of efficiency wage considerations would lead to different wage rates per plant, depending on the alternative wage in the same region and industry.

Some evidence supporting the shirking model is given by Dickens et al. (1989). They argue that the simplest economic theories of crime predict that profit-maximizing firms should combine low expenses on monitoring with large penalties for employee crime. In fact, firms' outlays on monitoring of employees are considerable. Probably, large penalties are ruled out by legal restrictions or would have an adverse impact on worker morale. Besides spending on monitoring, the firm might pay high wages to reduce employee crime. So, the explanations which are offered for large outlays on monitoring are also consistent with the payment of premium wages. Unfortunately, the authors do not provide any formal test of the hypothesized relationship between wages, monitoring costs and employee crime.

An interesting case to study the relationship between wages and output is the increase of wages from 2.34 to at least 5 dollars per day in 1914 by Henry Ford. The motivation behind the measure is somewhat unclear. Whereas Raff (1988) concludes that Ford was 'driven by the threat of collective action' (p. 387), Bulow and Summers (1986) cite that 'the theory (that management was trying to avert the threat of unionization M.L.) is not supported by real evidence' (p. 379). Anyway, Raff and Summers (1987) conclude that the wage increase has reduced labour tumover and has increased labour productivity. As training costs to perform the relative simple tasks were probably low, the increase of labour productivity is best explained by the improvement of worker morale. The authors conclude that the wage increase by Ford provides some evidence in favour of the gift exchange model.

Direct evidence on the impact of wages on output is provided by Wadhwani and Wall (1988). The evidence is obtained by the estimation of a production function on panel data from 211 manufacturing companies in the UK over the period 1972-1982. To avoid simultaneity bias because of the endogeneity of the wage rate, the parameters are estimated by instrumental variables. The results show that the relative wage rate and the unemployment level have a positive impact on firm-level output. There is also some evidence that the relative wage change has a positive impact on 
productivity. The authors interpret this result as evidence in favour of a gift exchange model in which workers adapt their wage norms to past achievements.

The results summarized above suggest that the empirical evidence supports the efficiency wage theory. However, the question arises whether the beneficial effects of a high wage policy on shirking, turnover and output are strong enough to compensate its costs. Cappelli and Chauvin (1991) estimate that the wage costs to reduce the number of disciplinary problems by one are 121,000 dollars. A company representative suggested them that the administrative costs associated with a dismissal can run as high as 75,000 dollars. They further argue that due to imperfect monitoring the real reduction in shirking exceeds the observed reduction. So, the benefits of reduced shirking may outweigh the increase of labour costs. Bulow and Summers (1986) cite evidence that at Ford productivity increased by 51 per cent following the introduction of the high wage policy. Raff and Summers (1987) estimate that 6 to 19 per cent of the increase of wage costs was offset by reduced tumover. They do not provide an estimate of the impact of the high wage policy on productivity via improved morale. Probably the increase of wages by Henry Ford was not totally offset by the increase of productivity. Wadhwani and Wall (1988) estimate that the elasticity of the wage rate with respect to output is between 0.35 and unity; the elasticity of unemployment with respect to effort, which is measured by labour productivity, is about 0.15 . If the wage elasticity is below unity, the higher productivity does not fully compensate the higher wage costs. Overall, high wage rates seem to reduce shirking and turnover and to boost output, but the effect may be too weak to make the high wage rate profitable. Note that neither the finding that the benefits of high wages do not fully compensate wage costs nor the finding of a wage elasticity of effort below unity necessarily provide evidence against the efficiency wage theory. As argued in section 3, an extension of the standard efficiency wage model leads to an elasticity below unity; see also Akerlof and Yellen (1986, pp. 14-16).

\section{Concluding remarks}

The efficiency wage theory argues that it may be profitable to the firm to pay more than the market-clearing wage in order to prevent workers from shirking, to reduce labour tumover, to improve worker morale or to attract applicants with high ability. The standard models provide an explanation of natural or structural unemployment. The theory can explain the cyclical variability of unemployment if one additionally assumes that changing wages and/or prices is costly. The theory can explain the persistence of unemployment if one assumes that wage norms adapt slowly. 
There are two objections to conclude that efficiency wages explain unemployment. One objection is that more complex contracts can be devised which provide incentive effects without causing unemployment. Another objection is that efficiency wages do not cause unemployment if there is a secondary sector with firms for which it is not profitable to pay more than the market-clearing rate.

The efficiency wage theory can be tested directly via the hypothesized wage-productivity relationship or indirectly via wage differentials for observationally equivalent workers. A weakness of the indirect empirical evidence is that other theories can explain wage differentials as well. The direct evidence, although scarce, provides some support for the hypothesis that high wages improve productivity. The empirical evidence does not establish whether efficiency wages cause unemployment.

The interaction between efficiency wage and insider-outsider effects are studied by Lindbeck and Snower (1991). Unlike their conclusion, these effects are shown to reinforce one another, at least if the insider has complete market power.

There are several routes for further research on efficiency wages. Firstly, the theory should make clear under what conditions more complex contracts are feasible and under what conditions efficiency wages must be paid. Preferably, this should be done in a dynamic general equilibrium context; see Hoon and Phelps (1992). Secondly, further empirical research should shed more light on the relative importance of efficiency wage considerations in wage determination and unemployment. Thirdly, although the relevance of the efficiency wage theory in explaining wage determination and unemployment in Westem Europe is limited because of the dominance of trade unions, the theory may be helpful in explaining wage drift; see chapter 5 . 


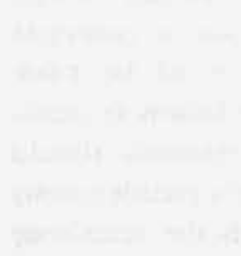

자.

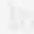

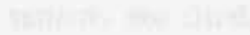

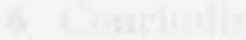

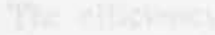

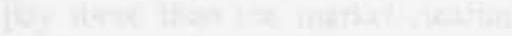

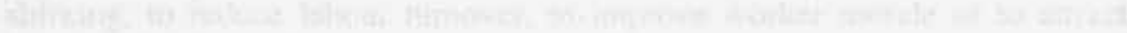

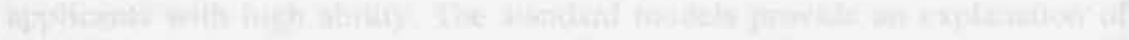

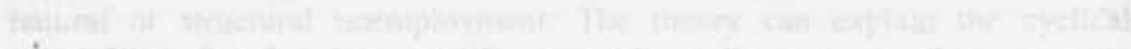
T:

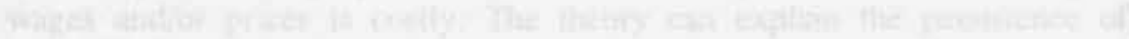

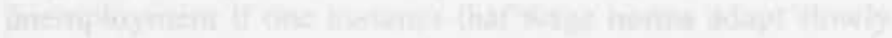




\title{
5 An efficiency wage model of wage drift: evidence from the Netherlands (1972-1983)
}

\begin{abstract}
The purpose of this chapter is to provide an explanation for wage drift, which is the phenomenon that wages change faster (sometimes slower) than contract wages. The hypothesis put forward is that the firm's rationale for paying more than obliged stems from efficiency wage considerations. Empirical results for the private sector in the Netherlands (1972-1983) suggest that this explanation makes sense. The estimates also reveal that lower contract wage changes are partially compensated by higher wage drift and vice versa. This suggests that wage drift weakens the impact of wage moderation by trade unions.
\end{abstract}




\section{Chapter 5}

\section{Introduction}

A comparison between actual wage rates and contract wage rates on unionized labour markets reveals that actual wage rates rise mostly somewhat faster than contract wage rates. The difference between the relative change in the actual wage rate and the relative change in the contract wage rate is called wage drift. According to Phelps Brown (1962), 'wage drift has been conspicuous in the democracies with predominantly industry-wide settlements - in Scandinavia, the Netherlands, the United Kingdom and Australia' (p. 339). Calmfors and Forslund (1989) state that in the last decade wage drift has contributed to about 65 and 40 per cent of total wage increases in the manufacturing sector in Norway and Sweden, respectively. Between 1972 and 1983 the average weekly wage rate in the Dutch private (manufacturing and service) sector increased 7.5 per cent, the average contract wage rate increased 7.4 per cent, the average wage drift being 0.1 per cent. Although the mean was relatively small, the variance in wage drift was pretty large. It varied from -1.6 per cent in 1981 to 1.2 per cent in 1976 (CBS (1984)). The data, which exclude overtime and which are corrected for structural changes in the labour force, are illustrated in figure 1 .

Earlier authors, such as Hansen and Rehn (1956), Marquand (1960), Phelps Brown (1962), Isaac (1965), Gould (1967), Gillion (1968), Gerfin (1969), Jacobsson and Lindbeck (1969, 1971), Isachsen (1977), Schager (1981), Söderström and Uddén-Jondal (1982), Gahlen and Ramser (1986) and Holmlund (1986), have attributed wage drift to excess demand for labour, productivity increases of piece workers, price increases, excess profits, distortions of the relative wage structure, and tax changes. As can be seen from table

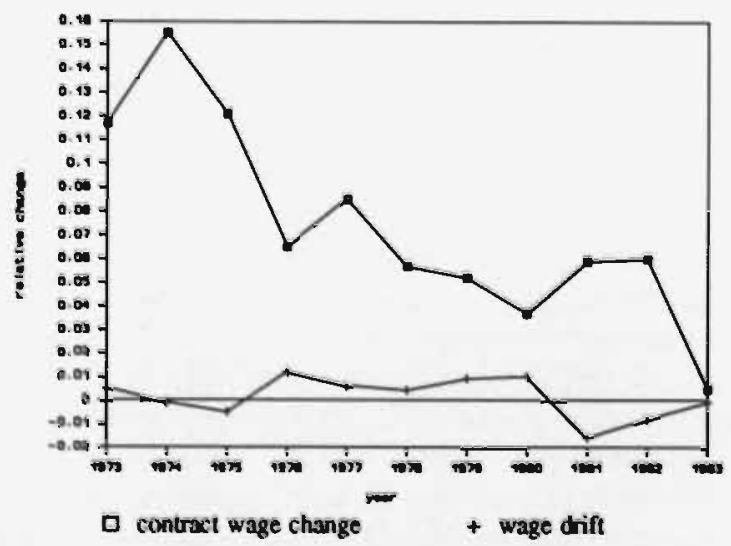

Figure 1 Contract wage change and wage drift 


\section{Table 1 Empirical studies of wage drift}

study
Gerfin (1969)

Jacobsson/Lindbeck (1969)

Jacobsson/Lindbeck (1971)

Isachsen (1977)

Schager (1981)

Słderstrőm/UddénJondal (1982) sample

West-German industry. annual observations from 1947 to 1954

Swedish manufacturing sector, annual observations from 1955 to 1967

Sweden, industry sector, building sector, trade sector and oher sectors, annual observations from 1951 (or 1956) to 1970

Swedish manufacturing sector, annual observations from 1955 to 1974

Swedish SAF-LO area (including manufacturing, transportation, trade and other private services), annual observations from 1966 to 1979

Swedish manufacturing sector, annual observations from 1960 to 1979

Norwegian manufacturing sector, annual observations, aggregate data from 1963 to 1986 and disaggregated data for six industries from 1970 to 1985 independent variables

constant, themployment rate minus vacancy rate, change in labour produc. tivity tone period lagged)

constant, inverse unemployment rate, number of vacancies, change in labour produclivity. gross profits in per een of total sales

constant, number of vacancies minus number of unernployed, gap between industry wages and contract wages in trade sector and other sectors

constant, inverse unemployment rate, relative change in manufacturing output price, central wage negotiation dummy

constant, number/ duration of vacancies, profits (measured by percentage yield on equity capital in real terms) and central wage negotiation dummy

constant, number of vacancies minus number of unemployed, price change in the tradable sector, relative wage coefficient

constant. vacancy rate, inventories, payroll tax, share of labour in gross product and trend estimation resules

wage drif depents negatively on unemployment rate minus vacancy rate and positively on change in labour productivity

inverse unemployment rale (or number of vacancies) has a positive impact on wage drift: lahour productivity and profits are insignificant

wage drift depends posi. tively on number of minus number of unem. ployed; wage drift in trade sector and in other sectors depends positively on wage gap

output price and inverse unemployment rate have a positive impact on wage drift; dummy is insignificant; wage drift equation is not stable over time

wage drift depends positively on duration of vacancies and on profits; duration of vacancies performs better than number of vacancies

wage drift depends positively on excess demand for labour and on price changes; relative wage effect, restoring wage structure, is small, but significant

wage drift depends positively on vacancy rate and negatively on inventories and payroll taxes; in the disaggregated dala appears a relative wage effect restoring the wage structure 


\section{Chapter 5}

1, the empirical results support the Phillips-curve relationship between wage drift and excess demand for labour. The effect of other variables is less clear.

A deficiency of the earlier literature is that often no sound choice-theoretical foundation for the hypothesized relationship is provided. An exception is a more recent paper by Holden (1989). He argues that wage drift is negatively related to inventories, because large inventories reduce the firm's costs of a strike. Holden's explanation is based on the assumption that workers bargain collectively at the firm level after the wage negotiations at industry level. Unlike Scandinavian practice, wage drift in the Netherlands arises mainly through interaction between the employer and the individual employee. Whereas strikes are a common threat in collective bargaining, the individual worker is more likely to quit, to shirk or simply to become less productive if (s)he considers the wage rate to be too low. Therefore, wage drift in countries like the Netherlands requires a different explanation.

Another problem with the earlier literature is that little attention has been paid to the relationship between wage drift and contract wage formation. Phelps Brown (1962) already observed that there is sorne disagreement about the impact of contract wage changes on wage drift. One position is that wage drift is an independent additive to contract wage changes. In this case one can say, the lower the contract wage change, the lower the total sum of wage changes. The other position is that contract wage changes and wage drift are just alternative ways of arriving at the same rate of change, which is e.g. determined by demand and supply. Now the total sum of wage change is independent of the contract wage change. In other words, the lower the contract wage change, the higher the wage drift. The opposite relationship, the impact of wage drift on contract wage changes, has hardly been touched at all, whereas most authors analyzing wage drift take contract wages as given.

The purpose of this chapter is twofold. Firstly, to provide an explanation for wage drift which is settled between the employer and the individual employee. Secondly, to investigate the relationship between contract wage changes and wage drift. The proposed explanation for wage drift is based on the efficiency wage hypothesis, which can be summarized as: the higher the wage rate, the higher the individual worker's effort. The analysis results in a model which explains simultaneously contract wage changes and wage drift. The analysis differs from earlier work in two aspects. Firstly, in the present study contract wages and wage drift are explained simultaneously, whereas in earlier wage drift studies contract wages are taken as given. If the presented model is correct, the negative impact of wage drift on contract wages reveals that the latter cannot be assumed to be exogenous. Secondly, the earlier explanations of wage drift fit in the tradition of Phillips (1958), relating the change in the wage rate to the unemployment rate (or level). The presented model joins more recent practice of relating the wage level to the unemployment rate or, equivalently, of relating the wage change to the change in the unemployment 
rate. This relationship, which is sometimes called the wage curve, is found in e.g. Sargan (1964), Layard and Nickell (1986), Blanchflower and Oswald (1990), and Graafland (1991).

A limitation of the model is that the efficiency wage interpretation of wage drift cannot be tested formally. Under the altemative hypothesis that the individual worker's effort does not depend on the wage rate, there is no reason for the employer to pay more than the contract wage rate. The presented model collapses to the standard monopoly union model. Merely the existence of wage drift falsifies the alternative hypothesis. However, the efficiency wage hypothesis can be tested informally by checking both the descriptive (or predictive) power of the model and the validity of the restrictions derived from theory. The efficiency wage hypothesis is tested in this limited sense on data from the private sector in the Netherlands (1972-1983). The empirical analysis should also provide some insight into the relationship between contract wage changes and wage drift.

The set up of this chapter is as follows. A specification of the individual worker's effort is offered in section 2. Section 3 presents the efficiency wage model of wage drift. A contract wage equation is derived in section 4. Section 5 presents the empirical results. Section 6 concludes the chapter.

\section{The individual worker's effort}

The efficiency wage theory, which is surveyed in chapter 4 , argues that there is a positive relationship between the wage paid by the firm and the worker's productivity. The model presented below employs an extended version of the effort function proposed by Akerlof (1982). The effort function is based on the assumption that for psychological reasons a worker is more productive if (s)he is offered a higher wage rate. This does not exclude other interpretations of a positive relationship between the wage rate and the worker's effort, however.

Relatively little empirical specifications of the effort function are found in the efficiency wage literature. Akerlof $(1982 ;$ p. 561) proposes the following specification

$$
e=-\gamma_{0}+\gamma_{1}\left(W / W_{f}\right)^{\gamma_{2}}, \gamma_{0}, \gamma_{1}>0,0<\gamma_{2}<1 \text {, }
$$

where e denotes effort, $W$ the nominal wage rate and $W_{f}$ the reference wage rate. Akerlof argues that the restriction $0<\gamma_{2}<1$ is necessary to insure that the wage elasticity of effort is decreasing in W, which is necessary for a maximum. The negative intercept is required to prevent the firm from setting the wage rate equal to zero, giving infinite effort per dollar. The reference wage rate specified by Akerlof is based on the assumption that the typical worker has a chance of being unemployed (u) receiving the unemployment benefit $B$ and a chance of finding another job (1-u) receiving the wage rate 


\section{Chapter 5}

paid by other firms $\left(\mathrm{W}_{2}\right)$. In empirical work the reference wage rate cannot simply be computed as a weighted arithmetic mean of the available indices for the alternative wage and unemployment benefit, because the index numbers do not reflect any difference in absolute magnitude between the two variables. The problem of scaling is reduced to a missing multiplicative constant, which is irrelevant after taking relative differences, by computing the reference wage rate as a weighted geometric mean of the alternative wage and the unemployment benefit

$$
W_{f}=W_{a}^{1-i} B " .
$$

In order to translate Akerlof's effort function to our context the following definition is introduced

$$
W=\left(1+w_{g}\right) W_{e},
$$

where $W_{c}$ and $w_{k}$ denote the contract wage rate and the relative wage gap, respectively. The wage gap is related to wage drift $\left(w_{3}\right)$ via

$$
w_{d}=\Delta \ln \left(1+w_{g}\right)=\Delta \ln W-\Delta \ln W_{\varepsilon},
$$

where $\Delta$ denotes the first-difference operator. In words, (4) says that wage drift is defined as the relative change in the actual wage rate minus the relative change in the contract wage rate. The reference wage rate, defined in (2), is based on the assumption that the individual worker's chance to get another job is (1-u). Search theory suggests that this assumption is somewhat too simple. Therefore, it is relaxed by supposing that due to some matching technology the chance to get a job $(1-q)$ is a function of the unemployment rate and the vacancy rate

$$
q=q(u, v), q_{1}>0, q_{2}<0,
$$

where $u$ and $v$ denote the unemployment rate and the vacancy rate, respectively. Further, B can be replaced by defining

$$
b=B / W_{a}, 0<b<1 \text {, }
$$

where $b$ is the replacement ratio. Using (5) and (6), the reference wage rate is defined as

$$
W_{f}=W_{a} b^{q(u, v)} \text {. }
$$

The choice of the altemative wage rate $W_{2}$ will depend on the context. At sectoral level it can be set equal to the aggregate wage rate or the manufacturing wage rate. Assuming that workers aim at a certain share in value added (the 'fair' share, see McDonald and Solow (1981)), value added per worker seems a good alternative at aggregate level. Finally, I allow for the possibility that the individual worker compares either his gross wage rate $\left(\gamma_{3}=0\right)$ or his net 
wage rate $\left(\gamma_{3}=1\right)$ to the reference wage rate. Denoting the employees' tax rate by $s_{2}$, the effort function can be defined as

$$
\begin{aligned}
& e\left(w_{g}, W_{c}, W_{s}, 1-s_{2}, u, v, b\right)=-\gamma_{0}+\gamma_{1}\left[W_{c}\left(1+w_{g}\right)\left(1-s_{2}\right)^{\gamma_{s}} /\left(W_{a} b^{\text {(us,v) }}\right)\right]^{\gamma_{3}} . \\
& \gamma_{0}, \gamma_{1}>0,0<\gamma_{2}<1,0 \leq \gamma_{3} \leq 1 .
\end{aligned}
$$

It is easy to see that the effort function has the appropriate sigmoid shape in the relative wage gap ( $\left.w_{g}\right)$. Further, the effort becomes constant (namely $e=1$ ) if both $\gamma_{0}$ and $\gamma_{2}$ approach zero and $\gamma_{1}$ approaches one. ${ }^{1}$

\section{Efficiency wage model of wage drift}

Let the representative firm maximize its short-run profit function (II) by choosing the relative wage gap $\left(\mathrm{w}_{\mathrm{g}}\right)$ and the employment level $(\mathrm{N})$; the capital stock $(K)$ is assumed to be predetermined. Assuming that the firm is small, the unemployment rate and the vacancy rate may be taken as given. The contract wage rate, the alternative wage rate, the tax rate, and the replacement ratio are supposed to be exogenous for the firm as well. Let the firm's production technology be described by the production function $f(K, e N)$, which is increasing and concave in $\mathrm{K}$ and $\mathrm{eN}$, constant returns to scale, twice continuously differentiable, and which satisfies the Inada conditions. Then the firm's optimization problem may be written as

$$
\begin{aligned}
& \max \Pi=P f(K, e N)-W_{c}\left(1+w_{g}\right) N \\
& w_{g}, N \\
& \text { s.t. } w_{g}, N \geq 0 .
\end{aligned}
$$

Assuming an interior solution, the first-order conditions become

$$
P f_{2} e_{1}-W_{c}=0
$$

and

$$
P f_{2} e-W_{c}\left(1+w_{g}\right)=0 .
$$

The Solow (1979) equation becomes

1 The model may be generalized by making the value of $\gamma_{j}(j=0,1,2)$ dependent on the individual $\mathrm{i}$. This may also provide a rationale for the institutional setting in which the union sets the contract wage and the firm the wage drift: if there is heterogeneity of labour, it may be optimal for the firm to pay only some workers more than the contract wage. 


\section{Chapter 5}

$$
\left(1+w_{8}\right) \frac{e_{1}}{e}=1
$$

The Solow equation can be used to derive an empirical wage drift equation. Taking natural logarithms and first differences, one obtains

$$
\Delta \ln \left(1+w_{g}\right)=\Delta \ln e-\Delta \ln e_{1} .
$$

Letting the subscript -1 denote the value one period lagged, this can be approximated by

$$
\frac{\Delta\left(1+w_{8}\right)}{\left(1+w_{g}\right)_{-1}}=\frac{\Delta e}{e_{-1}}-\frac{\Delta e_{1}}{\left(e_{1}\right)_{-1}}=\frac{\left(e_{1}\right)_{-1} \Delta e-e_{-1} \Delta e_{1}}{e_{-1}\left(e_{1}\right)_{-1}} .
$$

Taking a first-order Taylor series approximation of e respectively $e_{1}$ around $e_{.1}$ respectively $\left(e_{1}\right)_{1}$ gives

$$
\begin{aligned}
& \frac{\Delta\left(1+w_{g}\right)}{\left(1+w_{g}\right)}=\frac{e_{1}^{2}-e e_{11}}{e e_{1}} \Delta\left(1+w_{g}\right)+\frac{e_{1} e_{2}-e e_{12}}{e e_{1}} \Delta W_{c}+\frac{e_{1} e_{3}-e e_{13}}{e e_{1}} \Delta W_{d}+ \\
& \frac{e_{1} e_{4}-e e_{14}}{e e_{1}} \Delta\left(1-s_{2}\right)+\frac{e_{1} e_{5}-e e_{15}}{e e_{1}} \Delta u+\frac{e_{1} e_{6}-e e_{16}}{e e_{1}} \Delta v+\frac{e_{1} e_{7}-e e_{17}}{e e_{1}} \Delta b .
\end{aligned}
$$

Note that the subscripts -1 have been dropped to simplify notation. Combining terms in $\Delta\left(1+w_{g}\right)$ and using the Solow condition to replace e by $\left(1+w_{g}\right) e_{1}$ gives

$$
\begin{aligned}
\frac{\Delta\left(1+w_{g}\right)}{\left(1+w_{g}\right)}= & \frac{e_{2}-\left(1+w_{g}\right) e_{12}}{\left(1+w_{g}\right)^{2} e_{11}} \Delta W_{c}+\frac{e_{3}-\left(1+w_{g}\right) e_{13}}{\left(1+w_{g}\right)^{2} e_{11}} \Delta W_{a}+\frac{e_{4}-\left(1+w_{g}\right) e_{14}}{\left(1+w_{g}\right)^{2} e_{11}} \Delta\left(1-s_{2}\right) \\
& +\frac{e_{5}-\left(1+w_{g}\right) e_{15}}{\left(1+w_{g}\right)^{2} e_{11}} \Delta u+\frac{e_{6}-\left(1+w_{g}\right) e_{16}}{\left(1+w_{g}\right)^{2} e_{11}} \Delta v+\frac{e_{7}-\left(1+w_{g}\right) e_{17}}{\left(1+w_{g}\right)^{2} e_{11}} \Delta b .
\end{aligned}
$$

Using the specification of the effort function (8) and using approximations like $\Delta \mathrm{W}_{\mathrm{c}}=\left(\mathrm{W}_{\mathrm{v}}\right)_{-1} \Delta \ln \mathrm{W}_{\mathrm{e}}$, one obtains

$$
\Delta \ln \left(1+w_{s}\right)=-\Delta \ln W_{c}+\Delta \ln W_{a}-\gamma_{3} \Delta \ln \left(1-s_{2}\right)+q_{1} \ln b \Delta u+q_{2} \ln b \Delta v+q \Delta \ln b .
$$

Recall that the subscripts -1 of the level variables have been dropped. Let $w_{c}$ and $w_{\mathrm{a}}$ denote $\ln \mathrm{W}_{\mathrm{c}}$ and $\ln \mathrm{W}_{\mathrm{a}}$, respectively. Equation (17) can be (log)linearized by taking a first-order Taylor series expansion around the steady state $(\Delta u=\Delta v=\Delta \ln b=0)$. It is easy to see that the resulting wage drift equation contains no level variables but only variables in first differences: 


$$
\begin{aligned}
& w_{d}=\gamma_{10}-\gamma_{14} \Delta w_{c}+\gamma_{12} \Delta w_{a}-\gamma_{13} \Delta \ln \left(1-s_{2}\right)+\gamma_{14} \Delta u+\gamma_{15} \Delta v+\gamma_{16} \Delta \ln b, \\
& \gamma_{11}=\gamma_{12}=1,0 \leq \gamma_{13}=\gamma_{3} \leq 1, \gamma_{14}<0, \gamma_{15}>0,0<\gamma_{16}<1 .
\end{aligned}
$$

Note that the parameter $\gamma_{16}$ is of the order of magnitude of $q($.$) , which is the$ probability to remain unemployed. In other words, according to the presented model the effect of changes of the replacement ratio on wage drift is small. Note further that the parameters of the wage drift equation (18) are not related to the parameters $\gamma_{0}, \gamma_{1}$ and $\gamma_{2}$. Although these parameters determine the magnitude of the relative wage gap (see equation (11)), they do not determine the change of it. Evidence in favour of the efficiency wage model cannot be obtained by testing directly the theoretical restrictions on the parameters of the effort function. Only indirect evidence is obtained via the estimates of the determinants of effort on wage drift. Note further that wage drift is independent of the capital stock. If the initial capital stock is multiplied by a factor $\lambda$, the optimal employment level becomes $\lambda$ times as large as well, leaving effort and wage drift unaffected.

\section{Union wage setting}

Assume that the contract wage rate is set unilaterally by a monopoly union. Less restrictive would be the assumption that union and firm bargain about the wage rate, as in the right-to-manage model. This model has not been chosen because it is difficult to make the theoretical concept bargaining power operational. Fortunately, there appears to be little difference between the wage equations derived from the monopoly model and from the right-to-manage model; see Hoel and Nymoen (1988). A third possibility is to assume that the bargaining outcome is on the contract curve, as in the efficient bargain model. This assumption does not seem realistic, because bargaining about employment is rare in the Netherlands.

Let union preferences with respect to the contract wage rate and the employment level be represented by the quasi-concave utility function $\mathrm{G}$. Assume that the union maximizes its utility function taking the workers' effort level and the firm's wage gap as given. As the bargaining outcome of the monopoly model is on the labour demand curve, the union chooses the contract wage rate by solving

$$
\begin{aligned}
& \max G\left(W_{c}, N\right) \\
& W_{c}, N
\end{aligned}
$$

$$
\text { s.t. } P f_{2} e-W_{c}\left(1+w_{g}\right)=0 \text {. }
$$

From the first-order conditions follows that the optimal contract wage rate 


\section{Chapter 5}

satisfies

$$
W_{c}=-\frac{P f_{22} e^{2} N}{1+W_{g}} \frac{W_{c} G_{1}}{N G_{2}} .
$$

Assume that the production function is of Cobb-Douglas form, with the capital stock being fixed in the short run

$$
Y=f(K, e N)=A K^{\alpha}(e N)^{1-\alpha}, 0<\alpha<1,
$$

where $Y$ denotes the output level. The parameter $A$ captures technical progress, which is assumed to be exogenous. An advantage of using a Cobb-Douglas specification, instead of e.g. a CES specification, is that the unobserved effort level can be eliminated from the contract wage equation. Assume further that the union's preferences can be described by the utility function proposed in chapter 3 (omitting insider-outsider effects)

$$
G\left(W_{c}, N\right)=W N^{\zeta * \eta n-\theta b}, \zeta, \eta, \theta \geq 0 .
$$

The intuition behind this utility function is that the higher the unemployment rate and/or the lower the replacement ratio, the higher the weight the union attaches to employment. Under these specifications of the production technology and the union's preferences the contract wage equation becomes

$$
W_{c}=\alpha(1-\alpha) \frac{P Y}{\left(1+w_{g}\right) N} \frac{1}{\zeta+\eta u-\theta b} .
$$

Taking logs and first differences, and linearizing by taking a first-order Taylor series expansion around the steady state $(\Delta \mathrm{u}=\Delta \mathrm{b}=0)$ gives

$$
\begin{aligned}
& \Delta w_{c}=\Delta p+\Delta(y-n)-w_{d}+\gamma_{24} \Delta u+\gamma_{2 s} \Delta b, \\
& \gamma_{24}<0, \gamma_{25}>0,
\end{aligned}
$$

where p, $y$ and $n$ denote $\ln P, \ln Y$ and $\ln N$, respectively. Note that the contract wage equation, as the wage drift equation, contains only explanatory variables which are in first differences. At the outset it is unclear whether the union is primarily interested in the gross or the net wage rate. The relationship between the gross wage rate $\left(W_{s}\right)$ and the net wage rate $\left(W_{n}\right)$ is given by $W_{s}\left(1-s_{2}\right)=W_{n}$. Taking logs and first differences, and rearranging terms gives $\Delta w_{3}=\Delta w_{n}-\Delta \ln (1-$ $s_{2}$ ). Therefore, the contract wage equation is modified by including the employees' tax term $-\Delta \ln \left(1-s_{2}\right)$

$$
\begin{aligned}
& \Delta w_{c}=\gamma_{20}-\gamma_{21} w_{d}+\gamma_{22} \Delta p+\gamma_{23} \Delta(y-n)+\gamma_{24} \Delta u+\gamma_{25} \Delta b-\gamma_{26} \Delta \ln \left(1-s_{2}\right), \\
& \gamma_{21}=\gamma_{22}=\gamma_{23}=1, \gamma_{24}<0, \gamma_{25}>0,0 \leq \gamma_{26} \leq 1 .
\end{aligned}
$$

If the tax rate coefficient is equal to zero the union does not shift taxes to the 
employer; if the coefficient is equal to one, taxes are fully shifted.

The Nash equilibrium is found by combining the reaction functions (18) and (25). The equilibrium can be illustrated graphically as the point of intersection of the reaction curves in the $\left(w_{d}, \Delta w_{c}\right)$ space. If the two reaction curves have different slopes, i.e. if $\gamma_{11} \neq 1 / \gamma_{21}$, then there exists an equilibrium and it is unique. If the two curves have the same slope, there is a multitude of equilibria or there is no equilibrium at all. As a matter of fact, the theoretical model suggests that the two curves are identically sloped $\left(\gamma_{11}=1 / \gamma_{21}=1\right)$. This problem can be solved by relaxing the assumption that the incentive effect of contract wage changes and wage drift is the same. If, for example, under sectoral contract wage determination a higher contract wage increases the reference wage as well, the incentive effect of wage drift may exceed the incentive effect of a similar contract wage change $\left(\gamma_{11}<1\right)$. The equilibrium is stable if the union's reaction curve (25) is steeper than the firm's reaction curve (18), i.e. if $\gamma_{11}<1 / \gamma_{21}$. As the estimates satisfy this restriction, the equilibrium is stable and unique. ${ }^{2}$

\section{Data and empirical results}

Usually, wage drift is calculated as the difference between the relative increase in average hourly earnings (including overtime) and the relative increase of contract wage rates. The change in earnings is measured on the basis of the changing actual composition of the employees, whereas the change in the contractual wage rate is based on some constant group of workers. Apart from the effects of changes in overtime and in shiftwork, the wage drift figures are biased by structural changes in the composition of employment, such as changes between low-paid and high-paid jobs, between younger and older workers or between male and female workers. Further, wage drift figures include changes in the remuneration system (e.g. from piece rates to time rates). The uncorrected figures are called gross wage drift and the corrected figures net wage drift; cf. Isaac (1965) and Gerfin (1969).

Gross wage drift data are easy to obtain. As the correction for structural changes requires detailed information about the composition of the group of employees, there are only small sets of net wage drift data available. The result is that the researcher can choose either a large set of poor quality data or a small set of high quality data. Some authors, such as Gerfin (1969) for WestGermany and Holden (1989) for Norway, argue that the biases in the gross

${ }^{2}$ Different slopes of the contract wage curve (25) and the wage drift curve (18) may also be defended by introducing heterogeneity of labour. See footnote 1 . Whereas a change in the contract wage affects all workers, a change in the wage gap only some of them. 


\section{Chapter 5}

wage drift data are relatively small. According to CBS (1984), the average wage drift in the private sector in the Netherlands between 1972 and 1983 is about 0.1 per cent, whereas the average wage increase due to structural changes is about 0.8 per cent. These figures clearly show that for the Netherlands the biases are in proportion far too large to be neglected in empirical work. Therefore, the empirical results are based on a small set of weekly earnings (excluding overtime) in the private sector in the Netherlands (1972-1983) which are corrected for structural changes; see CBS (1984). Consumer price indices, and unemployment and vacancy rates are obtained from the same source. Tax rates, replacement ratios and labour productivity data are from CPB. Changes in the unemployment rate and in the vacancy rate are illustrated in figure 2.

In the empirical work the reference wage rate is approximated by the consumer price index, labour productivity and a trend; after taking first differences the trend becomes a constant. A priori, it is not clear whether wage drift results from current or past labour market characteristics. For this reason weighted averages of current and lagged differenced unemployment and vacancy rates are incorporated. The weights of the current unemployment rate and those of the current vacancy rate (both in first differences) are restricted to be the same. In symbols, the expression $\gamma_{14} \Delta u+\gamma_{15} \Delta v$ is replaced by $\gamma_{14}\left(\mu \Delta u_{-1}+(1-\mu) \Delta u\right)+\gamma_{1 s}\left(\mu \Delta v_{-1}+(1-\mu) \Delta v\right), 0 \leq \mu \leq 1$. As contract wages for, say, 1973 are determined before the 1973 unemployment rate is available, the unemployment rate of 1972 seems more relevant. Therefore, the unemployment rate appears with a lag of one year in the contract wage equation. In 1976, 1980 and 1981 the government introduced wage control measures which reduced price compensation in the contract wage rates. The compensations

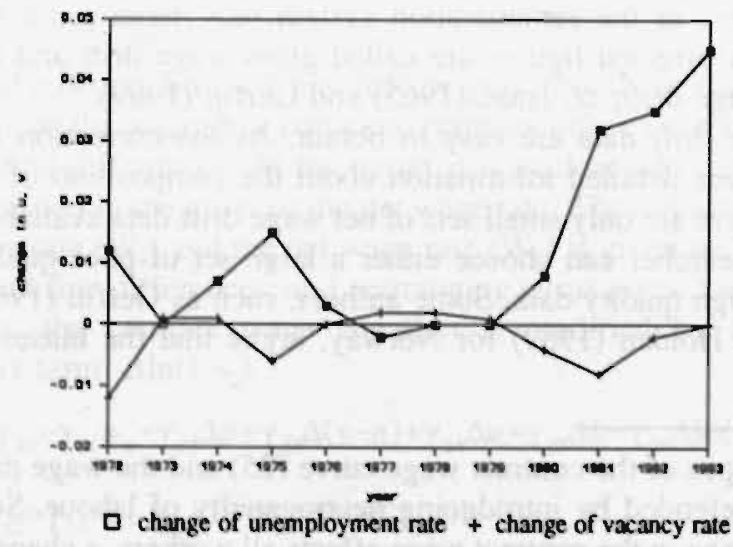

Figure 2 Change of unemployment and vacancy rate 
were cut with $3.7,2.5$ and 2.0 per cent, respectively. It seems reasonable to assume that the union seeks to catch up in the years after the wage controls. Therefore, a wage control dummy (wcdum) is included which has the value $-0.037,-0.025$ and -0.02 for 1976,1980 and 1981 , respectively, and the value $0.037,0.025$ and 0.02 for 1977,1982 and 1983, respectively. For other years the dummy has the value zero. If the estimated wage control parameter has the value one, the wage control measures were fully effective; if it is zero, the measures were ineffective.

Before turning to the estimation results, let me briefly comment on the identification of the wage drift and the contract wage equation. Approximating the reference wage rate by consumer prices, labour productivity and a trend leaves little difference between the determinants of contract wages and those of wage drift. This might give rise to identification problems. Fortunately, current unemployment and current and lagged vacancy rates are probably significant determinants of wage drift, but not of contract wages. On the other hand, wage control measures are more likely to affect contract wages than wage drift. Assuming that these variables are significant, there is no identification problem. It should be noted that most of the previous authors estimate a wage drift equation only, which might give rise to identification and simultaneity problems.

Unfortunately, the number of observations is too small to estimate with instrumental variables. Therefore, the wage drift equation (18) and the contract wage equation (25) are estimated by three-stage least squares. The consumption price parameter in the contract wage equation is set equal to one to reflect wage indexation clauses. These were generally adopted in union wage contracts during the estimation period. The other parameters are freely estimated. As can be seen from table 2, the reported estimates have the correct signs and are mostly significant. Note, however, that the results should be interpreted cautiously, because the data set is rather small.

In the wage drift equation the estimated coefficient on the contract wage change is (absolutely) significantly smaller than one. The estimate implies that every 1 per cent decrease of the contract wage rate increases wage drift by 0.7 per cent. Possibly the reason that the coefficient is below one is that the reference wage rate changes with the contract wage rate. If this is the case, an increase of the contract wage rate has less impact on effort than an increase of the wage gap. The coefficient on consumer price inflation does not significantly differ from unity. The estimate of the unemployment rate is absolutely smaller and that of the vacancy rate greater than one. Note that the unemployment rate and the vacancy rate enter with a lag of 0.65 year. The labour productivity term enters with a coefficient considerably below one. Apparently, the reference wage rate is a function of both a trend of 0.4 per cent and of labour productivity growth. The tax rate and the replacement ratio appeared insignificant and are omitted. The insignificance of the tax rate 


\section{Chapter 5}

Table 2 Estimation results

$$
\begin{aligned}
w_{d}= & 0.0037-0.72 \Delta w_{c}+1.03 \Delta p_{c}+0.063 \Delta(y-n) \\
& (0.0010)(0.04)(0.06)(0.017) \\
- & 0.72\left(0.65 \Delta u_{-1}+0.35 \Delta u\right)+1.31\left(0.65 \Delta v_{-1}+0.35 \Delta v\right) \\
& (0.04)(0.04) \quad(0.12)
\end{aligned}
$$

R-squared: 0.99, DW: 2.07 .

$$
\begin{aligned}
\Delta w_{c}= & 0.019-0.97 w_{d}+1 \Delta p_{c}+0.31 \Delta(y-n)-1.47 \Delta u_{-1}+0.50 \Delta b \\
& (0.002)(0.17)(-)(0.06) \quad(0.11) \quad(0.06) \\
& +0.30 w c d u m . \\
& (0.05)
\end{aligned}
$$

R-squared: 0.99, DW: 2.29

\section{notes}

a Data pertain to the private sector in the Netherlands (1972-1983).

b Estimation is carried out by the 3SLS routine of TSP 4.1.

c Standard errors are given in parentheses.

suggests that the worker compares his gross wage rate to the reference wage rate. Obviously, the worker recognizes that if he earned the reference wage rate he should pay taxes as well.

The wage drift coefficient in the contract wage equation is (absolutely) insignificantly different from unity. This suggests that trade unions correctly anticipate on wage drift in setting contract wages. Contract wages increase with a trend of nearly 2 per cent and with one third of labour productivity growth. The effect of an increase of the unemployment rate on contract wage changes is about twice as large as the one on wage drift. Unlike the result for the wage drift equation, the replacement ratio is a significant determinant of contract wage changes. The wage control measures do not appear to be very effective. If the government reduces price compensation with 1 per cent, contract wage increases are reduced by only 0.3 per cent. In the year after the wage control measure the forgone wage increase is caught up. An attempt to 
include the weighted dummy without the catch-up effect was less successful. As in the wage drift equation the employees' tax rate did not play a role and is omitted. One might wonder why the employers' tax rate is not incorporated in this study, despite its significance in the wage equation reported in chapter 3. The reason is that the wage rate data used in chapter 3 , which were obtained from CPB, include employers' taxes, whereas the wage rate data used in this study, which are from CBS, do not.

As set out in the introduction the presented model does not allow formal testing of the efficiency wage hypothesis. Nevertheless, the results can be interpreted as weak evidence in favour of the hypothesized relationship. The fit of the model is reasonably good. The estimates are of the correct sign and magnitude, and mainly significant. The only unexpected result is that the replacement ratio appeared to be insignificant in explaining wage drift. Although other explanations are possible, I am inclined to interpret the results as weak evidence in favour of the efficiency wage hypothesis.

\section{Concluding remarks}

This chapter presents a model of contract wage rates, which are determined by a monopoly trade union, and of wage drift, which is set by a representative employer. The explanation offered for the employer's behaviour of paying more than obliged is based on the efficiency wage hypothesis: the employees are assumed to be more productive if the wage rate is increased. The resulting wage drift equation is not of the Phillips-curve type, whereas the change (not the level) of the unemployment rate enters as explanatory variable. The empirical estimates, which are obtained from aggregate data of the Dutch private sector (1972-1983), support the proposed explanation. With respect to the relationship between contract wage changes and wage drift, the estimates suggest the following. One per cent more wage drift implies one per cent less contract wage change, whereas one per cent more contract wage change results in only 0.7 per cent less wage drift. Apparently, the impact of wage moderation by trade unions is weakened by wage drift. Government intervention by wage control measures does not appear to have much effect on contract wage changes.

Theoretically, the model can be improved by studying the impact of the capital stock on wage determination. Empirically, the study can be improved by using a larger data set, or by using panel data on industry wages. 


\title{
6 Insider-outsider vs. human capital effects in union wage formation
}

\begin{abstract}
This chapter proposes an altemative approach to introduce heterogeneity of labour in standard models of union wage formation. In the well-known insider-outsider approach the union makes a distinction between members and nonmembers or between employed and unemployed workers. In the human capital approach, which is proposed in this chapter, the firm makes a distinction between trained and untrained workers. The two approaches appear to have quite different implications with respect to employment of unprivileged workers (outsiders respectively untrained workers) under monopoly unionism and with respect to the slope of the contract curve under efficient bargaining.
\end{abstract}




\section{Chapter 6}

\section{Introduction}

A standard assumption in union wage bargaining theory (see Oswald (1985) or chapter 2 for a survey) is that labour is homogeneous. That the union does not differentiate between workers can be seen from the standard union utility functions, such as the expected utility function and the utilitarian utility function. These functions reflect the assumptions that all workers are union members and that the union attaches equal weight to all members. That the firm does not differentiate between workers can be seen either from the production or revenue function. The function reflects the assumption that all workers have equal skills and ability and are equally productive. Because of the homogeneity assumption the firm (or the union) can assign jobs and lay-offs by random draw. The homogeneity assumption, which is rather unrealistic, can be relaxed.

One approach to introduce heterogeneity of labour is to distinguish between insiders and outsiders. The distinction between insiders and outsiders can be made in various ways. In Carruth and Oswald (1987) and in Jones and McKenna (1989) the insiders are union members, the outsiders are nonmembers. According to e.g. Blanchard and Summers $(1986,1987)$, Gottfries and Hom (1987) and Huizinga and Schiantarelli (1992) the group of insiders is equivalent to the incumbent workforce, whereas the outsiders are the unemployed. In Graafland (1992) and in chapter 3 the insiders are the employed and short-term unemployed, the outsiders are the long-term unemployed.

Unfortunately, it remains unclear why the adopted distinctions between insiders and outsiders in union preferences are relevant to explain wage formation and employment. The distinction between members and nonmembers only makes sense if members are privileged in the distribution of jobs. Generally, the union is mainly involved in wage determination and not in the selection process of new workers. This suggests that the distinction between members and nonmembers is only meaningful in socalled 'closed shops'. The other distinctions, between employed and unemployed workers and between employed and short-term unemployed workers and long-term unemployed workers, are surely relevant, but it remains unclear why the union should make them. It makes sense to introduce one of these distinctions in union preferences if there is a strong relationship between membership and employment status. This might be the case if bargaining is at firm level. Under sectoral or national bargaining the relationship between membership and employment status is probably loose. In the Netherlands, where 80 per cent of the employees is covered by a collective wage agreement while less than 30 per cent is union member, there is no tight relationship between membership and employment status. 
In this context it remains unclear why the union should favour the interests of the employed only.

The purpose of this chapter is to present another approach to introduce heterogeneity of labour in models of union wage formation. It may be called the human capital or duration approach. The difference between the insider-outsider approach and the human capital or duration approach may be characterized as follows. In the insider-outsider approach the union differentiates between workers, whereas the firm does not. ' In the human capital approach the firm makes a distinction between 'trained' and 'untrained' workers, whereas the union does not. The rationale for the firm to make a distinction between trained and untrained workers is a difference in costs. The human capital approach is inspired by the work by Lindbeck and Snower (1986), who state that it is costly to exchange a firm's current, full-fledged employees (the trained workers) for unemployed workers (the untrained workers). ${ }^{2}$ A similar approach has been proposed independently in an empirical study by Graafland (1990). ${ }^{3}$ The human capital models of union wage formation, which are presented in this chapter, are static and do not include uncertainty in labour demand. Actually, the models can be considered as the human capital version of the insider-outsider models proposed by Carruth and Oswald (1987). The simple structure of the models facilitates comparing the implications of the two approaches. It appears that the implications are quite different. Firstly, in the insider-outsider approach (with no uncertainty in labour demand) a monopoly union will never set the wage rate such that outsiders are hired, whereas in the human capital approach it can be fully rational for a monopoly union to let in outsiders. Secondly, in the insider-outsider approach the contract curve in the efficient bargain model coincides with the downward-sloping labour demand curve for employment levels beyond the number of insiders, whereas in the human capital approach it is found to be upward sloping. An innovative

This does not hold for Lindbeck and Snower (1986, 1987a, 1988). In these papers the productivity difference between insiders and outsiders is the cause of the insiders' bargaining power.

2 As the proposed human capital approach is inspired by the work by Lindbeck and Snower, it may be called an insider-outsider approach as well. To emphasize the difference with so-called insider-outsider models in which the distinction between workers is based on union preferences, this term is not adopted.

3 Whereas Graafland (1990) presents a human capital version of the monopoly union model only, this chapter considers both the monopoly model and the efficient bargain model. 
aspect of this chapter, besides the introduction of human capital effects in wage bargaining models, is a correction of the picture of the contract curve in Carruth and Oswald (1987).

The rest of this chapter is arranged as follows. The insider-outsider approach to introduce heterogeneity of labour in union wage determination models as proposed by Carruth and Oswald and by Jones and McKenna is summarized in section 2 . Some additional derivations, which are necessary to draw correctly the contract curve of the model by Carruth and Oswald, are relegated to an appendix. Section 3 presents the human capital approach. The concluding remarks are to be found in section 4 .

\section{The insider-outsider approach}

\subsection{Union's and firm's preferences}

In the insider-outsider approach the distinction between workers is based on union preferences. The insiders are the members of the union, the outsiders are the nonmembers. The distinction between these two groups is relevant if the union pays more attention to the utility of its members than of nonmembers. The strongest assumption in this respect, which is adopted by Black and Bulkley (1984) and by Carruth and Oswald (1987), is that the union is totally indifferent to employment of nonmembers. Assuming the union has utilitarian preferences, the utility function $\mathrm{G}$ becomes

$$
\begin{gathered}
G(W, N)=M g(W)+\delta_{N M}(N-M)[g(W)-g(B)], W>B, \\
g^{\prime}(.)>0, g^{\prime \prime}(.) \leq 0, \delta_{N M}=1 \text { for } N \leq M, \delta_{N M}=0 \text { for } N>M,
\end{gathered}
$$

where $\mathrm{W}$ is the wage rate, $\mathrm{B}$ is the alternative wage or unemployment benefit, $\mathbf{N}$ is employment, $\mathrm{M}$ is union membership and $\mathrm{g}($.$) is the individual$ worker's utility function. The altemative wage or unemployment benefit and union membership are assumed to be exogenous. Nickell and Andrews (1983) and Jones and McKenna (1989) assume that the union attaches a value to employment of nonmembers which is positive but less than the value of employment of members. Jones and McKenna motivate this assumption by arguing that the union values a large membership and that some of the employed outsiders might enter the union. The utilitarian utility function proposed by these authors can be written as

$$
\begin{aligned}
& G(W, N)=M g(W)+\delta_{N M}(N-M)[g(W)-g(B)]+\left(1-\delta_{N M}\right) q(N-M) g(W) \\
& W>B, g>0, g^{\prime \prime} \leq 0, \delta_{N M}=1 \text { for } N \leq M, \delta_{N M}=0 \text { for } N>M, 0 \leq q \leq 1 .
\end{aligned}
$$


Note that this is a generalization of the utilitarian utility function proposed by Carruth and Oswald. By setting $q=0$, (2) reduces to (1).

The firm is assumed to maximize short-run profits. The short-run profit function can be written as

$$
\Pi(W, N)=R(N)-W N, R^{\prime}(.)>0, R^{\prime \prime}(.)<0,
$$

where $R(N)$ is a strictly concave revenue function. Throughout this chapter wages, benefits, revenues and profits are assumed to be deflated by a general price index, in other words they are defined in real terms.

The preferences of union and firm play a central role in the insideroutsider version of the monopoly union model and the efficient bargain model, as presented by Carruth and Oswald (1987) and Jones and McKenna (1989). These models are considered in 2.2 and 2.3 , respectively.

\subsection{Monopoly union model}

In the monopoly union model the employment level is set by the firm such that profits are maximized. If the firm takes the wage rate as given, the profit-maximizing employment level is given implicitly by

$$
R^{\prime}(N)=W .
$$

Equation (4) can be inverted to give the conventional downward-sloping labour demand curve.

The wage rate is set by the monopoly union such that its utility is maximized. The union is constrained by the firm's labour demand function. If the union has utilitarian preferences the union solves

$$
\max _{W, N} G=M g(W)+\delta_{N M}(N-M)[g(W)-g(B)]+\left(1-\delta_{N M}\right) q(N-M) g(W),
$$

$$
\text { s.t. } R^{\prime}(N)=W \text {. }
$$

In Carruth and Oswald (1987) the union does not care at all about employment of nonmembers $(q=0)$. Under this assumption employment levels beyond union membership are not feasible. There is no point of tangency between the downward-sloping labour demand curve and the horizontal part of the union indifference curves. The maximum employment level which is feasible is that all members are employed $(\mathrm{N}=\mathrm{M})$. As can be seen from figure 1, this result obtains if the labour demand curve is flatter than the union indifference curve for $\mathrm{N}<\mathrm{M}$. Jones and McKenna (1989) criticize the result that nonmembers are never employed. They show that if the union does care about nonmembers $(0<q \leq 1)$, the equilibrium employment level may exceed union membership. This is illustrated in figure 2. 
Chapter 6

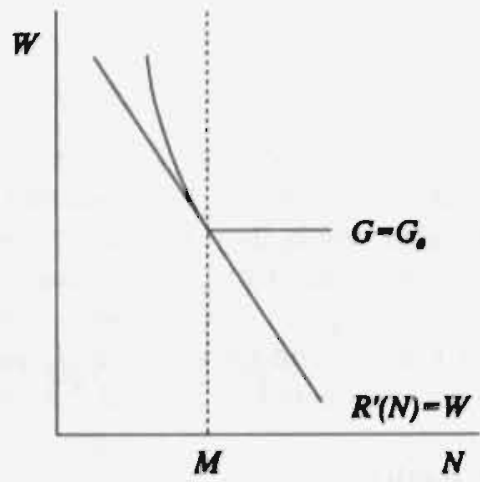

Figure 1 Monopoly model with strong insider-outsider preferences

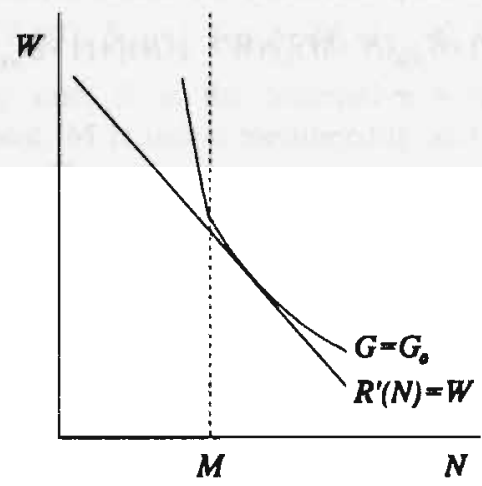

Figure 2 Monopoly model with weak insider-outsider preferences 
Whether the union cares about nonmembers has profound implications for wages and employment over the business cycle. Consider the impact of arise of the marginal revenues which is caused by either a rise of the relative output price or by a productivity shock. If wages and employment of union members are normal goods, both will rise. The increase of employment will continue until all members are employed. If the union does not care about nonmembers a further rise of the marginal revenues will increase the wage rate, but leave employment unaffected. If the union attaches a lower weight to nonmembers than to members, employment will remain sticky during a period of rising output price or productivity, while the wage rate will increase. The output price or productivity has to become very high, before employment will exceed union membership.

\subsection{Efricient bargain model}

In the efficient bargain model the union and the firm are assumed to negotiate about both wages and employment. Assuming that the union has utilitarian preferences as specified in (1) and does not value the employment of nonmembers, the bargaining outcome is found by solving

$$
\begin{aligned}
& \max G(W, N)=M g(W)+\delta_{N M}(N-M)[g(W)-g(B)], \\
& W, N
\end{aligned}
$$

$$
\text { s.t. } \Pi(W, N)=R(N)-W N \geq \Pi_{0}, W \geq B,
$$

where $\Pi_{0}$ is some minimum profit level. Initially, assume that in the optimum $\mathrm{N} \neq \mathrm{M}$. From the necessary conditions for a maximum of this Kuhn-Tucker problem follows the contract curve equation

$$
\frac{\delta_{N M}[g(W)-g(B)]}{\left[M+\delta_{N M}(N-M)\right] g^{\prime}(W)}=-\frac{R^{\prime}(N)-W}{N} .
$$

Consider the case $\mathrm{N}<\mathrm{M}$. By setting $\delta_{\mathrm{NM}}=1$ in (7), one obtains

$$
\frac{g(W)-g(B)}{g^{\prime}(W)}=-\left[R^{\prime}(N)-W\right] \text {. }
$$

The slope of the contract curve for $\mathrm{N}<\mathrm{M}$ is found by differentiating (8) to $\mathrm{N}$ :

$$
\frac{d W}{d N}=-\frac{R^{\prime \prime}(N) g^{\prime}(W)}{\left[R^{\prime}(N)-W\right] g^{\prime \prime}(W)}>0 \text { if } g^{\prime \prime}(.)<0
$$

In words, (9) says that, if the individual worker is risk averse, the contract curve is upward-sloping for employment levels below union membership. For $N>M$, the contract curve is found by setting $\delta_{N M}=0$ in (7). This results 
in

$$
R^{\prime}(N)-W=0 .
$$

In other words, the contract curve coincides with the downward-sloping labour demand curve for employment levels beyond union membership. Finally, assume $N=M$ in the optimum. Then the contract curve becomes vertical. According to Carruth and Oswald, the contract curve is upwardsloping, vertical and downward-sloping for, respectively, employment levels below, equal to and above union membership; see figure 3 . Their depiction of the contract curve is criticized in the appendix. The point is that it is misleading to draw the upward-sloping and downward-sloping parts of the contract curve in the same picture, because they actually pertain to different values of the exogenous parameters. It is shown that the contract curve can have three different shapes, depending on the profit-maximizing employment level evaluated at the alternative wage rate and on union membership; see figures 4-6. It is difficult to say which of the three situations is empirically most relevant. What is clear, however, is that under powerful unionism nonmembers will not be employed. This suggests that not only in the monopoly model, but also in the efficient bargain model, nonmembers' chances are bad if union preferences are as suggested by Carruth and Oswald.

It is easy to show that if union preferences are as supposed by Jones and McKenna, the contract curve beyond union membership can be either upward-sloping or downward-sloping, depending on the weight the union attaches to nonmembers. The efficient bargain model becomes

$$
\begin{aligned}
& \max _{W, N} G=M g(W)+\delta_{N M}(N-M)[g(W)-g(B)]+\left(1-\delta_{N M}\right) q(N-M) g(W), \\
& \text {. }
\end{aligned}
$$

$$
\text { s.t. } \Pi(W, N)=R(N)-W N \geq \Pi_{0}, W \geq B \text {. }
$$

From the necessary conditions for a maximum of the Kuhn-Tucker problem follows the contract curve equation

$$
\frac{\delta_{N M}[g(W)-g(B)]+\left(1-\delta_{N M}\right) q g(W)}{\left[M+\delta_{N M}(N-M)+\left(1-\delta_{N M}\right) q(N-M)\right] g^{\prime}(W)}=-\frac{R^{\prime}(N)-W}{N} .
$$

Consider the case $N<M$. Setting $\delta_{\mathrm{NM}}=1$ in (12) yields (8). This result is not surprising because the union utility function for $N<M$ is the same as before. The slope of the contract curve is given by (9), which implies that for $\mathrm{N}<\mathrm{M}$ the contract curve is upward-sloping. For $N>M$, the contract curve is found by setting $\delta_{\mathrm{NM}}=0$ in (12). This yields

$$
\frac{q g(W)}{[M+q(N-M)] g^{\prime}(W)}=-\frac{R^{\prime}(N)-W}{N} .
$$




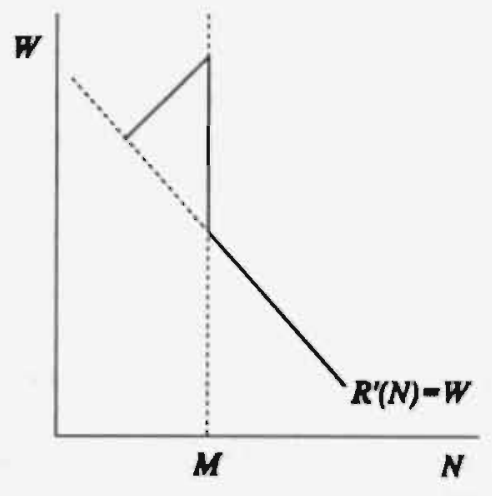

Figure 3 Contract curve according to Carruth and Oswald

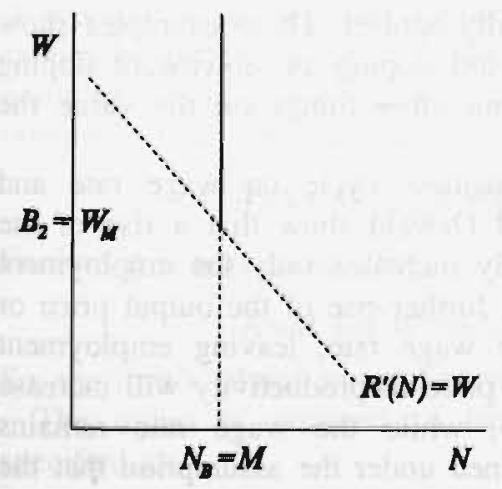

Figure 5 Contract curve for moderate benefits $\left(B=W_{M}, N_{B}=M\right)$

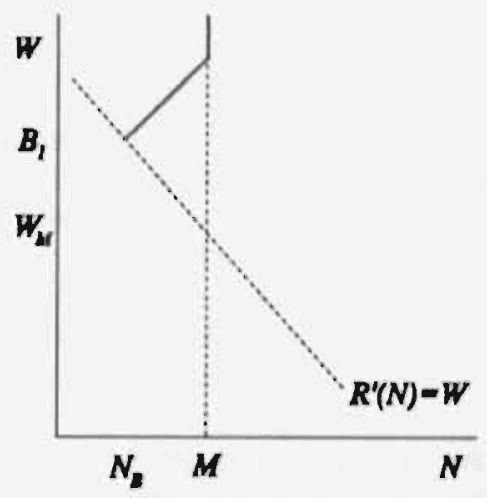

Figure 4 Contract curve for high benefits $\left(B>W_{M}, N_{B}<M\right)$

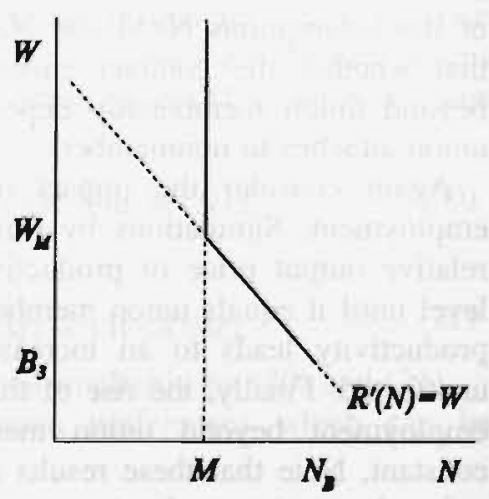

Figure 6 Contract curve for low benefits $\left(B<W_{M}, N_{B}>M\right)$ 
The slope of the contract curve is found by invoking the implicit function theorem and by differentiating to $\mathrm{N}$ :

$$
\frac{d W}{d N}=\frac{q(1-q) M g(W) g^{\prime}(W)+[M+q(N-M)]^{2}\left[g^{\prime}(W)\right]^{2} R^{\prime \prime}(N)}{[M+q(N-M)]\left[q N g(W) g^{\prime \prime}(W)+(1-q) M\left[g^{\prime}(W)\right]^{2}\right]}
$$

This expression is difficult to sign generally. In the limiting cases the sign is easily obtained. Consider the case $q=0$. Then (13) reduces to

$$
R^{\prime}(N)-W=0
$$

and (14) becomes

$$
\frac{d W}{d N}=R^{\prime \prime}(N)<0 \text {. }
$$

As in the model proposed by Carruth and Oswald, the contract curve coincides with the downward-sloping labour demand curve. Altematively, consider the case $q=1$. Then (13) reduces to

$$
\frac{g(W)}{g^{\prime}(W)}=-\left[R^{\prime}(N)-W\right]
$$

whereas (14) becomes

$$
\frac{d W}{d N}=\frac{R^{\prime \prime}(N)\left[g^{\prime}(W)\right]^{2}}{g(W) g^{\prime \prime}(W)}=-\frac{R^{\prime \prime}(N) g^{\prime}(W)}{\left[R^{\prime}(N)-W\right] g^{\prime \prime}(W)}>0 \text { if } g^{\prime \prime}(.)<0,
$$

which is equivalent to (9). In other words, if $q=1$ the slope of the contract curve is the same for $N<M$ and $N>M$. Of course, one should check which of the assumptions $\mathrm{N}<\mathrm{M}$ and $\mathrm{N}>\mathrm{M}$ actually applies. These examples show that whether the contract curve is upward-sloping or downward-sloping beyond union membership depends among other things on the value the union attaches to nonmembers.

Again consider the impact of the business cycle on wage rate and employment. Simulations by Carruth and Oswald show that a rise of the relative output price or productivity firstly increases only the employment level until it equals union membership. A further rise of the output price or productivity leads to an increase of the wage rate, leaving employment unaffected. Finally, the rise of the output price or productivity will increase employment beyond union membership, while the wage rate remains constant. Note that these results are obtained under the assumption that the union does not care about nonmembers. 


\section{The human capital approach}

\subsection{Firm's and union's preferences}

Altematively, let the distinction between workers be based on differences in human capital. Assume that the workers can be divided in two groups. One group consists of workers with a large stock of human capital, the other group of workers with a small stock of human capital. Call them 'trained workers' and 'untrained workers', respectively. The untrained workers are assumed to be more costly to the firm than the trained workers, because of training costs. Assume that the total number of trained and untrained workers willing to work in the representative firm equals $\mathrm{L}$. The number $\mathrm{L}$, which can be interpreted as union membership or firm-specific labour supply, is assumed to be fixed. Let the number of trained workers, which can be employed at costs $\mathrm{W}$, be $\mathrm{M}(\mathrm{M} \leq \mathrm{L})$. Then the number of untrained workers equals L-M. They can only be employed at costs $W+C$, where $C>0$ denotes training costs (in real terms). It is easy to see that it is profitable for the firm to hire trained workers sooner than untrained workers. The firm is assumed to maximize short-run profits. Ignoring the comer solutions $\mathrm{N}=0$ and $\mathrm{N}=\mathrm{L}$, the firm's optimization problem can be written as

$$
\max _{N} \Pi(W, N)=R(N)-W N-\delta_{N M}(N-M) C, R^{\prime}>0, R^{\prime \prime}<0,
$$

with $\delta_{N M}=0$ for $N \leq M, \delta_{N M}=1$ for $N>M$.

A problem in solving the optimization problem is that the profit function cannot be differentiated at $\mathrm{N}=\mathrm{M}$. The isoprofit curves are kinked at this point; cf. figure 7. Assuming an interior solution $(0<\mathrm{N}<\mathrm{M}$ or $\mathrm{M}<\mathrm{N}<\mathrm{L})$, one obtains as first-order condition

$$
R^{\prime}(N)-W-\delta_{N M} C=0, \text { for } 0<N<M \text { and } M<N<L
$$

Further, it is easy to see that

$$
N=M \text { for } W \text { such that } R^{\prime}(M)-C \leq W \leq R^{\prime}(M) \text {. }
$$

So, the firm's labour demand curve is defined implicitly by (20) and (21).

The union is assumed to have utilitarian preferences which can be specified as

$$
G(W, N)=N[g(W)-g(B)], g^{\prime}(.)>0, g^{\prime \prime}(.) \leq 0 .
$$

The assumption of utilitarian preferences is not essential. It is made to facilitate the interpretation of some results and to enable comparison with the results of section 2 . 


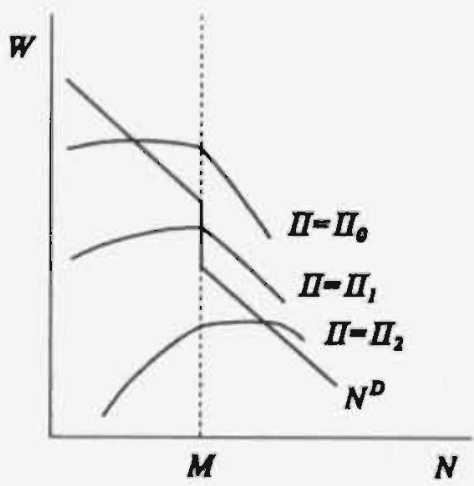

Figure 7 Kinked isoprofit curve and labour demand curve

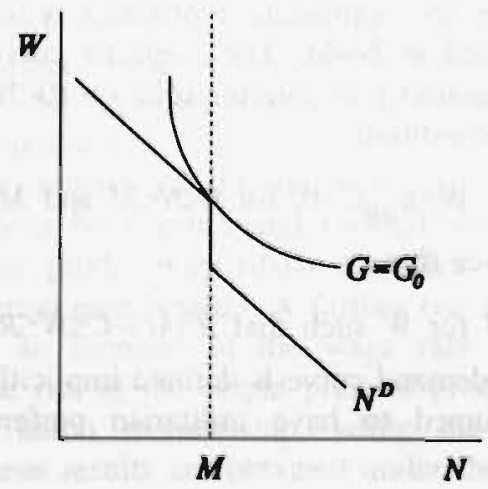

Figure 8 Corner solution in monopoly union model 
The monopoly model and the efficient bargain model which include a distinction between trained and untrained workers are presented in 3.2 and 3.3 .

\subsection{Monopoly union model}

In the monopoly model the union maximizes a utility function subject to the firm's labour demand curve. If the union's preferences are of the utilitarian form (22), the optimization problem can be stated as

$$
\max _{W, N} G(W, N)=N[g(W)-g(B)],
$$

s.t. (20), (21).

Assuming an interior solution $(\mathrm{N} \neq \mathrm{M})$, the first-order condition for a maximum can be written as

$$
\frac{g(W)-g(B)}{g^{\prime}(W)}=-N R^{\prime \prime}(N),
$$

which is also found in e.g. McDonald and Solow (1981). Together with the labour demand function (20) one has two equations in two unknowns. The second-order condition for a maximum is

$$
2 g^{\prime}(W) R^{\prime \prime}(N)+N g^{\prime \prime}(W)\left[R^{\prime \prime}(N)\right]^{2}+N g^{\prime}(W) R(N)^{\prime \prime \prime}<0,
$$

which is evaluated in the optimum. The first two terms are negative and nonpositive, respectively, by assumption. The sign of the last term is unknown. In the rest of this chapter the revenue function and the utility function are assumed to be such that the second-order condition is satisfied. The comer solution is

$$
W=R^{\prime}(M), N=M \text {. }
$$

The solution of this problem, which is illustrated in figure 8 , may lie on the upper part of the labour demand curve, on the lower part or at the comer $\mathrm{N}=\mathrm{M}$. From (24) and (26) follows that there is a range of wage rates which cannot be optimal. As can be seen from figure 8, the downward sloping union indifference curve cannot be tangent to the vertical part of the labour demand curve, except at the comer. This property of the human capital version of the monopoly model is stated more formally in proposition 1. Note that the proposition holds for all utility functions which are increasing and quasi-concave in $\mathrm{W}$ and $\mathrm{N}$. 


\section{Chapter 6}

\section{Proposition 1}

A monopoly union maximizing an increasing and quasi-concave utility function subject to a trained-untrained labour demand curve of a profitmaximizing firm will not choose a wage rate $W$ such that $W_{M}-C \leq W<W_{M}$, where $W_{M}$ is the wage rate which equals the marginal revenue after hiring the last trained worker $\left(W_{M}=R^{\prime}(M)\right)$. In the monopoly model $W_{M}$ is equal to the comer solution. $\mathrm{C}$ is the untrained worker's additional training costs.

\section{Proof}

From (21) it is clear that for $\mathrm{W}_{\mathrm{M}}-\mathrm{C} \leq \mathrm{W} \leq \mathrm{W}_{\mathrm{M}}$, the firm's labour demand is given by $\mathrm{N}=\mathrm{M}$. The union utility function is increasing in the wage rate. Therefore, $G\left[W_{M}, M\right]>G(W, M)$ with $W_{M}-C \leq W<W_{M}$. $\left[W_{M}, M\right]$ is feasible, because it is on the labour demand curve. So, a wage rate $W$ such that $W_{M^{-}}$ $\mathrm{C} \leq \mathrm{W}<\mathrm{W}_{\mathrm{M}}$ cannot be optimal.

When will the union choose a wage rate such that untrained workers will be hired? Assuming the second-order condition is satisfied, the conditions under which employment is below or above the number of trained workers are as follows. The optimal employment level is below the number of trained workers if

$$
\frac{g\left(W_{M}-C\right)-g(B)}{g^{\prime}\left(W_{M}\right)}<-M R^{\prime \prime}(M) .
$$

The optimal employment level exceeds the number of trained workers if both

$$
\frac{g\left(W_{M}-C\right)-g(B)}{g^{\prime}\left(W_{M}-C\right)}>-M R^{\prime \prime}(M)
$$

and

$$
N^{*}\left[g\left(W^{*}\right)-g(B)\right]>M\left[g\left(W_{M}\right)-g(B)\right]
$$

hold, where $\left(\mathrm{W}^{+} \cdot \mathrm{N}^{+}\right)$denotes the optimal pair of wage rate and employment under the restriction $N>M$. Equation (28) is a feasibility condition which ensures that the assumption $N^{+}>M$ is correct. Equation (29) is an optimality condition which guarantees that the union's utility in $\left(\mathrm{W}^{+}, \mathrm{N}^{+}\right)$exceeds the comer solution utility. In other words, it guarantees that the local optimum is also the global optimum. The comer solution applies if (27) and either (28) or (29) do not hold.

Intuitively, it is clear that training costs might hinder or reduce the employment of untrained workers. It is easy to show that a subsidy of training costs increases the probability that untrained workers are hired or increases the number of employed untrained workers if some of them are 
hired already. To show this note that a subsidy $S(0<S \leq C)$ is analytically equivalent to a reduction of training costs.

\section{Proposition 2}

Let the union's preferences be of the utilitarian type. Assume further that the firm's revenue function is concave and that the individual worker is risk averse. Assume, finally, that the second-order condition (25) holds. Then a subsidy of training costs in the insider-outsider version of the monopoly model (19) increases the probability that untrained workers are hired and enhances employment if some unirained workers are hired already.

\section{Proof}

To show that a subsidy of training costs increases the probability that untrained workers are hired, note that the left-hand side of the feasibility condition (28) is decreasing in C. So, the lower C, the more likely that the feasibility condition is satisfied and that untrained workers are hired. To show that employment of untrained workers is increased by a subsidy of training costs if some untrained workers are hired already, use the labour demand equation (20) to substitute for $\mathrm{W}$ in (24). By invoking the implicit function theorem, it can be shown that

$$
\frac{\partial N}{\partial C}=\frac{g^{\prime}(W)+N R^{\prime \prime}(N) g^{\prime \prime}(W)}{N\left[R^{\prime \prime}(N)\right]^{2} g^{\prime \prime}(W)+\left[2 R^{\prime \prime}(N)+R^{\prime \prime \prime}(N)\right] g^{\prime}(W)}<0 .
$$

The negative sign of the derivative implies that a subsidy of training costs has a positive impact on employment if some untrained workers are hired.

Finally, consider the development of wage rate and employment during the business cycle. If the union has utilitarian preferences it is easy to show that an increase of the relative output price or a productivity shock has a positive impact on employment. Only if employment equals the number of trained workers, a rise of the output price or of productivity leaves employment unaffected. If employment is below the number of trained workers, a price increase or productivity shock has no effect on employment in both models. If employment equals the number of trained workers, the output price or productivity and the wage rate are positively correlated. If employment exceeds the number of trained workers, a higher output price or a productivity shock does not alter the wage rate.

\subsection{Efficient bargain model}

The efficient bargain model requires that the union and the firm bargain about both the wage rate and the employment level. The outcome is on a contract curve which, generally speaking, does not coincide with the labour demand curve. The bargaining outcome is found by solving 


$$
\max _{W, N}\left[N[g(W)-g(B)]-G_{0}\right]\left[R(N)-W N-\delta_{N M}(N-M) C-\left[\Pi_{0}\right]^{1-\lambda},\right.
$$

\section{$0 \leq \lambda \leq 1$.}

where $G_{0}$ and $\Pi_{0}$ are the fall-back levels of the union and the firm, respectively. " For simplicity, the fall-back levels are assumed to be zero. By eliminating $\lambda$ from the two first-order conditions, one obtains an equation for the contract curve

$$
R^{\prime}(N)-W-\delta_{N M} C=-\frac{g(W)-g(B)}{g^{\prime}(W)}, N<M \text { or } N>M .
$$

Because the right-hand side is negative, (32) implies that in the efficient bargain model marginal revenue falls short of marginal cost. The slope of the contract curve is considered in proposition 3 .

\section{Proposition 3}

Let the union's preferences be represented by a utilitarian utility function. Let the worker be risk averse and the firm's revenue function be concave. Then the contract curve (32) is upward sloping for $N<M$ and $N>M$.

Proof

The slope of the contract curve is found by differentiating (32) to $\mathrm{N}$

$$
\frac{\partial W}{\partial N}=-\frac{R^{\prime \prime}(N) g^{\prime}(W)}{\left[R^{\prime}(N)-W-\delta_{N M} C\right] g^{\prime \prime}(W)}, N \neq M .
$$

Due to the concavity of the revenue function $\left(R^{\prime \prime}<0\right)$, the risk aversion of the individual worker $\left(\mathrm{g}^{\prime \prime}<0\right)$ and the inequality implied by $(32)\left(\mathrm{R}^{\prime}(\mathrm{N})-\mathrm{W}\right.$ $\delta_{\mathrm{NM}} \mathrm{C}<0$ ), the contract curve is upward sloping.

As is well-known, the contract curve is vertical if the worker is risk neutral.

So far the results hardly differ from those of the standard efficient bargain model as reported by McDonald and Solow (1981). The interesting

- The efficient bargain model of the insider-outsider approach is written as a constrained maximization problem, whereas the efficient bargain model of the human capital approach is written as a generalized Nash bargaining function. It is easy to show that the two formulations are equivalent.

s. The assumption that the fall-back levels are zero does not play a role in the derivation of the contract curve, but it affects the end points. If the fall-back levels are positive, the set of feasible solutions is reduced. For example, if $G_{0}>0$, the contract curve does not start at $W=B$. 
question is what happens if the employment level equals the number of trained workers. This is the subject of the following proposition.

\section{Proposition 4}

Let the union's preferences be represented by a utilitarian utility function and let the firm's revenue function be concave. Then the contract curve is vertical at $\mathrm{N}=\mathrm{M}$. If the second-order condition for a maximum is satisfied, the wage rate is an increasing function of the union's bargaining power.

\section{Proof}

Differentiating the Nash bargaining function (31) to W, and evaluating the first-order condition at $\mathrm{N}=\mathrm{M}$ gives

$$
\lambda\left[\frac{R(M)-W M}{M}\right]-(1-\lambda)\left[\frac{g(W)-g(B)}{g^{\prime}(W)}\right]=0 .
$$

The second-order condition for a maximum, which is assumed to be satisfied, can be written as

$$
1-(1-\lambda) \frac{[g(W)-g(B)]}{\left[g^{\prime}(W)\right]^{2}} g^{\prime \prime}(W)>0 .
$$

The relationship between the wage rate and the union's bargaining power becomes clear by differentiating the first-order condition (34) to $\lambda$. Invoking the implicit function theorem, one obtains

$$
\frac{\partial W}{\partial \lambda}=\frac{\frac{R(M)-W M}{M}+\frac{g(W)-g(B)}{g^{\prime}(W)}}{1-(1-\lambda) \frac{g(W)-g(B)}{\left[g^{\prime}(W)\right]^{2}} g^{\prime \prime}(W)}>0 .
$$

Equation (36) implies that the wage rate is an increasing function of the union's bargaining power at $\mathrm{N}=\mathrm{M}$.

In the derivations above it is simply assumed that the contract curve exists for both $\mathrm{N}<\mathrm{M}, \mathrm{N}=\mathrm{M}$ and $\mathrm{N}>\mathrm{M}$. This is not necessarily true, however. Consider the case that the union's bargaining power is zero. This case is of special interest, because this is the lowest point of the contract curve. If $\lambda=0$, the union is forced to accept a wage rate equal to the altemative wage. Substituting $W=B$ in the contract curve equation (32) gives

$$
R^{\prime}(N)-B-\delta_{N M} C=0 \text {. }
$$

For employment levels below the number of trained workers, $\delta_{\mathrm{NM}}=0$. Because of the concavity of the revenue function, a necessary and sufficient condition for $\mathrm{N}<\mathrm{M}$ to hold, is that 


$$
W_{M}=R^{\prime}(M)<B .
$$

For employment levels above the number of trained workers, $\delta_{N M}=1$. Because of the concavity of the revenue function, a necessary and sufficient condition for $\mathbf{N}>\mathbf{M}$ to hold, is that

$$
W_{M}=R^{\prime}(M)>B+C \text {. }
$$

If neither (38), nor (39) holds, the optimal employment level (for $\lambda=0$ ) must equal the number of trained workers. Graphically, if (38) holds, the contract curve starts at $\mathrm{N}<\mathrm{M}$. If (38) holds, the contract curve consists of only one part in the region $\mathrm{N}>\mathrm{M}$. If neither (38), nor (39) holds, the contract curve starts with a vertical part at $\mathrm{N}=\mathrm{M}$. Figures 9-10 illustrate the contract curve under the assumption of risk aversion.

Again, consider the question whether a subsidy of training costs increases the probability that untrained workers are hired or whether it enhances employment of untrained workers if some of them are hired already. For the efficient bargain model it is possible to derive a quite general result.

\section{Proposition 5}

Let the individual worker be risk averse or risk neutral and let the union have utilitarian preferences. Let the firm's revenue function be concave. Let the wage rate and the employment level be determined according to the efficient bargain model (31), and let the fall-back levels be zero. Then a subsidy of training costs increases the probability that untrained workers are hired and it enhances employment if some untrained workers are hired already.

Proof

To show that a subsidy of training costs increases the probability that untrained workers are hired, it is sufficient to note that the lower $\mathrm{C}$, the higher the probability that the feasibility condition (39) is satisfied. To show that a subsidy of training costs enhances employment if some untrained workers are hired already, combine the two first-order conditions for a maximum of (31) to eliminate W. By invoking the implicit function theorem it can be shown that

$$
\begin{aligned}
& \qquad \frac{\partial N}{\partial C}=\frac{(1-\lambda) N^{2} g^{\prime}(W)-\lambda g^{\prime \prime}(W) \Pi(W, N)(N-\lambda M)}{D} \\
& \text { with } \\
& D=g^{\prime}(W)(1-\lambda) N^{2} R^{\prime \prime}(N)+ \\
& {[\lambda /(1-\lambda)] g^{\prime \prime}(W) \Pi(W N)\left[\lambda \Pi(W, N)-(1-\lambda)^{2} N^{2} R^{\prime \prime}(N)\right] N .}
\end{aligned}
$$

By assumption, employment exceeds the number of trained workers (N>M) and the individual worker is risk averse or risk neutral, so the nominator is 
Insider-outsider vs. human capital effects

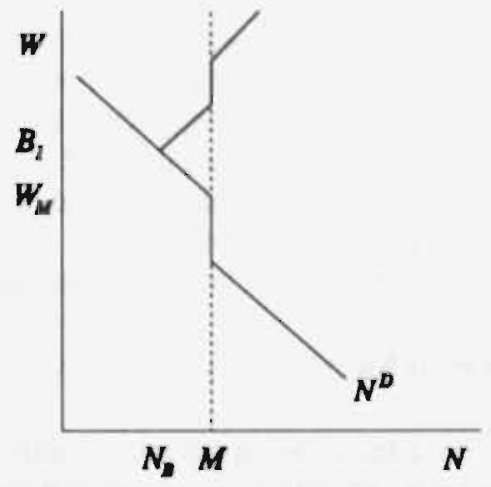

Figure 9 Contract curve for high benefits $\left(B>W_{M}, N_{B}<M\right)$

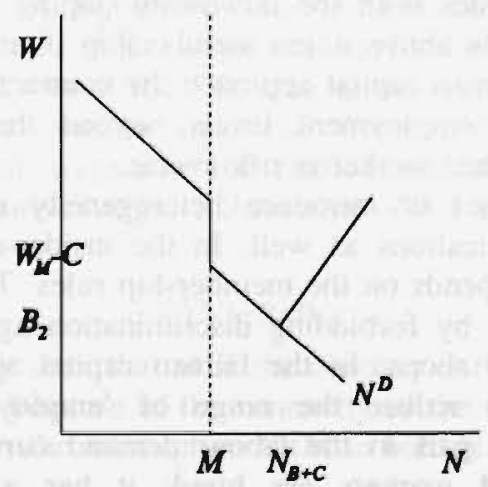

Figure 10 Contract curve for low benefits $\left(B<W_{M}-C, N_{B+C}>M\right)$ 
positive. The firm's revenue function is concave, which implies that the denominator is negative. Therefore, $\partial \mathrm{N} / \partial \mathrm{C}$ is negative.

The development of wage rate and employment level during the business cycle in the efficient bargain model is qualitatively nearly the same as in the monopoly model. The only difference is that if employment exceeds the number of trained workers, a higher output price or productivity does not alter the wage rate in the monopoly model, but reduces the wage rate in the efficient bargain model. The comparative statics imply that the spill-over effects from the product market to the labour market are not unanimous.

\section{Concluding remarks}

This chapter presents an alternative approach to introduce heterogeneity of labour in standard models of union wage formation. In the well-known insider-outsider approach the union makes a distinction between members and nonmembers. In the human capital approach, which is proposed in this chapter, the firm makes a distinction between trained and untrained workers. The two approaches appear to have quite different implications with respect to the employment possibilities of unprivileged workers under monopoly unionism and the slope of the contract curve under efficient bargaining between union and firm. In the insider-outsider approach a monopoly union will never be willing to let in outsiders. In the human capital approach it can be fully rational for a monopoly union to choose a wage rate such that untrained workers will be hired. In the insider-outsider approach the contract curve coincides with the downward-sloping labour demand curve for employment levels above union membership if union and firm bargain efficiently. In the human capital approach the contract curve is found to be upward sloping for employment levels beyond the number of trained workers if the individual worker is risk averse.

The two approaches to introduce heterogeneity of labour have quite different policy implications as well. In the insider-outsider approach the employment level depends on the membership rules. The government might enhance employment by forbidding discrimination against nonmembers or by forbidding closed shops. In the human capital approach a subsidy of training costs might reduce the range of 'employment stickiness', by reducing the vertical part in the labour demand curve or in the contract curve, if all trained workers are hired; it has a positive impact on employment if some untrained workers are already hired.

An important drawback of the models presented in this chapter is that they are static and incomplete, because the number of untrained workers is assumed to be predetermined. The number of trained workers may be made endogenous by relating it to the number of previously employed workers. 
The resulting models may be useful to explain unemployment persistence. This dynamic human capital approach is somewhat similar to the insideroutsider approach proposed by Blanchard and Summers (1986, 1987) and Gottfries and Horn (1987). An important difference is that in the human capital approach it is the firm that cares about the employment status of workers, whereas in the insider-outsider approach it is the union. Dynamic insider-outsider models with uncertainty and their implications for unemployment persistence are surveyed in chapter 7. The dynamic implications of human capital on union wage formation have to be elaborated in future research.

\section{Appendix Derivation of the contract curve}

The derivation of the contract curve by Carruth and Oswald, which results in figure 3 , is incomplete. There are two questions which deserve further consideration before a figure is drawn. Firstly, when are the assumptions $N<M$ and $N>M$, respectively, correct? Secondly, what happens at $N=M$ ? Answering the first question seems difficult, because an explicit solution for $\mathrm{N}$ cannot be obtained without specifying a utility function and a revenue function. Nevertheless, it is possible to show that the assumptions apply for different values of the exogenous parameters.

Introduce the following notation. Consider for a moment the case of a profit-maximizing firm which is free to choose the employment level according to the labour demand curve. Let $W_{M}$ denote the wage rate at which the profit-maximizing firm will hire exactly all union members, i.e. $W_{M}=R^{\prime}(M)$. Further, let $N_{B}$ denote the number of workers the profitmaximizing firm will hire if the wage rate equals the alternative wage, i.e. $N_{B}$ is defined implicitly by $R^{\prime}\left(N_{B}\right)=B$. Due to the monotony of $R^{\prime}(),. N_{B}$ is uniquely defined. Now, consider again the situation that the union and the firm bargain about both wage rate and employment. Assume that the wage rate equals the alternative wage. Substituting $\mathrm{W}=\mathrm{B}$ in the contract curve equation (8) gives

$$
R^{\prime}(N)-B=0 \text {. }
$$

From (A.1) it is easily seen that at $B$ the contract curve coincides with the labour demand curve. Because of the concavity of the revenue function $R$, a necessary condition for the assumption $\mathrm{N}<\mathrm{M}$ to hold is that

$$
W_{M}<B
$$

or equivalently,

$$
N_{B}<M \text {. }
$$

Substituting $\mathrm{W}=\mathrm{B}$ in the contract curve equation (10) also results in (A.1). 
Again the contract curve coincides with the labour demand curve at $\mathrm{W}=\mathrm{B}$. Because of the concavity of $R$, a necessary condition for $N>M$ to hold is that

$$
W_{M}>B
$$

or equivalently,

$$
N_{B}>M \text {. }
$$

If $W_{M}=B$, neither $N<M$, nor $N>M$ can hold, so $N=M$ must be true. Summarizing, if the wage rate equals the alternative wage, the bargaining outcome is on the labour demand curve. Whether the employment level is below, equal to or above union membership depends on the profitmaximizing employment level at the alternative wage and on union membership.

The case considered above is a limiting case, for B is the lowest value of W for which the contract curve is well-defined. Now, consider what happens if the union's bargaining power increases, such that the union is able to reach a higher isoprofit curve. Initially, assume $N_{B}<M$. Due to the continuity of the optimization problem, the optimal wage rate and employment level are found by moving along the upward-sloping contract curve. In other words, if the union's power increases, both the wage rate and the employment level increase. Alternatively, assume $N_{B}>M$. The wage rate and the employment level follow the downward-sloping contract curve in northwestern direction. So the wage rate increases while the firm is allowed to reduce the employment level according to the labour demand curve. Irrespective of its initial level, employment approaches membership if union bargaining power increases.

This brings us to the second question, what happens if employment equals union membership? Firstly, it will be argued that an increase in union bargaining power (a lower value of $\Pi_{0}$ ) does not affect the employ ment level if it equals union membership. Both a movement in southwestem direction along the upward-sloping contract curve and a movement in southeastern direction along the downward-sloping contract curve imply a reduction of union utility. As a larger choice set cannot lead to a lower union utility level, the conclusion is that if employment equals union membership, an increase in the union's bargaining power does not affect employment. Secondly, it is shown that an increase in the union's bargaining power has a positive impact on the wage rate. Because employment remains unchanged, the union's optimization problem (6), reduces to 


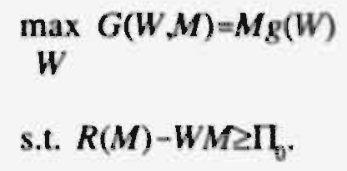

Not surprisingly, in the optimum the constraint holds as an equality. In other words, the optimal wage rate is

$$
W=\frac{R(M)-\Pi_{0}}{M} .
$$

Differentiating (A.7) to $\Pi_{0}$ gives

$$
\frac{\partial W}{\partial \Pi_{0}}=-\frac{1}{M}<0 .
$$

Therefore, if the union is able to force the firm to accept a lower profit level, the optimal wage rate increases at $\mathrm{N}=\mathrm{M}$.

The upshot of this discussion is that the contract curve can have three different shapes. Firstly, if $N_{B}<M\left(W_{M}<B\right)$, the contract curve is upwardsloping for $\mathrm{N}<\mathrm{M}$ and vertical at $\mathrm{N}=\mathrm{M}$. Irrespective of the union's bargaining power, no outsiders will be employed. Secondly, if $N_{B}=M$ $\left(\mathrm{W}_{\mathrm{M}}=\mathrm{B}\right)$, the contract curve is vertical at $\mathrm{N}=\mathrm{M}$. Irrespective of the union's bargaining power, employment equals union membership. Thirdly, if $N_{B}>M$ ( $\left.\mathrm{W}_{\mathrm{M}}>\mathrm{B}\right)$, the contract curve is vertical at $\mathrm{N}=\mathrm{M}$ and downward-sloping at $\mathrm{N}>\mathrm{M}$. Nonmembers are employed if the union's bargaining power is low. The result is depicted in figures 4-6. Note that the figures are drawn for different values of the alternative wage or unemployment benefit (B), keeping union membership (M) constant. Alternatively, one might draw the figures for different values of $\mathrm{M}$, keeping $\mathrm{B}$ constant. This completes the derivation of the contract curve. 


\title{
7 Insider-outsider effects and the persistence of unemployment
}

\begin{abstract}
This chapter provides a review of theoretical and empirical work on insider-outsider and duration effects in union wage formation. The innovative aspect of the chapter is that the different theoretical models are classified according to the hypothesized impact of previous employment, unemployment and long-term unemployment on the wage rate. The survey of empirical results shows that the effect of previous employment on the wage rate is generally insignificant. Unemployment and long-term unemployment (besides short-term unemployment) appear to have a significant negative impact. Micro-studies reveal that both firmspecific and aggregate variables play a role in wage determination. The insider-outsider and the duration effects are too weak to cause full hysteresis.
\end{abstract}




\section{Chapter 7}

\section{Introduction}

Unemployment appears to be persistently high in Western Europe. In the Netherlands, for example, unemployment fluctuated around two per cent in the sixties, increased to around six per cent in the late seventies and increased further to fifteen per cent in the early eighties. In the late eighties and early nineties the unemployment rate started to diminish to some seven per cent now. The increase of unemployment in the late seventies and early eighties may be attributed to higher oil prices (see Bruno and Sachs (1985)) and to real wage increases in response to increases of taxes and benefits and a widening gap between consumer prices and producer prices (see Layard and Nickell (1985, 1986, 1987), Bean et al. (1986) and chapter 3). In the late eighties oil prices fell and taxes and benefits were reduced, at least in the Netherlands, but unemployment does not decrease as fast as predicted by the models. In other words, the models mentioned before are unable to explain the persistence of unemployment. There are at least three theories which deal with this problem. Firstly, capital shortage theory states that after a recession the capital stock is too small to employ the whole labour force. This explanation, which is discussed by Bean (1989), is further neglected. Secondly, insider-outsider theory argues that after a recession wages are increased before unemployment is reduced because wage determination is dominated by employed 'insiders', who do not take into account the interests of unemployed 'outsiders'. Thirdly, duration theory suggests that long-term unemployed have little influence on wage determination because they reduce search effort or firms do not want to hire them. This may be due either to the loss of human capital during long spells of unemployment or to discrimination ('stigmatization') by employers.

The distinction between insider-outsider theory and duration theory is not as clear as it might seem at first sight. Actually, it depends on the definition of insiders and outsiders; the altemative definitions are discussed in chapter 3. Especially if the insiders are the employed or short-term unemployed and the outsiders are the long-term unemployed the implications for wage determination in insider-outsider theory are close to that of duration theory.

The purpose of this chapter is, firstly, to evaluate whether insider-outsider and/or duration effects in wage formation are able to explain unemployment persistence and, secondly, to evaluate the empirical evidence. ${ }^{1}$ The innovative aspect of the chapter is that the theoretical models are classified according to

1 This chapter does not consider the question why unemployed workers do not underbid union wages. This question, which is considered at length by Lindbeck and Snower (1986, 1987a, 1988), is considered of minor importance because of legal restrictions in many countries. 
the hypothesized impact of previous employment, unemployment and longterm unemployment on the wage rate. The paper closest to this is Blanchard (1991). This review provides a more formal presentation of the theoretical models and pays more attention to the empirical results. The survey about unemployment by Nickell (1990) has a much wider scope than this chapter.

The rest of this chapter is set up as follows. Section 2 considers the role of previous employment in union wage formation and unemployment persistence. The role of unemployment and of long-term unemployment are considered in section 3 and 4 respectively. Whereas sections 2 and 3 concentrate on insideroutsider theory, section 4 refers to duration theory as well. Section 5 explains the link between the theoretical and the empirical work. The empirical results on insider-outsider and duration effects in wage determination are surveyed in section 6 . The conclusions and the suggestions for further research are given in section 7.

\section{Previous employment and wage determination}

Persistence of unemployment may be caused by insiders setting wages in their own interest. This results in either a negative relationship between the current wage rate and previous employment (Gottfries and Horn (1987)) or in a positive relationship between the wage change and the lagged employment change (Blanchard and Summers (1986)). Firstly, these papers are reviewed separately. At the end of the section the relationship between the models is discussed. Although this section is based largely on the papers mentioned, similar models are presented by Solow (1985) and Sampson (1988).

Gottfries and Horn (1987) assume that union membership consists of all previously employed workers. The firm's labour demand is subject to exogenous demand shocks. The monopoly union is assumed to set the real wage rate, before knowing the realization of this shock. After its realization the firm is supposed to set the employment level according to the labour demand curve. If the shock tums out to be favourable, some outsiders will be hired as well. In Gottfries and Hom (1987) the union's preferences are represented by an expected utility function. For mathematical convenience a simpler utility function, adopted from Blanchard and Summers (1986), is utilized in the present chapter. For the same reason labour demand is not represented by a general functional form and a multiplicative shock as in Gottfries and Horn, but by a loglinear function with an additive shock. The simplified model suffices to derive their main results.

Let the firm's labour demand be represented by

$$
n=\alpha-\beta w_{r}+\varepsilon,
$$

where $n$ and $w_{r}$ denote labour demand and the real wage rate, respectively (all variables are in logs). The demand shock $\varepsilon$ is assumed to have zero mean. Of 


\section{Chapter 7}

course, the demand shock should be restricted in order to prevent labour demand becoming less than zero. The union is assumed to set the real wage rate such that the expected employment level equals union membership (m)

$$
E n\left(w_{r}\right) *=m,
$$

where the asterisk indicates optimality. By taking expectations of (1), substituting (2) and by replacing membership $m$ by previous employment $n_{-1}$ one obtains

$$
w_{r}^{*}=\frac{\alpha}{\beta}-\frac{n_{-1}}{\beta} .
$$

Differentiating to the lagged employment level gives

$$
\frac{\partial w_{r}}{\partial n_{-1}}=-\frac{1}{\beta}<0 .
$$

Replacing union membership by lagged employment in (2) and by differentiating to it, leads to

$$
\frac{\partial E n}{\partial n_{-1}}=1>0 .
$$

Equations (4) and (5) confirm the result by Gottfries and Horn (1987) that 'the smaller the number of workers employed in the previous period, the higher the optimal wage, and hence the lower the expected employment level in the current period' (p. 881). By integrating the wage setting equation in a simple macro-economic model, the authors show that 'a monetary shock has a persistent effect on employment' (p. 883).

In Blanchard and Summers (1986) the trade union sets the nominal wage rate (in logs: $w$ ); the firm determines the price level (p) and the employment level. Labour demand, which is assumed to be dynamic, is specified as:

$$
n=s n_{-1}-(1-s) \beta(w-p)+\varepsilon \text {. }
$$

Note that for notational convenience the constant term is omitted. Unlike Gottfries and Hom (1987), Blanchard and Summers interpret the term $\varepsilon$ not as a demand shock but as a productivity shock. They assume that $\varepsilon$ follows a random walk. The monopoly union is supposed to set the wage rate such that expected labour demand equals a weighted average of union membership and lagged employment:

$$
E n=(1-\gamma) m+\gamma n_{-1} \text {. }
$$

If $\gamma=1$, the previous employment level determines the wage rate. There results hysteresis. If $\gamma=0$, the target employment level is independent of history. In this case there is no hysteresis. By taking expectations of $(6)$ and substituting 
(7) one obtains

$$
w=E p+\frac{1}{\beta(1-s)}\left[-(1-\gamma) m+(s-\gamma) n_{-1}+E \varepsilon\right]
$$

and

$$
n=(1-\gamma) m+\gamma n_{-1}+[\varepsilon-E \varepsilon+(1-s) \beta(p-E p)] .
$$

Equation (8) shows there is a negative relationship between the wage rate and the desired employment level, as in Gottfries and Hom (1987). Equation (9) shows that if the union cares about previously employed only $(\gamma=1)$, the employment level follows a random walk. In this case there results full hysteresis. If the union cares about all workers $(0<\gamma \leq 1, \mathrm{~m}=1 \mathrm{~s}$ with is denoting the $\log$ of the labour force), employment follows a first-order process around the level of the labour force. In general, the higher the weight from outsiders in union preferences, the lower the persistence of employment. The relationship between union preferences and (un)employment persistence is further elaborated in Blanchard and Summers (1987).

Equation (8) plays an important role in empirically testing insider-outsider theory. This equation cannot be estimated directly, because Blanchard and Summers assume expected productivity to be correlated with past productivity and thus with past employment. Lagging (6) and substituting in (8) yields:

$$
\Delta w=k+\left(E p-p_{-1}\right)+\frac{1}{\beta(1-s)}\left[(1+s-\gamma) n_{-1}-s n_{-2}\right]
$$

where $\Delta$ is the first-difference operator and $k=-[1 / \beta(1-s)](1-\gamma) \mathrm{m}$. For reasons not made clear Blanchard and Summers (1986) neglect the term k in their empirical work. Their testing procedure concentrates on the coefficients of employment lagged once and twice. If there is full hysteresis $(\gamma=1)$, real wage growth depends positively on the change of the employment level. If there is no hysteresis at all $(\gamma=0)$, the ratio of the coefficient of employment lagged twice to the coefficient of employment lagged once cannot exceed $1 / 2$ (in absolute value).

The model derived above can be made more in line with standard wage equations by assuming that the labour force is constant (a heroic assumption). Using the approximation

$$
l s \approx n+u,
$$

where $u$ denotes the unemployment rate, this results in

$$
\Delta w=k^{\prime}+\left(E p-p_{-1}\right)+\frac{1}{\beta(1-s)}\left[s \Delta u_{-1}+(1-\gamma) u_{-1}\right],
$$

where $k^{\prime}=[(1-\gamma) / \beta(1-s)]\left(1 s_{-1}-m\right)$. Note that the constant term drops if $m=l s_{-1}$. The resulting wage equation is very close to a standard Phillips curve which allows 
for a rate of change effect à la Lipsey. Under full hysteresis the real wage growth depends negatively on the change (rather than the level) of unemployment. However, this result can also be interpreted as evidence in favour of the wage curve approach. This is easily seen by taking first differences of the wage curve equation. Whereas there is evidence that the wage curve approach is more able to explain wages than the Phillips curve approach (see Blanchflower and Oswald (1990)), this procedure is likely to confirm the hypothesis of hysteresis, even if it is wrong.

Comparison of the testing procedures proposed by Gottfries and Hom (1987) and Blanchard and Summers (1986) reveals another serious problem, namely their sensitivity to the underlying assumptions. By taking first differences, the model by Gottfries and Hom (1987) implies a negative relationship between the wage change and the lagged employment change under hysteresis. Blanchard and Summers (1986) argue there is a positive relationship between the wage change and the lagged employment change. At first sight its seems strange that testing the same hypothesis can lead to different expected signs. The discrepancy is due to two differences in the assumptions. Firstly, Gottfries and Hom assume that the shocks are uncorrelated, whereas Blanchard and Summers assume that they follow a random walk. Secondly, in Gottfries and Hom employment adjusts instantaneously, whereas in Blanchard and Summers employment adjusts gradually. Finally, the testing procedure by Blanchard and Summers has the problem that under full hysteresis the parameter of the lagged employment change cannot be estimated, because the variable itself will be zero (apart from an irrelevant error term). Because of these problems, empirical studies using one of these testing procedures must be interpreted with care.

\section{Unemployment and wage determination}

Altematively, unemployment persistence may be caused by the absence of a negative impact of unemployment on the wage rate. If the union feels responsible for both employed and unemployed workers, union membership may be set equal to the labour force. Replacing union membership by the labour force in equation (7) shows that the union either sets wages in the interest of all previously employed $(\gamma=1)$, or sets wages such that there results full employment $(\gamma=0)$, or somewhere in between. Whereas the current magnitude of the labour force is probably unknown at the time of wage determination, let us use the lagged value. Union membership may then be approximated by

$$
m=l s_{-1} \approx n_{-1}+u_{-1} .
$$

Substituting (13) in (8) yields 


$$
w=E p-\frac{1}{\beta} n_{-1}-\frac{1-\gamma}{\beta(1-s)} u_{-1}+E \varepsilon .
$$

Note that the lagged employment level will have a negative impact on the wage rate, irrespective of whether there is hysteresis or not. If the expected value of the shock is zero, this equation can easily be estimated. If the (lagged) unemployment rate appears to have a significant impact on the wage rate this provides evidence against full hysteresis. Nickell and Wadhwani (1988) interpret the significance of aggregate unemployment in a firm-level wage equation in this way.

A problem with this testing procedure is that the significance of the unemployment rate does not necessarily imply that the union cares about unemployed. This is easily shown by dropping the assumption that wages are determined by a monopoly union. Assume, alternatively, that wages are determined in a bargaining process between union and firm and that the employment level is set unilaterally by the firm. These assumptions are wellknown from the right-to-manage model; see Nickell (1982) and Nickell and Andrews (1983). Let the bargaining process be described by an asymmetric Nash bargaining model. The outcome depends on the alternative options available to union and firm during the bargaining process and on the parties' relative bargaining power. It is quite likely that the aggregate unemployment rate affects these alternative options and/or the relative bargaining power. So an alternative interpretation of a significant unemployment effect in wage determination is that it weakens the union's power to realize the insiders' purposes; see e.g. Lindbeck and Snower (1987a).

\section{Long-term unemployment and wage determination}

Finally, unemployment persistence may be caused by the ineffectiveness of long-term unemployment to depress wages. Both insider-outsider and duration theory suggest that long-term unemployed may have a different impact on wages than short-term unemployed. Firstly, long-term unemployed may resign from the union. For this reason the union may give a lower weight to the preferences of long-term unemployed. This hypothesis is found in Graafland (1992) and in chapter 3. Secondly, long-term unemployment may cause deterioration of skills. In order to save training costs, employers might prefer to hire short-term unemployed. Thirdly, employers may interpret long-term unemployment as a signal that the worker is not as good as others, otherwise he/she would have been hired before. This might be called the stigma effect. Fourthly, long-term unemployed may reduce search intensity. Whereas the first is an insider-outsider effect, the last three are duration effects.

Unfortunately, it is difficult to discriminate between insider-outsider and duration effects. Both result in a wage equation in which the wage rate 


\section{Chapter 7}

depends negatively on the unemployment rate and positively on the long-term unemployment rate (or negatively on the long-term unemployment rate and more negatively on the short-term unemployment rate). If the empirical evidence supports this hypothesis, further research is necessary to find out which of the reasons mentioned above causes this effect. It should be noted that most authors who investigate the impact of long-term unemployment on the wage rate do not provide an explanation for long-term unemployment itself. For this reason the models are incomplete.

\section{Transition to empirical work}

The various contributions on insider-outsider theory and duration theory reviewed in the previous sections provide several testable hypotheses. Firstly, Blanchard and Summers (1986) and Gottfries and Hom (1987) suggest that the wage rate depends on the number of previously employed. Blanchard and Summers (1986) assume that the union sets the wage rate such that the expected employment level equals a weighted average of past employment and union membership. This results in a Phillips curve wage equation in which the expected real wage growth depends positively on the change (rather than the level) of employment. Gottfries and Horn (1987) derive another testing framework by incorporating the membership effect. By assuming that union membership consists of all previously employed workers they argue that the wage level depends negatively on the lagged employment level.

Secondly, as noted by Nickell and Wadhwani (1988), the model by Blanchard and Summers (1986) implies that after allowing for the impact of previous employment on wage determination aggregate unemployment should be insignificant. Although the insignificance of unemployment provides evidence in favour of insider-outsider theory, the significance of unemployment does not falsify the theory. It is quite likely that unemployment enters an insider-outsider wage equation, because unemployment affects the bargaining power of the insiders.

Thirdly, a limited effect of long-term unemployment on wage determination provides evidence in favour of insider-outsider theory or duration theory. It is an insider-outsider effect if the union cares more about employed and shortterm unemployed than about long-term unemployed; see Graafland (1992) and chapter 3. It is a duration effect if it results from a reduction of search intensity by long-term unemployed workers or from an increase of training costs during long-term unemployment.

Before turning to the empirical results, consider the level of aggregation. Generally, the theoretical models can be estimated and tested at both micro and aggregate level. The choice of the aggregation level depends on the centralization of wage determination. Furthermore, the availability of data plays a role. An advantage of firm or industry data (besides not requiring unrealistic 
assumptions which allow aggregation) is that these allow the assessment of the relative impact of internal (firm-specific) variables like output price, labour productivity or profit per worker and of extemal (aggregate) variables like the aggregate wage rate and the unemployment rate. The hypothesis that internal or firm-specific variables are important in wage determination is proposed by Gregory (1986). If extemal variables appear to be insignificant this provides evidence in favour of insider-outsider theory. The theoretical foundation for this type of wage equation is provided by a model in which wages are determined in a bargaining process to share rents between workers and firm.

\section{Empirical results}

The results of testing these hypotheses are summarized in table 1. The effect of previous employment on wage determination was firstly studied by Blanchard and Summers (1986). They find strong evidence in favour of their insider-outsider hypothesis for the UK, Germany and France, but not for the US. This result is criticized by Alogoskoufis and Manning (1988). These authors argue that Blanchard and Summers wrongly approximate the natural rate of unemployment by a linear instead of a quadratic time trend. Alogoskoufis and Manning (1988) do not attribute the differential experiences in Europe, the US and Japan to insider-outsider effects, but to sluggishness in labour demand in Europe. The estimation results obtained by Graafland (1988, 1989) confirm the conclusion by Blanchard and Summers that insider-outsider effects are more important in Europe than in the US. In my opinion the evidence in favour of the insider-outsider theory is not as strong as it seems to be at first sight. Firstly, Blanchard and Summers and Graafland adopt a Phillips curve approach and assume labour supply to be constant. As argued before, this results in a testing framework which favours the hypothesis of hysteresis. Secondly, Blanchard and Summers (1986) and Alogoskoufis and Manning (1988) do not include labour productivity in the regression equation. For these two reasons I do not put much faith in the results reported above. Microeconomic studies cast further doubt on the relevance of previous employment. Christofides and Oswald (1989) obtain an insignificant effect of the change in the employment level on the rate of change of the real wage for Canada. Nickell and Wadhwani (1990) report positive effects of the change in the employment level on the wage rate (not wage growth) in the UK, but this result appears not to be robust if an altemative sample is used. Holmlund and Zetterberg (1991) find a marginally significant positive effect of the lagged employment level on the wage rate for Germany and insignificant effects for Norway, Sweden, Finland and the US. Overall, the empirical evidence favours neither the insider-outsider hypothesis by Blanchard and Summers (1986), nor the one by Gottfries and Hom (1987). 


\section{Chapter 7}

\section{Table 1 Empirical studies on insider-outsider effects in wage formation}

study

Blanchard/Summers

(1986)

Layard/Nickell (1987). Nickell (1987)

\begin{abstract}
Alogoskoufis/Manning (1988)
\end{abstract}

Grainand (1988)

Nickell/Wadhwani (1988)

\section{data}

annual aggregate data for France, Germany. UK and US (19531984)

annual aggregate data for UK (1956-1983)

annual aggregate data for France, Germany, UK. US and Japan (1951-1986)

annual aggregate data for the Netherlands. France. Germany, UK and US (1962-1985)

annual data for 219 UK firms (1974-1982) testing framework

Phillips curve wage equation which includes current and lagged (un)employment or (un)employment lagged once and twice besides consumer price (in rate of change) and time trend

real wage level cquation which includes unemployment mite (in logs) and ratio of long-term to total unemployment, price equation and labour demand equation

real wage level equation which includes unemployment rate and labour supply (both variables once and twice lagged)

Phillips curve wage equation which includes unemployment rate and either lagged unemployment rate or long-term unemployment rate

nominal wage level equation which includes both firm specific variables (output price, sales per man, financial variables) and market variables (aggregate wage. industry and aggregate unemployment)

\section{testing result}

by comparing coeffi. cients on current and lagged (un)employment the hysteresis effect appears to be the largest for UK, somewhat less for France and Germany and the lowest for US

the unemployment rate has a negative impact on the wage, the long. term unemployment ratio has a positive impact (duration effect)

hysteresis effect is somewhat lower for US than for European countries but not significantly: sluggishness in labour demand in France, UK and possibly in Germany, but not in US and Japan

hysteresis effect in the Netherlands is as relevant as in Germany and UK, and more relevant than in France and US; long-lerm unemployment has no wage depressing effect in the: Netherlands

besides firm specific variabies industry and aggregate unemployment appear to be significant 
study

Christofides/Oswald
(1989)

Pencavel (1989)

Blanchflower/Oswald (1990)

Blanchflower et al. (1990) data

quarterly data from contracts between 420 Camadian establishments and 68 unions (19781984)

annual aggregate data for UK (1953-1979)

four cross-section data sets on establishments, adult workers and young workers in UK (1979-1986)

cross-section data for 2019 UK establishments (1984)

\section{testing framework}

real wage equation (rate of change) which includes real industrial product price change, levei and change of regional unemployment rate (wage curve and Phillips curve) and lagged change in employment level

real wage level equation which includes employ. ment lagged once and twice and lagged labour force, employment equation and labour force equation

real wage level equation which allows for nonlinear unemployment rate effects (either $u$ and $\mathbf{u}$ squared or $\log \mathbf{u}$ and $(\log u)$ cubed) and includes long-term unemployment ratio

nominal wage level equation which includes firm specific variables (financial performance, oligopolistic position, employment change and union form) and market variables (county unemployment rate and county wage rate)

annual data for 219 UK manufacturing firms (1974-1982) nominal wage level equation which includes both firm specific variables (revenue per head, financial variables) and market variables (aggregate wage, industry and aggregate unemployment)

\section{testing result}

product price appears to have a positive and significant impact: the change of the unemployment rate perfoms better than the level of the unemployment rate (rejection of Phillips curve); lagged employ. ment level appears to be insignificant (no hysteresis effect)

labour force appears to have a significant negative impact on the real wage rate, so unemployed outsiders matter in union objective

relationship between wage rate and unemployment rate is nonlinear; long-term unemployment ratio appears to be insignificant after allowance for nonlinearity (no duration effect)

both firm specific and market variables appear to be significant, only in unskilled nonunion sector firm specific variables are absent; wage elasticity w.r.t. outside wage is near to unity in this sector, for other sectors it is close 100.5

relative weight of firmspecific and of market variables in wage determination is 0.11 and 0.89 , respectively; a change in firm's employment has a positive impact on the wage rate (hysteresis effect), but this result is not robust 


\section{study}

Holmiund/Retterberg

(1991)

Lever (199/b), chapter 3

Granfland (1992)

Nickel/Kong (1992) data

annual industry data for Norway, Sweden, Finland, Germany and US (1965.1985)

annual aggregate data for the Nethertands (1965-1987)

real wage level equation which includes both aggregate and long-term unemployment rate, labour demand equation

real wage level equation which includes longterm unemployment rate and long-term unemployment ratio, replacement ratio of long-term unemployed, lay-off mate and vacancy rate

annual data for 14 twodigit industrial sectors in Britain (1961-1985) nominal wage level equation which includes hoth industry specific variables (output price. material input price, capital intensity. technical progress) and aggregate variables (aggregate wage, industry unemployment. aggregate unemploy. ment, tax me)

\section{testing resuht}

industry specific variables appear to be important in US, moderately in Germany and Iargely negligible in the Nordic countries; wage elasticity w.r.t. aggregate wage is 0.7 for US and close to unity for the Nordic countries and for Germany; impact of lagged industry employment on wage rate is insignificant or wrongly signed (no hysteresis effect)

unemployment rate has a negative impaci on the wage, long-term unemployment rate appears insignificant (i.c. no duration effect)

both long-term unemployment rate and longterm unemployment ratio appear to be negative: replacement ratio of long-term unemployed has a positive impact; lay-off rate and vacancy rate have a negative and positive influence, respectively

industry variables are significant, their impact is positively related to union's power, unemployment has a negative impact on the wage rate (no pure hysteresis) 
Unemployment appears to be significant in almost all empirical studies of wage determination. The role of this variable is investigated explicitly by Nickell and Wadhwani (1988, 1990). Estimating a firm-level wage equation on UK data, they find strong evidence that aggregate and industry-wide unemployment exerts a downward pressure on the wage rate, even after allowing the firm's employment to affect wages. Pencavel (1989), using aggregate data from the UK, reports that the labour force has a significant negative impact on the real wage rate. Although he does not use unemployment as explanatory variable, his study shows that union wage determination does not depend on the number of insiders only, but also on the number of unemployed outsiders. The question whether the significance of unemployment results from union preferences or is due to its impact on union's bargaining power is not considered explicitly in these studies. Many authors choose the second interpretation; see e.g. Christofides and Oswald (1989), Blanchflower et al. (1990), Nickell and Wadhwani (1990) and Holmlund and Zetterberg (1991).

The role of long-term unemployment in wage determination is studied by Layard and Nickell (1987), Nickell (1987), Blanchflower and Oswald (1990), Graafland $(1988,1990)$ and in chapter 3. As it is difficult to discriminate between insider-outsider effects and duration effects, the discussion of the empirical results in these two areas are combined. After including both the unemployment rate and the long-term unemployment ratio in the aggregate wage equation for the UK, Layard and Nickell (1987) and Nickell (1987) find that the long-term unemployment ratio has a positive coefficient. This result is interpreted as evidence in favour of the duration hypothesis. Blanchflower and Oswald (1990), using UK microeconomic data, criticize this result by showing that the long-term unemployment ratio becomes insignificant after allowing for nonlinear effects of the unemployment rate on the wage rate. The estimation results of Graafland (1988), using a Phillips curve approach, suggest that long-term unemployed have no influence on wage determination in the Netherlands. Graafland argues that this result supports the duration hypothesis. In a later study Graafland (1992) finds that, besides the short-term unemployment rate or the lay-off rate, both the long-term unemployment rate and the long-term unemployment ratio have a negative impact on the wage rate. Graafland (1992) interprets this result as evidence against the hypothesis that trade unions do not care about long-term unemployed. The results in Graafland (1988), which imply that long-term unemployed have no impact on the wage rate, are hard to reconcile to the results in Graafland (1992), which imply they have. Perhaps the discrepancy in empirical results should be attributed to the use of alternative specifications, namely the Phillips curve approach in Graafland (1988) and the wage curve approach in Graafland (1992). In chapter 3 , finally, the long-term unemployment rate is found to be insignificant after including the unemployment rate itself. The conclusion drawn from this result 
is that the union cares about long-term unemployed. Combining the results of these studies, I tend to conclude that long-term unemployment has a negative impact on the wage rate. Therefore, I would say that there is neither convincing evidence in favour of the duration hypothesis nor for the hypothesis that trade unions do not care about long-term unemployed. However, the results are too mixed to draw definite conclusions.

The question whether wage rates are determined by firm-specific (or internal) variables or by market (or external) variables is investigated empirically in work by Gregory (1986), Nickell and Wadhwani $(1988,1990)$, Christofides and Oswald (1989), Blanchflower et al. (1990), Holmlund and Zetterberg (1991) and Nickell and Kong (1992). Whereas Gregory (1986) uses a Phillips curve approach, the other authors adopt a wage curve approach. Gregory finds that labour utilization performs better than unemployment in explaining Australian aggregate wage changes. Empirical work by Nickell and Wadhwani $(1988,1990)$ indicates that wage determination in the UK is dominated by market variables, although firm-specific variables play a role as well. Blanchflower et al. (1990) obtain similar results, although they find no evidence of firm-specific effects in the unskilled nonunion sector of the UK. According to Holmlund and Zetterberg (1991) external variables are more important in Norway, Sweden, Finland and Germany than in the US. This result suggests that under centralized wage determination external variables are more important than under decentralized wage determination. Christofides and Oswald (1989) also find limited influence of aggregate variables on wage determination in Canada. Nickell and Kong (1992) conclude that both internal and external variables affect industry wages in the UK. Further, they find that the impact of internal factors increases with union bargaining power. The extreme hypothesis that external variables like unemployment do not matter in wage determination is decisively rejected.

\section{Concluding remarks}

The conclusions of this review are the following.

(i) The effect of previous employment on the wage rate appears to be small or insignificant.

(ii) There is firm evidence that unemployment plays a role in wage determination. This does not falsify insider-outsider theory: it is quite likely that unemployment enters the wage equation because it affects the alternative options available to the bargaining parties.

(iii) Long-term unemployment is significant in wage determination as well. Possibly, the negative impact of long-term unemployment on the wage rate is (absolutely) smaller than the impact of short-term unemployment. Duration effects appear to be weak or absent. 
(iv) Estimation of wage equations at firm or industry level reveals that besides external or aggregate variables, internal or fim-specific variables have an impact on wages. The impact of internal variables appears to be small in the Scandinavian countries, somewhat larger in Germany and the UK, and to be the largest in the US. The significance of the intemal or firm-specific variables suggests that bargaining or rent-sharing models provide a better explanation for wage determination than the standard competitive model.

(v) Insider-outsider and duration effects may cause some persistence in unemployment; the effects are, however, not strong enough to cause full hysteresis.

Further research is required at the following issues.

(i) The discrimination between rival theories of wage and employment determination is hardly touched. For example, it is unclear whether unemployment affects wage determination because unions care about unemployed or because it weakens the bargaining power of the employed workers.

(ii) There is little empirical evidence whether wages and employment adjust symmetrically to positive and negative shocks.

(iii) The impact of training costs on wage determination, emphasized by Lindbeck and Snower (1988), is not tested empirically.

(iv) More empirical work, preferably at micro level, is necessary to check the robustness of the results obtained so far. 


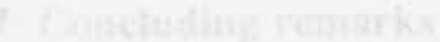

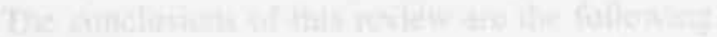

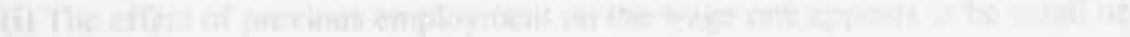

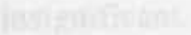

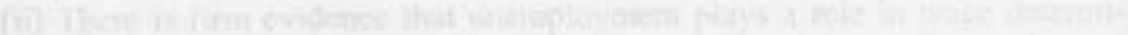

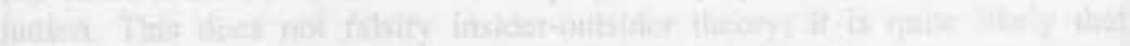

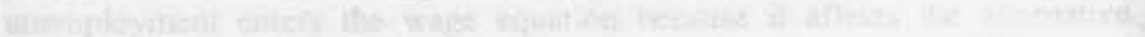

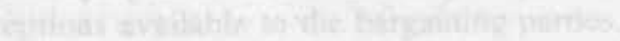

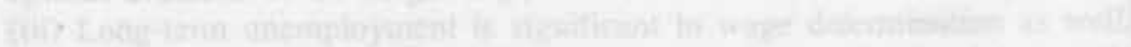

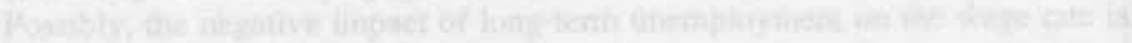

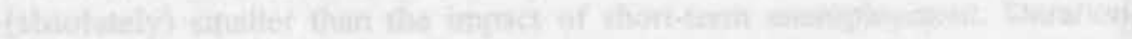

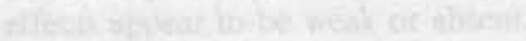




\section{Concluding remarks}

\section{Abstract}

This chapter summarizes and concludes the study. Furthermore, it discusses some policy implications and offers some suggestions for further research. 


\section{Summary and conclusions}

The results of the study can be summarized as follows. Chapter 2 shows that trade unions are economic agents whose behaviour can be integrated in economic theory to explain wage formation and employment. The impact of trade unions on unemployment is less clear. This issue is taken up in the next chapter.

Chapter 3 presents an empirical model of union wage setting, employment and unemployment. The model is estimated with annual aggregate data for the Dutch private sector from 1965 until 1987. The results suggest that the increase of taxes and that of the discrepancy between consumer and producer prices (partially due to value added taxes) and the increase of benefits have caused an increase of the equilibrium unemployment rate in the Netherlands in this period.

Chapter 4 considers whether efficiency wage effects can explain unemployment. The efficiency wage theory argues that it may be profitable for the firm to pay more than the market clearing wage to increase the workers' productivity. A theoretical objection is that more complex contracts can be devised which provide incentives to workers without causing unemployment. There is some empirical evidence that high wages improve worker productivity; whether the effect is sufficiently strong and wide-spread to cause unemployment is questionable. Further, the chapter shows a new result with respect to the interaction between efficiency wage and insideroutsider effects. The insider-outsider theory argues that employed workers (insiders) have more market power than unemployed (outsiders). This market power enables the insiders to obtain wages above the market clearing level, while outsiders remain unemployed. The theoretical model shows that efficiency wage and insider-outsider effects reinforce one another if the insider has complete market power. Whether this result also holds in other situations remains to be assessed.

Chapter 5 presents an empirical application of the efficiency wage theory and the theory of union wage formation. The efficiency wage theory is used to explain wage drift, whereas the theory of union wage formation is used to explain contract wage changes. The estimates for the Netherlands (19721983) imply that there is an inverse relationship between contract wage changes and wage drift. In other words, wage drift reduces the impact of wage moderation by trade unions on employment.

The analysis of chapter 6 is also based on the theory of union wage formation. The central question is whether the probability for unemployed workers to get a job depends on the cause of their unemployment. Two possible causes of unemployment are distinguished. The first cause of unemployment is insider-outsider effects. In this situation the union does not care about unemployed. The second cause of unemployment is lack of 
human capital. This lack may be caused by the duration of unemployment. It appears that the probability for unemployed workers to get a job depends on the cause of their unemployment. Under monopoly unionism unprivileged workers (outsiders, untrained workers) are more likely to be hired if their unemployment was due to a lack of human capital than if the union does not care about them. Under efficient bargaining unprivileged workers prefer powerful unionism if their unemployment was due to a lack of human capital. If their unemployment is due to the fact that the union does not care about them, powerful unionism may hinder their employment.

Chapter 7 considers the empirical implications of insider-outsider effects on wages, employment and unemployment persistence. Furthermore, it provides a survey of empirical studies in this area. It appears that there is little evidence in favour of a lagged employment effect on the wage rate. It is clear that unemployment has a negative impact on wages. Long-term unemployment reduces wages as well, but perhaps at a lower rate than short-term unemployment. The insider-outsider and duration effects are not strong enough to cause full hysteresis.

\section{Policy implications}

The study has the following policy implications. The study of union wage formation, employment and unemployment of chapter 3 implies that pay-roll and income taxes, social security contributions, indirect taxes and benefits may increase equilibrium unemployment. It seems desirable to stabilize or decrease the tax burden, to reduce the number of workers on sick leave, etc. The analysis of contract wage changes and wage drift in chapter 5 suggests that the impact of wage moderation by trade unions is diminished by wage drift. It further indicates that wage control measures by the government are not very effective. The theoretical models in chapter 6 suggest that human capital matters in wage formation. The policy implication of the models is that a subsidy of training costs may enhance employment of untrained workers such as long-term unemployed. It is even better, but also more difficult, to prevent losses of human capital by eliminating long-term unemployment.

\section{Suggestions for further research}

The study is concluded by offering some suggestions for further research. The study of the determinants of equilibrium unemployment in chapter 3 concentrates on imperfect competition in the labour market. If the determination of wages and prices is considered as 'a battle of the mark-ups' (see Layard and Nickell (1986)), the analysis can be improved by including 
imperfect competition in the product market. An empirical study along these lines is provided by Nickell and Kong (1992) for 14 two-digit industrial sectors in Britain. Chapter 4 shows that insider-outsider and efficiency wage effects reinforce one another if the insider has complete market power. It would be interesting to generalize this result in case the insider has no complete market power. The empirical study of contract wage changes and wage drift in chapter 5 could be repeated on a larger data set, for example on panel data of several industries. Chapter 6 presents a static analysis of the impact of human capital or duration effects on wage formation and employment. The dynamic impact of human capital or duration effects on unemployment can be investigated by integrating wage formation theory and matching theory in a single model. The survey in chapter 7 shows that insider-outsider effects may cause unemployment persistence. An interesting subject for further research is whether wages and employment adjust symmetrically in booms and slumps. 


\section{References}

Abraham, Filip (1989), Unions and the govemment: what does economic theory (not) tell us?, in: Die Gewerkschaft in der okonomischen Theorie, Okonomie und Gesellschaft 7, Campus, Frankfur.

Addison, John T. (1989), On modeling union behavior, in: Die Gewerkschaft in der ökonomischen Theorie, Okonomie und Gesellschaft 7. Campus, Frankfurt.

Addison, John T. and Barry T. Hirsch (1989), Union effects on productivity, profits, and growth: has the long run arrived?, Joumal of Labor Economics 7 (1), pp. 72-105.

Akerlof, George A. (1982), Labor contracts as partial gift exchange, Quarterly Journal of Economics 97, pp. 543-569.

Akerlof, George A. (1984), Gift exchange and efficiency-wage theory: four views, American Economic Review, Papers and Proceedings 74 (2), pp. 79-83.

Akerlof, George A. and Janet L. Yellen (1985), A near-rational model of the business cycle, with wage and price inertia, Quarterly Joumal of Economics 100, Supplement, pp. 823-838.

Akerlof, George A. and Janet L. Yellen (eds.) (1986), Efficiency wage models of the labor market, Cambridge University Press, Cambridge, England.

Akerlof, George A. and Janet L. Yellen (1990), The fair wage-effort relationship and unemployment, Quarterly Joumal of Economics 105 (2), pp. 255-283.

Alogoskoufis, George and Alan Manning (1988), Wage setting and unemployment persistence in Europe, Japan and the USA, European Economic Review 32, pp. 698-706.

Ball, Laurence and David Romer (1989), Are prices too sticky?, Quarterly Journal of Economics 104 (3), pp. 507-524.

Bean, Charles R. (1989), Capital shortage, Economic Policy 4 (1), pp. 1153. 
Bean, Charles R., Richard Layard and Stephen J. Nickell (1986), The rise in unemployment: a multi-country study, Economica 53, pp. S1-S22.

Bean, Charles R. and Peter J. Tumbull (1988, Employment in the British coal industry: a test of the labour demand model, Economic Joumal 98, pp. 1092-1104.

Binmore, Ken, Ariel Rubinstein and Asher Wolinsky (1986), The Nash bargaining solution in economic modelling, Rand Joumal of Economics 17 (2), pp. 176-188.

Black, Jane M. and I. George Bulkley (1984), Union utility maximisation and optimal contracts, in: Gilian Hutchinson and John Treble (eds.), Recent advances in labour economics, Croom Helm, London, pp. 4357.

Black, Jane M. and I. George Bulkley (1989), Do trade unions reduce job opportunities of non-members?, Economic Joumal 99, pp. 177-186.

Blanchard, Olivier J. (1991), Wage bargaining and unemployment persistence, Journal of Money, Credit and Banking 23 (3), pp. 277-292.

Blanchard, Olivier J. and Lawrence H. Summers (1986), Hysteresis and the European unemployment problem, in: Stanley Fisher (ed.), NBER Macroeconomics Annual, vol. 1, Cambridge, pp. 15-87.

Blanchard, Olivier J. and Lawrence H. Summers (1987), Hysteresis in unemployment, European Economic Review 31, pp. 288-295.

Blanchflower, David G. and Andrew J. Oswald (1990), The wage curve, Scandinavian Joumal of Economics 92 (2), pp. 215-235.

Blanchflower, David G., Andrew J. Oswald and Mario D. Garrett (1990), Insider power in wage determination, Economica 57, pp. 143-170.

Booth, Alison L. (1984), A public choice model of trade union behaviour and membership, Economic Joumal 94, pp. 883-898.

Brown, Charles and James Medoff (1989), The employer size-wage effect, Joumal of Political Economy 97 (5), pp. 1027-1059. 
Brown, James N. and Orley Ashenfelter (1986), Testing the efficiency of employment contracts, Joumal of Political Economy 94. (3), pp. S40S87.

Bruno, Michael and Jeffrey D. Sachs (1985). Economics of worldwide stagflation, Harvard University Press, Cambridge.

Bruyne, Guido de and Paul van Rompuy (1990), Price and wage determination in a unionized economy; the case of Belgium, Public Economics Research Paper no. 4, Catholic University Leuven.

Budd, Alan, Paul Levine and Peter Smith (1988), Unemployment, vacancies and the long-term unemployed, Economic Joumal 98, pp. 1071-1091.

Bulow, Jeremy I. and Lawrence H. Summers (1986), A theory of dual labor markets with application to industrial policy, discrimination, and Keynesian unemployment, Journal of Labor Economics 4 (3), pp. $376-414$.

Burton, John (1981), Are trade unions economic or political entities?, discussion paper (series A), University of Birmingham.

Calmfors, Lars and John Driffill (1988), Centralization of wage bargaining, Economic Policy, April, pp. 13-61.

Calmfors, Lars and A. Forslund (1989), Wage setting in Sweden, in: Lars Calmfors (ed.), Wage formation in the Nordic countries, Center for business and policy studies, SNS, Stockholm.

Cappelli, Peter, and Keith Chauvin (1991), An interplant test of the efficiency wage hypothesis, Quarterly Journal of Economics 106 (3), pp. 769-787.

Card, David (1986), Efficient contracts with costly adjustment: short-run employment determination for airline mechanics, American Economic Review 76 (5), pp. 1045-1071.

Carmichael, H. Lome (1985), Can unemployment be involuntary?: comment, American Economic Review 75 (5), pp. 1213-1214.

Carmichael, H. Lome (1990), Efficiency wage models of unemployment: one view, Economic Inquiry 28, pp. 269-295. 
Carruth, Alan A. and Andrew J. Oswald (1985), Miners' wages in post-war Britain: an application of a model of trade union behaviour, Economic Joumal 95, pp. 1003-1020.

Carruth, Alan A., Andrew J. Oswald and Lewis Findlay (1986), A test of a model of trade union behaviour: the coal and steel industries in Britain, Oxford Bulletin of Economics and Statistics 48 (1), pp. 1-18.

Carruth, Alan A. and Andrew J. Oswald (1987), On union preferences and labour market models: insiders and outsiders, Economic Journal 97. pp. $431-445$.

Carruth, Alan A. and Andrew J. Oswald (1989), Pay determination and industrial prosperity, Oxford University Press, Oxford.

Cartter, Allan M. (1959), Theory of wages and employment, Irwin, Homewood, Illinois.

CBS (1984), Verdiende lonen versus regelingslonen; de ontwikkeling in de jaren 1972-1983, in: Supplement bii de sociaal-economische maandstatistiek 10, Centraal Bureau voor de Statistiek, The Hague.

CBS (1987), Statistiek van de vakbeweging 1987. Staatsuitgeverij, The Hague.

CED (1987), Rapport flexibiliteit van de arbeidsmarkt en werkloosheid, Sociaal Economische Raad, The Hague.

Christofides, Louis N. and Andrew J. Oswald (1989), Real wage determination in collective bargaining agreements, working paper no. 3188, National Bureau of Economic Research. Cambridge, Massachusetts.

Coe, David T. (1988), Hysteresis effects in aggregate wage equations, chapter 14 in Rod Cross (ed.), Unemployment, hysteresis and the natural mate hypothesis, Basil Blackwell, Oxford.

Dertouzos, James N. and John H. Pencavel (1981), Wage and employment determination under trade unionism: the International Typographical Union, Joumal of Political Economy 89 (6), pp. 1163-1181. 
Dickens, William T. and Lawrence F. Katz (1987), Inter-industry wage differences and industry characteristics, chapter 3 in: Kevin Lang and Jonathan S. Leonard (eds.), Unemployment and the structure of labor markets, Basil Blackwell, Oxford.

Dickens, William T., Lawrence F. Katz, Kevin Lang and Lawrence H. Summers (1989), Employee crime and the monitoring puzzle, Joumal of Labor Economics 7 (3), pp. 331-347.

Driffill, John (1985), Macroeconomic stabilization policy and trade union behaviour as a repeated game, Scandinavian Joumal of Economics 87 (2), pp. $300-326$.

Dunlop, John T. (1944), Wage determination under trade unions. Macmillan, New York.

Eberts, Randall W. and Joe A. Stone (1986), On the contract curve: a test of alternative models of collective bargaining, Joumal of Labor Economics 4 (1), pp. 66-81.

Edgeworth, F.Y. (1881), Mathematical psychics: an essay on the applications of mathematics to the social sciences, Kegan Paul and Co., London.

Farber, Henry S. (1978a), Individual preferences and union wage determination: the case of the United Mine Workers, Journal of Political Economy 86 (5), pp. 923-942

Farber, Henry S. (1978b), The United Mine Workers and the demand for coal: an econometric analysis of union behaviour, Research in Labor Economics 2, pp. 1-74.

Farber, Henry S. (1986), The analysis of union behavior, in: Orley Ashenfelter and Richard Layard (eds.), Handbook of labor economics, vol. 2, Amsterdam, pp. 1039-1089.

Fehr, Emst (1990), Cooperation, harassment, and involuntary unemployment: comment, American Economic Review 80 (3), pp. 624-630.

Fellner, William (1947), Prices and wages under bilateral monopoly, Quarterly Joumal of Economics 61 (3), pp. 503-532. 
Foster, James E. and Henry Y. Wan, Jr. (1984), Involuntary unemployment as a principal-agent equilibrium, American Economic Review 74, pp. 474-486.

Freeman, R.B. (1988), Labour market institutions and economic performance, Economic Policy, April 1988, pp. 64-80.

Gahlen, Bemhard and Hans Jürgen Ramser (1986), Effizienzlohn, Lohndrift und Beschäftigung. Arbeitspapiere zur Strukturanalyse, Beitrag 34, Institut für Volkswirtschaftslehre, Universität Augsburg.

Gerfin, Harald (1969), Ausmass und Wirkung der Lohndrift, in: Helmut Arndt (ed.), Lohnpolitik und Einkommensverteilung, Schriften des Vereins für Socialpolitik, Duncker \& Humblot, Berlin, pp. 471-522.

Gillion, C. (1968), Wage-rates, eamings, and wage-drift, National Institute Economic Review 46, pp. 52-84.

Gottfries, Nils and Henrik Horn (1987), Wage formation and the persistence of unemployment, Economic Joumal 97, pp. 877-884.

Gould, F.W. (1967), The dynamics of wage drift, Economic Record 43, pp. 371-394.

Graafland, Johan J. (1988), Hysteresis in unemployment in the Netherlands, De Economist 136 (4), pp. 508-523.

Graafland, Johan J. (1989), Can hysteresis explain different labour market operations between Europe and the United States?, Applied Economics 21, pp. 95-111.

Graafland. Johan J. (1990), Long-term unemployment and wage formation in the Netherlands, research memorandum 66, Central Planning Bureau, The Hague.

Graafland, Johan J. (1991), From Phillips curve to wage curve: implications for policy analysis, mimeo., Central Planning Bureau, The Hague.

Graafland, Johan J. (1992), Insiders and outsiders in wage formation: the Dutch case, Empirical Economics 17 (4). pp. 583-602.

Gregory, R.G. (1986), Wages policy and unemployment in Australia, Economica 53. pp. S53-S74. 
Grossman, Gene M. (1983), Union wages, seniority and unemployment, American Economic Review 73, pp. 277-290.

Hall, Robert E. and David M. Lilien (1979), Efficient wage bargains under uncertain supply and demand, American Economic Review 69 (5), pp. 868879.

Hansen, Bent and Gösta Rehn (1956), On wage drift: a problem of money wage dynamics, in: Twenty-five economic essays in honour of Erik Lindahl, Stockholm, pp. 87-138.

Harris, John R. and Michael P. Todaro (1970), Migration, unemployment and development: a two-sector analysis, American Economic Review 60 (1). pp. 126-142.

Harsanyi, John C. and R. Selten (1972), A generalized Nash solution for two person bargaining games with incomplete information, Management Science 18, pp. 80-106.

Hersoug, Tor (1984), Union wage responses to tax changes, Oxford Economic Papers 36, pp. 37-51.

Hersoug, Tor, Knut N. Kjaer and Asbjorn Rodseth (1986), Wages, taxes and the utility maximizing trade union: a confrontation with Norwegian data, Oxford Economic Papers 38, pp. 403-423.

Hirsch, Barry T. and John T. Addison (1986), The economic analysis of unions: new approaches and evidence, Allen and Unwin, London.

Hoel, Michael and Ragnar Nymoen (1988), Wage formation in Norwegian manufacturing: an empirical application of a theoretical bargaining model, European Economic Review 32, pp. 977-997.

Holden, Steinar (1989), Wage drift and bargaining: evidence from Norway, Economica 56, pp. 419-432.

Holmlund, Bertil (1986), Centralized wage setting, wage drift and stabilization policies under trade unionism, Oxford Economic Papers 38, pp. 243-258.

Holmlund, Bertil and Johnny Zetterberg (1991), Insider effects in wage determination: evidence from five countries, European Economic Review 35, pp. 1009-1034. 
Hoon, Hian Teck and Edmund S. Phelps (1992), Macroeconomic shocks in a dynamized model of the natural rate of unemployment, American Economic Review 82 (4), pp. 889-900.

Hom, Henrik and Lars E.O. Svensson (1986), Trade unions and optimal labour contracts, Economic Joumal 96, pp. 323-341.

Huizinga, F. and F. Schiantarelli (1992), Dynamics and asymmetric adjustment in insider-outsider models, Economic Joumal 102, pp. 14511466.

Isaac, J.E. (1965), Wage drift in the Australian metal industries, Economic Record 41 (94), pp. 145-172.

Isachsen, Ame J. (1977), A note on wage drift: the case of Sweden, Scandinavian Joumal of Economics 79, pp. 366-374.

Jackman, Richard, Christopher A. Pissarides and S. Savouri (1990), Labour market policies and unemployment in the OECD, Economic Policy, pp. $450-490$.

Jacobsson, Lars and Assar Lindbeck (1969), Labor market conditions, wages and inflation: Swedish experiences 1955-1967, Swedish Joumal of Economics 2, pp. 64-103.

Jacobsson, Lars and Assar Lindbeck (1971), On the transmission mechanism of wage change, Swedish Joumal of Economics 3, pp. 273-293.

Johnson, George E. (1975), Economic analysis of trade unionism, American Economic Review, Papers and Proceedings 65 (2), pp. 23-28.

Jones, Stephen R.G. and C.J. McKenna (1989), The effect of outsiders on union contracts, European Economic Review 33, pp. 1567-1573.

Katz, Lawrence F. (1986), Efficiency wage theories: a partial evaluation, in: Stanley Fischer (ed.), Macroeconomics Annual, NBER, pp. 235-289.

Kidd, David P. and Andrew J. Oswald (1987), A dynamic model of trade union behaviour, Economica 54, pp. 355-365.

Klundert, Theo van de (1988), Wage differentials and employment in a twosector model with a dual labour market, research memorandum 314 , Tilburg University. 
Kraft, Komelius (1989), Gewerkschaften, Löhne und Produktivităt, in: Die Gewerkschaft in der ökonomischen Theorie, Okonomie und Gesellschaft 7, Campus, Frankfurt.

Krueger, Alan B. and Lawrence H. Summers (1987), Reflections on the inter-industry wage structure, chapter $\mathbf{2}$ in: Kevin Lang and Jonathan S. Leonard (eds.), Unemployment and the structure of labor markets, Basil Blackwell, Oxford.

Krueger, Alan B. and Lawrence H. Summers (1988), Efficiency wages and the inter-industry wage structure, Econometrica 56 (2), pp. 259-293.

Layard, Richard (1989), European Unemployment: cause or cure, discussion paper no. 368, Centre for Labour Economics, London School of Economics.

Layard, Richard and Stephen J. Nickell (1985), The causes of British unemployment, National Institute Economic Review, pp. 62-85.

Layard, Richard and Stephen J. Nickell (1986), Unemployment in Britain, Economica 53, pp. S121-S169.

Layard, Richard and Stephen J. Nickell (1987), The labour market, ch. 5 in Rudiger Dombusch and Richard Layard (eds.), The performance of the British economy, Oxford University Press, Oxford.

Layard, P. Richard G., Stephen J. Nickell and Richard Jackman (1991), Unemployment: Macroeconomic performance and the labour market, Oxford University Press, Oxford.

Lazear, Edward P. (1979), Why is there mandatory retirement?, Joumal of Political Economy 87 (6), pp. 1261-1284.

Lazear, Edward P. (1981), Agency, eamings profiles, productivity, and hours restrictions, American Economic Review 71 (4), pp. 606-620.

Lazear, Edward P. and Robert L. Moore (1984), Incentives, productivity, and labor contracts, Quarterly Joumal of Economics 99, pp. 275-295.

Leibenstein, Harvey (1957), The theory of underdevelopment in densely populated backward areas, chapter 6 in: Harvey Leibenstein (ed.), Economic backwardness and economic growth, Wiley, New York. 
Leontief, Wassily W. (1946), The pure theory of the guaranteed annual wage contract, Journal of Political Economy 54 (1), pp. 76-79.

Lever, Marcel H.C. (1989), The labour demand curve model and the contract curve model: which explains the determination of wages and employment?, working paper 89.018, University of Limburg, Maastricht.

Lever, Marcel H.C. (1990a), Insiders and outsiders in union wage setting, mimeo., University of Limburg, Maastricht.

Lever, Marcel H.C. (1990b), Insiders and outsiders in union preferences: a comment, mimeo., University of Limburg, Maastricht.

Lever, Marcel H.C. (1991a), An efficiency wage model of wage drift: evidence from the Netherlands (1972-1983), research memorandum 91-016, University of Limburg, Maastricht.

Lever, Marcel H.C. (1991b), Union wage setting and unemployment in the Netherlands (1965-1987), Applied Economics 23 (10), pp. 1579-1585.

Lever, Marcel H.C. (1992), Insider-outsider effects in union wage determination, research memorandum 92-024, University of Limburg, Maastricht.

Lever, Marcel H.C. (1993a), Efficiency wages and unemployment: theory and empirical evidence, research memorandum 93-002, University of Limburg, Maastricht.

Lever, Marcel H.C. (1993b), Insider-outsider vs. human capital effects in union wage formation, research memorandum 93-011, University of Limburg, Maastricht.

Lever, Marcel H.C. and A.P. van Veen (1991), Union wage setting, employment and investment: a survey of theory and empirical evidence, Labour 5 (3), pp. 25-61.

Lewis, H. Gregg (1986), Union relative wage effects: a survey, Chicago University Press, Chicago, Illinois.

Lindbeck, Assar and Dennis J. Snower (1986), Wage setting, unemployment, and insider-outsider relations, American Economic Review, Papers and Proceedings 76 (2), pp. 235-239. 
Lindbeck, Assar and Dennis J. Snower (1987a), Union activity, unemployment persistence and wage-employment ratchets, European Economic Review 31, pp. 157-167.

Lindbeck, Assar and Dennis J. Snower (1987b), Efficiency wages versus insiders and outsiders, European Economic Review 31, pp. 407-416.

Lindbeck, Assar and Dennis J. Snower (1988), Cooperation, harassment, and involuntary unemployment: an insider-outsider approach, American Economic Review 78 (1), pp. 167-188.

Lindbeck, Assar and Dennis J. Snower (1991), Interactions between the efficiency wage and insider-outsider theories, Economics Letters 37. pp. 193-196.

Lockwood, Ben and Alan Manning (1989), Dynamic wage-employment bargaining with employment adjustment costs, Economic Joumal 99. pp. 1143-1158.

MacLeod, W. Bentley and James M. Malcomson (1989), Implicit contracts, incentive compatibility, and involuntary unemployment, Econometrica 57 (2), pp. 447-480.

MaCurdy, Thomas E. and John H. Pencavel (1986), Testing between competing models of wage and employment determination in unionized markets, Joumal of Political Economy 94 (3), pp. S3-S39.

Malcomson, James M. (1981), Unemployment and the efficiency wage hypothesis, Economic Joumal 91, pp. 848-866.

Malcomson, James M. (1983), Trade unions and economic efficiency, Economic Journal 93, Conference Papers, pp. 51-65.

Malcomson, James M. (1984), Work incentives, hierarchy, and internal labour markets, Joumal of Political Economy 92, pp. 275-295.

Malcomson, James M. and Nicola Sartor (1987), Tax push inflation in a unionized labour market, European Economic Review 31, pp. 15811596.

Manning, Alan (1987a), An integration of trade union models in a sequential bargaining framework, Economic Joumal 97, pp. 121-139. 
Manning, Alan (1987b), Collective bargaining institutions and efficiency: an application of a sequential bargaining model, European Economic Review 31, pp. 168-176.

Manning, Alan (1987c), Trade union power and jobs: theory and policy, International Review of Applied Economics, pp. 176-189.

Marquand, Judith (1960), Eamings-drift in the United Kingdom, 1948-57, Oxford Economic Papers 12, pp. 77-104.

Martinello, Felice (1989), Wage and employment determination in a unionized industry: the IWA and the British Columbia Wood Products Industry, Joumal of Labor Economics 7 (3), pp. 303-330.

McDonald, Ian M. and Robert M. Solow (1981), Wage bargaining and employment, American Economic Review 71 (5), pp. 896-908.

Menil, George de (1971), Bargaining: monopoly power versus union power, M.I.T. Press, Cambridge, Massachusetts.

Moene, Karl O. (1988), Unions' threats and wage determination, Economic Joumal 98, pp. 471-483.

Murphy, Kevin M. and Robert H. Topel (1987), Unemployment, risk, and earnings: testing for equalizing wage differences in the labor market, chapter 5 in: Kevin Lang and Jonathan S. Leonard (eds.), Unemployment and the structure of labor markets, Basil Blackwell, Oxford.

Nash, John F. (1950), The bargaining problem, Econometrica 18, pp. 155-162.

Nash, John F. (1953), Two-person cooperative games, Econometrica 21, pp. 128-140.

Nickell, Stephen J. (1982), A bargaining model of the Phillips curve, discussion paper no. 130, Centre for Labour Economics, London School of Economics.

Nickell. Stephen J. (1987). Why is wage inflation in Britain so high?, Oxford Bulletin of Economics and Statistics 49 (1). pp. 103-128.

Nickell, Stephen J. (1990), Unemployment: a survey, Economic Joumal 100, pp. $391-439$. 
Nickell, Stephen J. and Martin Andrews (1983), Unions, real wages and employment in Britain 1951-79, Oxford Economic Papers 35, pp. S183-S206.

Nickell, Stephen J. and Paul Kong (1992), An investigation into the power of insiders in wage determination, European Economic Review 36. pp. 1573-1599.

Nickell, Stephen J. and Sushil Wadhwani (1988), Unions, wages and employment: tests based on U.K. firm-level data, European Economic Review 32, pp. 727-733.

Nickell, Stephen J. and Sushil Wadhwani (1990), Insider forces and wage determination, Economic Joumal 100, pp. 496-509.

Oswald, Andrew J. (1982), The microeconomic theory of the trade union, Economic Joumal 92, pp. 576-595.

Oswald, Andrew J. (1984), Efficient contracts are on the labour demand curve: theory and facts, working paper no. 178, Industrial Relations Section, Princeton University.

Oswald, Andrew J. (1985), The economic theory of trade unions: an introductory survey, Scandinavian Journal of Economics 87 (2), pp. 160193.

Oswald, Andrew J. (1987a), Efficient contracts are on the labour demand curve: theory and facts, discussion paper no. 284, Centre for Labour Economics, London School of Economics.

Oswald, Andrew J. (1987b), New research on the economics of trade unions and labor contracts, Industrial Relations 26 (1), pp. 30-45.

Pencavel, John H. (1984a), The tradeoff between wages and employment in trade union objectives, Quarterly Joumal of Economics 99 (2), pp. 215-231.

Pencavel, John H. (1984b), The empirical performance of a model of trade union behavior, in: Jean-Jacques Rosa (ed.), The economics of trade unions: new directions, Kluwer-Nijhoff, Dordrecht, pp. 221-276. 
Pencavel, John H. (1985), Wages and employment under trade unionism: microeconomic models and macroeconomic applications, Scandinavian Journal of Economics 87 (2), pp. 197-225.

Pencavel, John (1989), Employment, wages, and unionism in a model of the aggregate labor market in Britain, working paper no. 3030, National Bureau of Economic Research, Cambridge, Massachusetts.

Pencavel, John H. and Bertil Holmlund (1988), The determination of wages, employment, and work hours in an economy with centralised wagesetting: Sweden 1950-83, Economic Joumal 98, pp. 1105-1126.

Phelps Brown, E.H. (1962), Wage drift, Economica 29, pp. 339-356.

Phillips, A.W. (1958), The relation between unemployment and the rate of change of money wage rates in the United Kingdom, 1861-1957, Economica 25, pp. 283-299.

Ploeg, Frederick van der (1987), Trade unions, investment, and employment: a non-cooperative approach, European Economic Review 31, pp. 1465-1492.

Raff, Daniel M.G. (1988), Wage determination theory and the five-dollar day at Ford, Joumal of Economic History 48 (2), pp. 387-399.

Raff, Daniel M.G. and Lawrence H. Summers (1987), Did Henry Ford pay efficiency wages?, Journal of Labor Economics 5 (4), pp. S57-S86.

Rompuy, Paul van, Guido de Bruyne and Carine van de Voorde (1988), Taxation, wages and employment in a unionized economy, Tiidschrift voor Economie en Management 33 (3-4), pp. 261-270.

Rosen, Sherwin (1970), Unionism and the occupational wage structure in the United States, Intemational Economic Review 11, pp. 269-286.

Rosén, Åsa (1989), Bargaining over effort, discussion paper 351, Centre for Labour Economics, London School of Economics.

Ross, Arthur M. (1948). Trade union wage policy, University of California Press, Berkeley and Los Angeles.

Rubinstein, Ariel (1982). Perfect equilibrium in a bargaining model, Econometrica 50 (1). pp. 97-109. 
Salop, Steven C. (1979), A model of the natural rate of unemployment, American Economic Review 69 (1), pp. 117-125.

Sampson, Anthony (1988), Unionized contracts with fixed wage rates and state-contingent employment levels, Economica 55, pp. 95-105.

Sargan, J.D. (1964), Wages and prices in the United Kingdom: a study in econometric methodology, reprinted in: D. Hendry and K. Wallis (eds.) (1984), Econometrics and quantitative economics, Basil Blackwell, Oxford.

Schager, Nils H. (1981), The duration of vacancies as a measure of the state of demand in the labor market. The Swedish wage drift equation reconsidered, in: Gunnar Eliasson, Bertil Holmlund and Frank P. Stafford (eds.), Studies in labor market behavior: Sweden and the United States, The Industrial Institute for Economic and Social Research, Stockholm.

Shapiro, Carl and Joseph E. Stiglitz (1984), Equilibrium unemployment as a worker discipline device, American Economic Review 74 (3), pp. 433-444.

Shapiro, Carl and Joseph E. Stiglitz (1985), Can unemployment be involuntary?: reply, American Economic Review 75 (5), pp. 1215-1217.

Söderström, Hans Tson and Eva Uddén-Jondal (1982), Does egalitarian wage policy cause wage drift? An empirical study of Sweden 19601979, seminar paper no. 203, Institute for Intemational Economic Studies, University of Stockholm.

Solow, Robert M. (1979), Another possible source of wage stickiness, Journal of Macroeconomics 1, pp. 79-82.

Solow, Robert M. (1985), Insiders and outsiders in wage determination, Scandinavian Journal of Economics 87 (2), pp. 411-428.

Solow, Robert M. (1986), Unemployment, getting the questions right, Economica 53, pp. S23-S34.

Stiglitz, Joseph E. (1986), Theories of wage rigidity, in: James L. Butkiewicz et al. (eds.), Keynes' economic legacy: contemporary economic theories, Praeger, New York, pp. 153-206. 
Stiglitz, Joseph E. (1987), The causes and consequences of the dependence of quality on price, Joumal of Economic Literature 25, pp. 1-48.

Svejnar, Jan (1986), Bargaining power, fear of disagreement, and wage settlements: theory and evidence from U.S. industry, Econometrica 54 (5), pp. 1055-1078.

Teulings, Coen N. and H.D. Webbink (1992), Efficiënte loontheorieën, Mens en Maatschappii 67 (3), pp. 273-295.

Veugelers, Reinhilde (1989), Wage premia, price-cost margins and bargaining power in Belgian manufacturing, European Economic Review 33 (1), pp. 169-180.

Wadhwani, Sushil and Martin Wall (1988), A direct test of the efficiency wage model using UK micro-data, discussion paper 313, Centre for Labour Economics, London School of Economics.

Weiss, Andrew (1980), Job queues and layoffs in labor markets with flexible wages, Joumal of Political Economy 88 (3), pp. 526-538.

Weiss, Andrew (1991), Efficiency wages: models of unemployment, layoffs, and wage dispersion, Clarendon Press, Oxford.

Yellen, Janet L. (1984), Efficiency wage models of unemployment, American Economic Review, Papers and Proceedings 74 (2), pp. 200-205. 


\section{Samenvatting}

Hoofdstuk 1 geeft aan dat het onderzoek gaat over de invloed van loonvorming op werkgelegenheid en werkloosheid. Het onderzoek maakt deel uit van het project "Arbeidsrnarkt en arbeidsorganisaties".

In hoofdstuk 2 wordt betoogd dat vakbonden beschouwd kunnen worden als economische agenten. De integratie van vakbonden in de economische theorie blijkt bij te kunnen dragen aan de verklaring van loonvorming en werkgelegenheid. De invloed van vakbonden op werkloosheid is tot nu toe minder duidelijk. Deze invloed wordt nader onderzocht in het volgende hoofdstuk.

Hoofdstuk 3 presenteen een empirisch model voor collectieve loonvorming, werkgelegenheid en werkloosheid. Het model wordt geschat met geaggregeerde data voor de Nederlandse private sector (1965-1987). De resultaten suggereren dat de stijging van de belasting- en premiedruk, de toenemende discrepantie tussen consumenten- en producentenprijzen (o.a. vanwege indirecte belastingen en de invloed van invoerprijzen) en de stijging van de uitkeringsvoet hebben bijgedragen aan de stijging van de werkloosheid in Nederland in deze periode.

Hoofdstuk 4 beschouwt de vraag in hoeverre de efficiëntieloon-theorie het bestaan van werkloosheid kan verklaren. Deze theorie zegt dat het voor de werkgever winstgevend kan zijn meer te betalen dan het marktruimend loon omdat dit leidt tot een hogere produktiviteit van de werknemers. De theorie impliceert dat de resulterende werkloosheid een evenwichtsverschijnsel is. Een theoretisch bezwaar tegen de efficièntieloon-verklaring is dat meer ingewikkelde contracten opgesteld kunnen worden die werknemers prikkels geven om goed te presteren zonder werkloosheid te veroorzaken. Empirisch gezien is er wel enig bewijs dat hoge lonen de produktiviteit van werknemers verbeteren. Het is echter twijfelachtig of deze effecten voldoende sterk en wijd verbreid zijn om werkloosheid te veroorzaken. Tenslotte toont het hoofdstuk een nieuw resultaat betreffende de relatie tussen efficiëntieloon-effecten en insider-outsider effecten. Met insider-outsider ' effecten wordt bedoeld dat werkenden (insiders) meer macht hebben dan werklozen (outsiders) in de loononderhandelingen. Hierdoor kunnen de werkenden loonsverhogingen afdwingen terwijl werklozen moeilijk aan een baan kunnen komen. Het theoretisch model toont aan dat efficiëntieloon- en

De term "outsider" kan vertaald worden met "buitenstaander". De term "insider" betekent zoiets als "ingewijde". Een vertaling voor insider analoog aan die voor outsider zou "binnenstaander" kunnen luiden. Aangezien deze vertalingen geen schoonheidsprijs verdienen is er voor gekozen de termen onvertaald te laten. 
insider-outsider effecten, die beiden een positieve invloed hebben op de loonvoet, elkaar versterken als de insider volledige marktmacht heeft. Of dit ook geldt in andere situaties is moeilijker te bewijzen.

Hoofdstuk 5 presenteert een empirische toepassing van de efficiëntieloontheorie en de theorie van collectieve loonvorming. De efficiëntieloontheorie wordt gebruikt om loondrift te verklaren. Dit is het verschijnsel dat de lonen sneller stijgen dan de contractlonen. De theorie van collectieve loonvorming wordt gebruikt om veranderingen van het contractloon te verklaren. De schattingen voor Nederland (1972-1983) impliceren een inverse relatie tussen veranderingen van het contractloon en loondrift. Een implicatie hiervan is dat loondrift het werkgelegenheidseffect van loonmatiging door vakbonden vermindert.

De analyse van hoofdstuk 6 is eveneens gebaseerd op de theorie van collectieve loonvorming. De centrale vraag is in hoeverre de kans op werkgelegenheid voor werkloze werknemers afhankelijk is van de oorzaak van hun werkloosheid. Er worden twee mogelijke oorzaken van werkloosheid onderscheiden. Ten eerste, werkloosheid die veroorzaakt wordt door insider-outsider effecten. Hierbij behartigt de vakbond alleen de belangen van de werkenden. Ten tweede, werkloosheid die veroorzaakt wordt door gebrek aan menselijk kapitaal. Dit gebrek aan menselijk kapitaal kan veroorzaakt zijn door langdurige werkloosheid. Onder een monopolistische vakbond hebben werkloze werknemers meer kans op werkgelegenheid als hun werkloosheid te wijten is aan gebrek aan menselijk kapitaal dan als de vakbond zich niet voor hun werkgelegenheid interesseert. Onder efficiënte onderhandelingen is een sterke vakbond voordelig voor werknemers die werkloos zijn wegens gebrek aan menselijk kapitaal. Als de vakbond zich niet voor hen interesseert, dan kan de sterkte van de vakbond hun werkgelegenheid juist belemmeren. Blijkbaar is de oorzaak van de werkloosheid van invloed op de kans op een baan.

Hoofdstuk 7 beschrijft de empirische implicaties van verschillende typen insider-outsider effecten op de loonvoet, de werkgelegenheid en de werkloosheid. Verder geeft het een overzicht van de empirische studies op dit terrein. De verschillende typen insider-outsider effecten blijken te leiden tot een negatieve invloed van de werkgelegenheid in de vorige periode, geen invloed van werkloosheid en geen invloed van langdurige werkloosheid op de loonvoet. Uit het empirisch overzicht blijkt dat er weinig bewijs is voor de invloed van vertragde werkgelegenheid op de loonvoet. Werkloosheid blijkt duidelijk een negatieve invloed te hebben op de loonvoet. Langdurige werkloosheid vermindert de lonen ook, maar mogelijk minder sterk dan kort durende werkloosheid. De gevonden insider-outsider effecten kunnen wel persistentie in de werkloosheid veroorzaken, maar geen volledige hysterese.

Hoofdstuk 8, tenslotte, bevat bovenstaande samenvatting. Verder geeft het de volgende beleidsimplicaties van het onderzoek: stabilisatie of verlaging 
van de belasting- en premiedruk draagt bij aan verlaging van de werkloosheid; loonmaatregelen van de overheid lijken weinig effectief; training en werkervaring voor langdurig werklozen draagt bij aan loonmatiging en zodoende aan hun werkgelegenheid. Tenslotte bevat het als suggesties voor verder onderzoek: een onderzoek naar de invloed van onvolkomen concurrentie op de goederenmarkt op de loonvoet en de evenwichtswerkloosheid; een verder empirisch onderzoek naar de relatie tussen contractlonen en loondrift op basis van paneldata voor meerdere sectoren; een onderzoek naar de dynamische implicaties van de effecten van menselijk kapitaal of werkloosheidsduur op loonvorming en werkloosheid. 


\section{Curriculum vitae}

Marcel Lever werd geboren op 18 november 1961 te Katwijk (ZH). Van 1974 tot 1980 volgde hij voorbereidend wetenschappelijk onderwijs aan het Christelijk Lyceum Amhem. Van 1980 tot 1986 studeerde hij algemene econometrie aan de Erasmus Universiteit Rotterdam. Tijdens zijn studie was hij enige tijd student-assistent bij de sectie algemene economie van de Faculteit der Juridische Wetenschappen van de EUR. Van 1986 tot 1993 was hij als wetenschappelijk assistent en als toegevoegd onderzoeker werkzaam bij de vakgroep algemene economie van de Faculteit der Economische Wetenschappen van de Rijksuniversiteit Limburg te Maastricht. Hij verrichtte onderzoek in het kader van het project "Arbeidsmarkt en arbeidsorganisaties". Sinds I april 1993 werkt hij als onderzoeker bij de afdeling Fundamenteel Onderzoek van het Economisch Instituut voor het Midden- en kleinbedrijf te Zoetermeer.

Marcel Lever was bom at Katwijk, the Netherlands, on 18 November 1961.

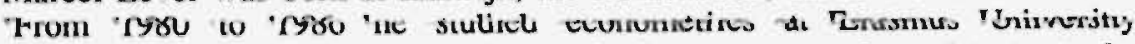
Rotterdam. During his study he worked as a research assistant at the Department of Economics of the Faculty of Law of EUR. From 1986 to 1993 he held a position as a researcher at the Department of Economics at the University of Limburg in Maastricht, the Netherlands. He participated in a research program on "Labour market and labour organizations". Since 1 April 1993 he has worked as a researcher at EIM Small Business Research and Consultancy at Zoetermeer, the Netherlands. 


\section{Union wage formation and (un)employment}

\section{by M.H.C. Iever}

Unemployment is one of the major social problems in Westem Europe. The experience of the last ten years (1983-1993) in the European Community has shown that unemployment can be high and persistent. This book considers the relevance of three alternative theories why wages do not adjust to provide more opportunities for employment.

Firstly, three standard models of union wage formation and employment are reviewed. One of these models is used to analyze the causes of the rise in the unemployment rate in the Netherlands between 1965 and 1987 . The results suggest that the increase in taxes and in the discrepancy between consumer and producer prices (among other things due to value added taxes), and the increase in benefits have caused a higher unemployment rate. Secondly, four different efficiency wage models are surveyed, It is argued that it is doubtful whether efficiency wage effects are sufficiently strong and widespread to cause unemployment. Nevertheless, the efficiency wage theory appears to be useful to explain wage drift. Empirical estimates for the Netherlands reveal that there is an inverse relationship between contract wage changes and wage drift.

Thirdly, the empirical implications of several insider-outsider models are considered. The survey of empirical evidence shows that the extreme versions of the models which imply full hysteresis must be rejected. Furthermore, it is argued that depreciation of human capital caused by long-term unemployment may affect union wage formation. The impact of insider-outsider and of human capital (or duration) effects on wages and (un)employment appears to be different.

Marcel Lever (1961) received a Master's degree in Econometrics at Erasmus University Rotterdam (1986). This book, which is the author's Ph.D. thesis, was written while he worked as a researcher at the Faculty of Economics and Business Administration of the University of Limburg in Maastricht. 